NASA/TM-2012-217411

(4)

Materials Selection for Aerospace Systems

Steven M. Arnold

Glenn Research Center, Cleveland, Ohio

David Cebon and Mike Ashby

University of Cambridge, Cambridge, United Kingdom

An errata was added to this document, October 2012 


\section{NASA STI Program . . . in Profile}

Since its founding, NASA has been dedicated to the advancement of aeronautics and space science. The NASA Scientific and Technical Information (STI) program plays a key part in helping NASA maintain this important role.

The NASA STI Program operates under the auspices of the Agency Chief Information Officer. It collects, organizes, provides for archiving, and disseminates NASA's STI. The NASA STI program provides access to the NASA Aeronautics and Space Database and its public interface, the NASA Technical Reports Server, thus providing one of the largest collections of aeronautical and space science STI in the world. Results are published in both non-NASA channels and by NASA in the NASA STI Report Series, which includes the following report types:

- TECHNICAL PUBLICATION. Reports of completed research or a major significant phase of research that present the results of NASA programs and include extensive data or theoretical analysis. Includes compilations of significant scientific and technical data and information deemed to be of continuing reference value. NASA counterpart of peer-reviewed formal professional papers but has less stringent limitations on manuscript length and extent of graphic presentations.

- TECHNICAL MEMORANDUM. Scientific and technical findings that are preliminary or of specialized interest, e.g., quick release reports, working papers, and bibliographies that contain minimal annotation. Does not contain extensive analysis.

- CONTRACTOR REPORT. Scientific and technical findings by NASA-sponsored contractors and grantees.
- CONFERENCE PUBLICATION. Collected papers from scientific and technical conferences, symposia, seminars, or other meetings sponsored or cosponsored by NASA.

- SPECIAL PUBLICATION. Scientific, technical, or historical information from NASA programs, projects, and missions, often concerned with subjects having substantial public interest.

- TECHNICAL TRANSLATION. Englishlanguage translations of foreign scientific and technical material pertinent to NASA's mission.

Specialized services also include creating custom thesauri, building customized databases, organizing and publishing research results.

For more information about the NASA STI program, see the following:

- Access the NASA STI program home page at http://www.sti.nasa.gov

- E-mail your question via the Internet to help@ sti.nasa.gov

- Fax your question to the NASA STI Help Desk at $443-757-5803$

- Telephone the NASA STI Help Desk at 443-757-5802

- Write to: NASA Center for AeroSpace Information (CASI) 7115 Standard Drive Hanover, MD 21076-1320 
NASA/TM-2012-217411

(4)

Materials Selection for Aerospace Systems

Steven M. Arnold

Glenn Research Center, Cleveland, Ohio

David Cebon and Mike Ashby

University of Cambridge, Cambridge, United Kingdom

An errata was added to this document, October 2012

National Aeronautics and

Space Administration

Glenn Research Center

Cleveland, Ohio 44135 
Trade names and trademarks are used in this report for identification only. Their usage does not constitute an official endorsement, either expressed or implied, by the National Aeronautics and Space Administration.

Level of Review: This material has been technically reviewed by technical management.

Available from

NASA Center for Aerospace Information 7115 Standard Drive

Hanover, MD 21076-1320
National Technical Information Service 5301 Shawnee Road Alexandria, VA 22312

Available electronically at http://www.sti.nasa.gov 


\author{
Errata \\ UIssued 2 FWber 2012 for \\ NASA/TM-2012-217411 \\ Materials Selection for Aerospace Systems \\ Steven M. Arnold, David Cebon, and Mike Ashby
}

January 2012

Figure 13(a) and (b): Figure and caption has been changed to read as follows: 
(a) Independent
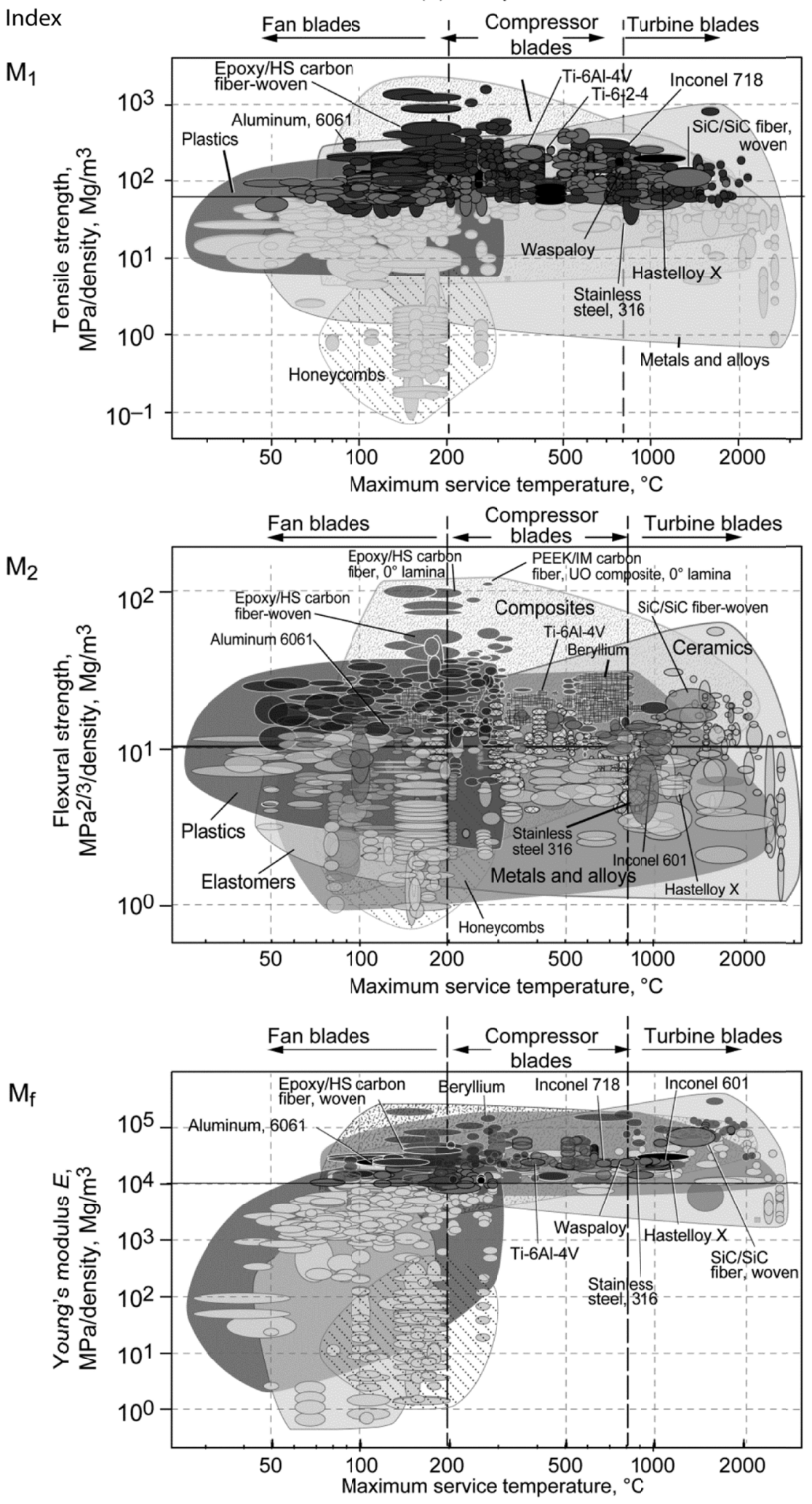

Figure 13.-Illustration of the interaction between three material indices for a blade subjected to tension, bending and vibration. (a) Independent; and (b) Interacting constraints. 
(b) Interacting constraints
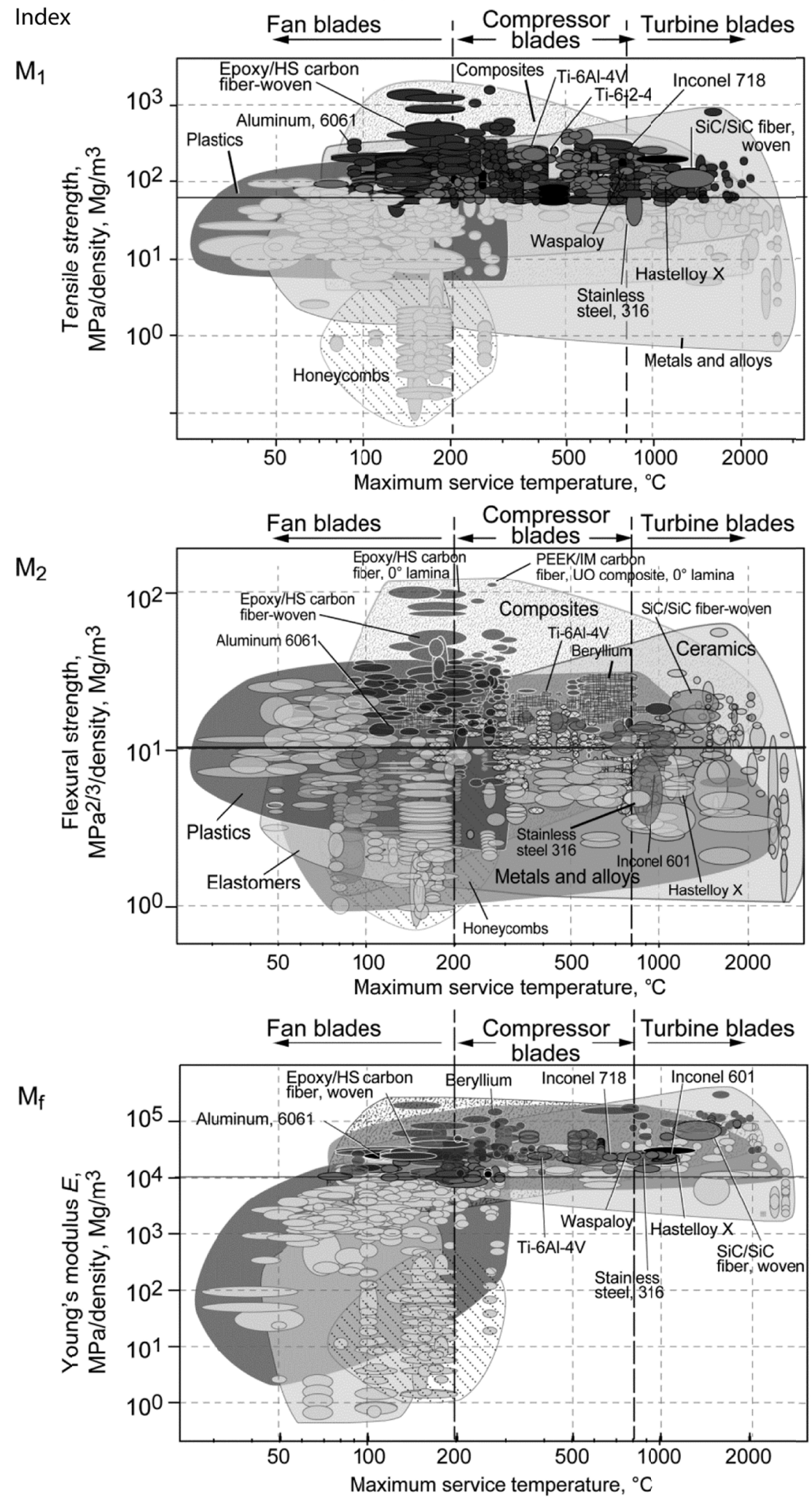

Figure 13.-Concluded. 
Section 3.3.6, text has been changed to read as follows:

\section{Example: Aluminum Metal Matrix Composite (MMC) Foams and Lattices}

The starting point is aluminum $20 \% \mathrm{SiC}(\mathrm{p}),{ }^{4}$ a mix that is the basis of one of the Cymat range of metal foams. The properties of two hybrids are compared a "Foam" and an "Octet lattice", that generates two sets of new records. They appear on the Modulus-Density chart of Figure 33 as lines of white and gray circles, respectively. The starting material, $\mathrm{Al} 20 \% \mathrm{SiC}(\mathrm{p})$, is identified at the upper right. The modeled foams, plotted white, are labeled with their relative densities in parentheses. Measured data for real aluminum-SiC(p) foams (shown as black ellipse in Fig. 33) are also labeled, underlined, with relative densities in parentheses, allowing a comparison. Note that the lattices, plotted in gray, lie at higher values of modulus for the same density. At a relative density of $3.5 \%(0.035)$ the lattice is predicted to be ten times stiffer than foam of that density.

Figure 33, figure and caption has been changed to read as follows:

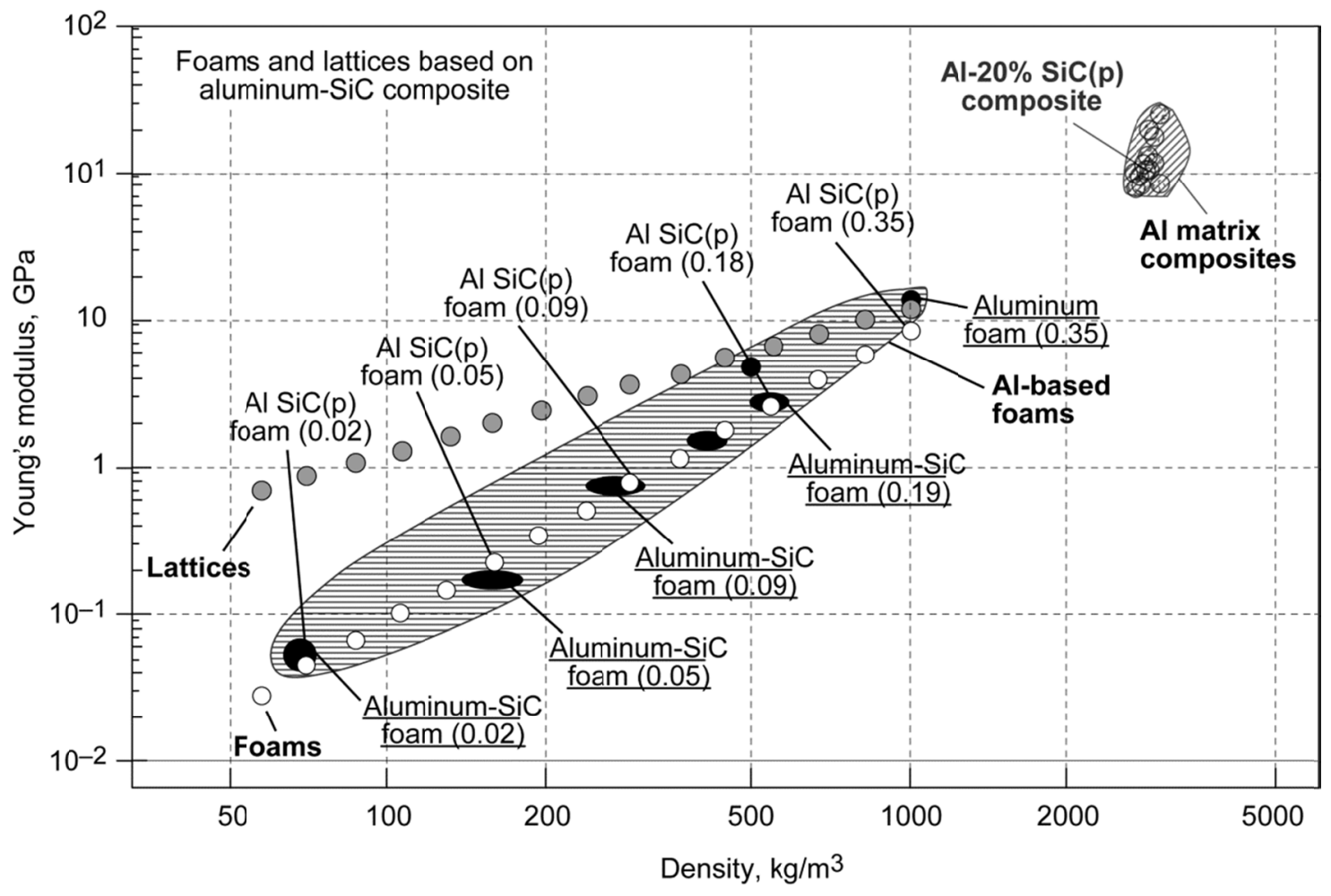

Figure 33.-The input window of the synthesizer, set for Cellular structures - Octet lattice. The chart shows some of the output. The starting material, Al $20 \% \mathrm{SiC}(\mathrm{p})$ appears at the upper right. The line of white ellipses show the modulus and density of foams made from $\mathrm{Al}-\mathrm{SiC}(\mathrm{p})$. They should be compared with the measured values for real aluminum $\operatorname{SiC}(p)$ foams, shown in black with underlined labels. The relative densities are listed in brackets. The modulus and density of lattices made of the same material are shown in gray for comparison. Chart generated by the CES Hybrid Synthesizer, (Ashby et al., 2010). 


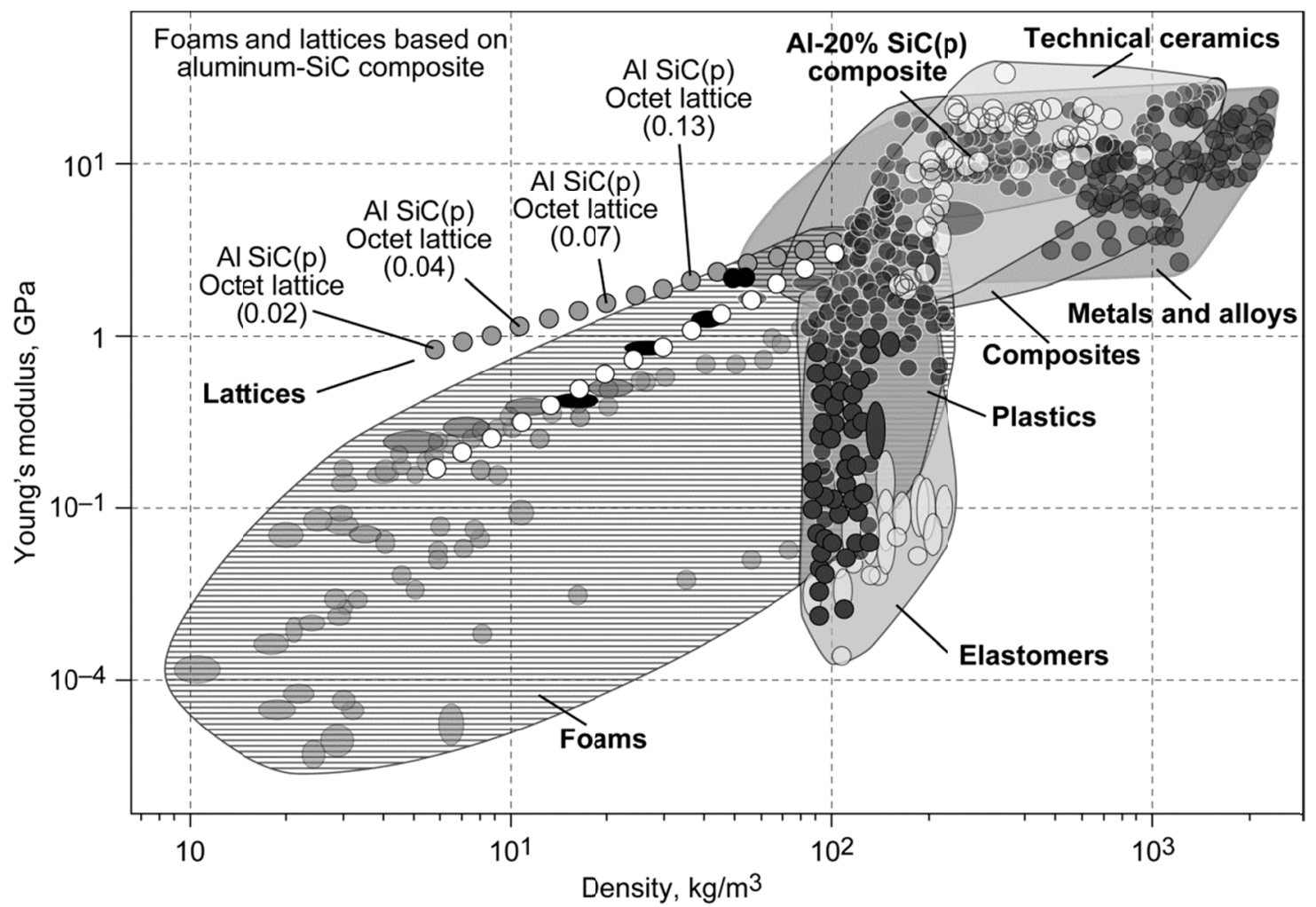

Figure 34.-The moduli of Al-SiC lattices compared to those of the other materials of engineering. The lattices lie outside the currently populated areas of the chart. Numbers in brackets are relative densities. Chart generated by the CES Hybrid Synthesizer, (Ashby et al., 2010). 



\section{Contents}

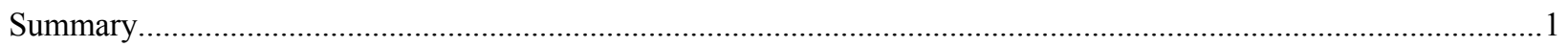

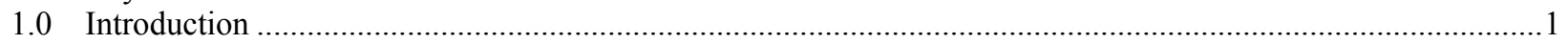

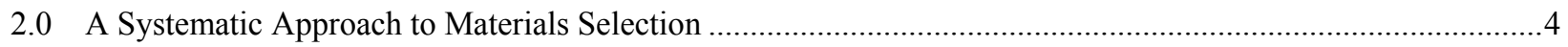

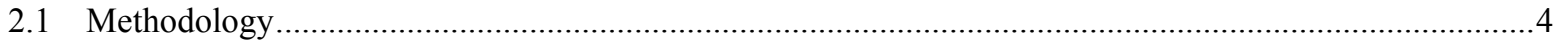

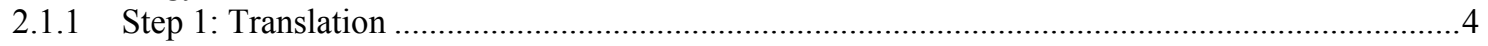

2.1.2 Step 2: Screening/Rejection ..........................................................................................

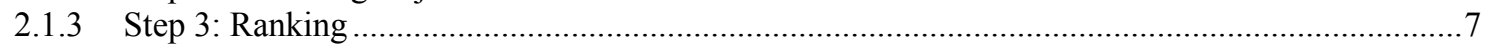

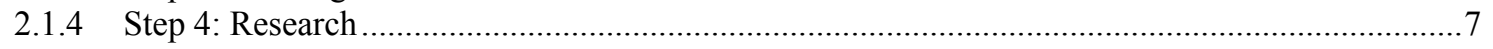

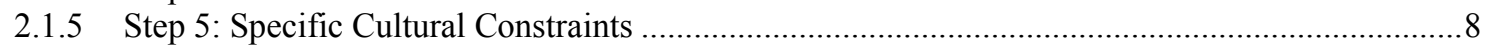

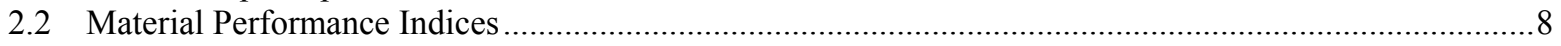

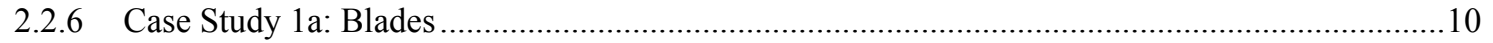

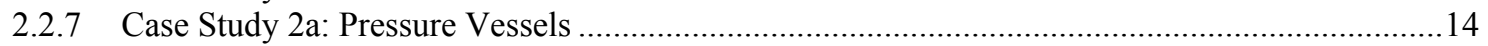

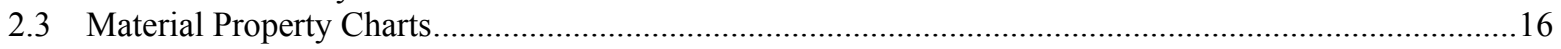

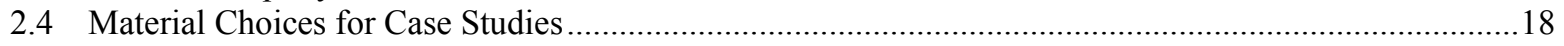

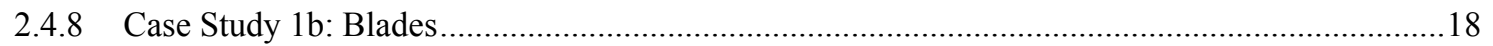

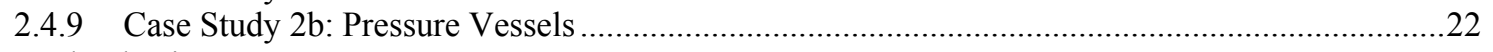

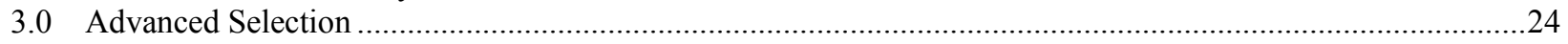

3.1 Materials for High Temperature Applications ..................................................................................24

3.1.1 Maximum and Minimum Service Temperature …...............................................................28

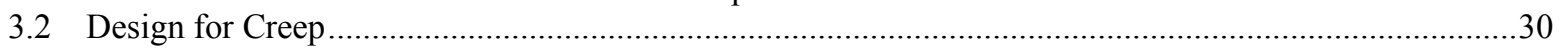

3.2.1 Constitutive Equation for Creep Deflection ...........................................................................

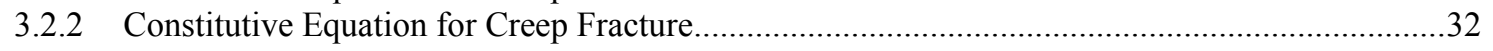

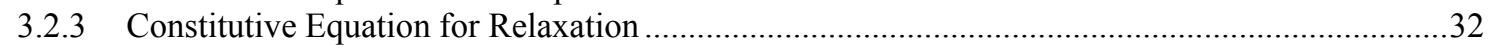

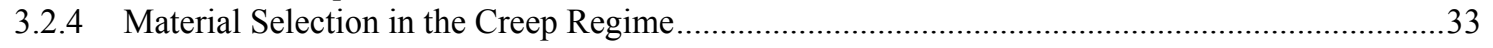

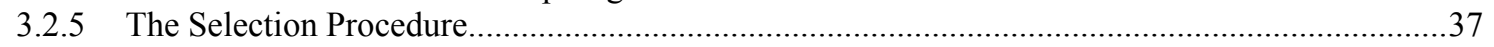

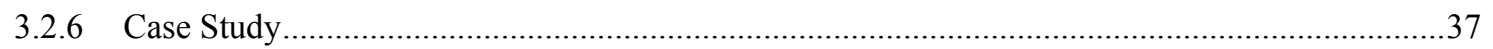

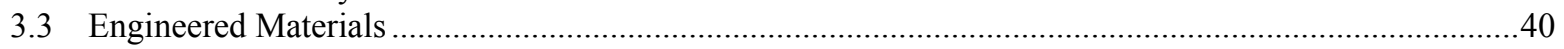

3.3.1 Holes in Material-Property Space .........................................................................................

3.3.2 Synthesizing the Properties of Cellular Structures: Foams and Lattices ......................................42

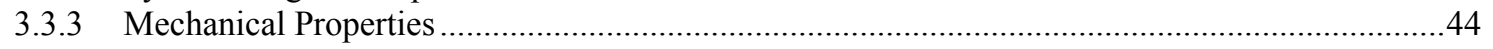

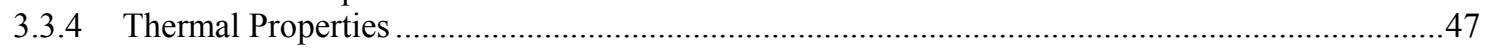

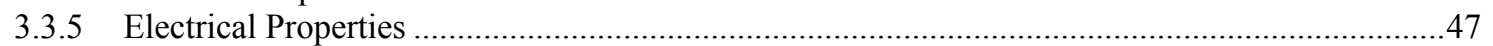

3.3.6 Example: Aluminum Metal Matrix Composite (MMC) Foams and Lattices ..................................48

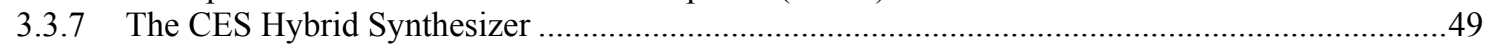

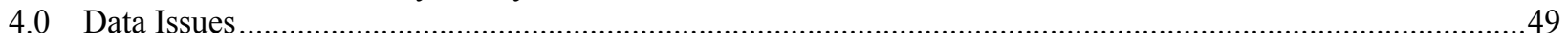

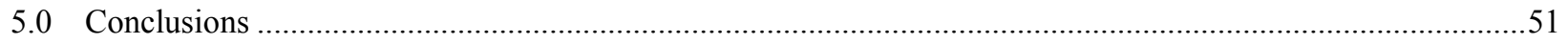

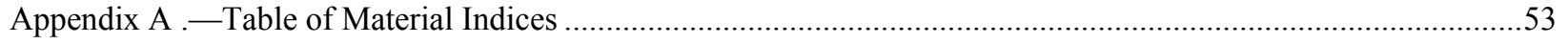

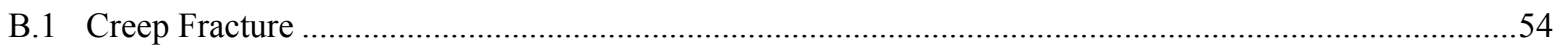

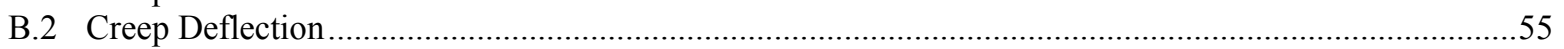

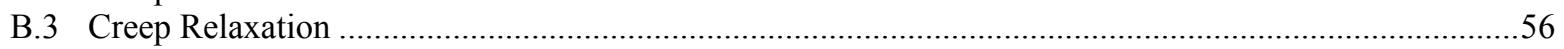

Appendix B .—Design Strength and Indices For Creep Deflection ........................................................................57

B.1 Simple Tension or Compression: Minimum Weight Design ......................................................................57

B.2 Bending of Beams, Minimum Weight Design .......................................................................................58

B.2.1 Torsion of Shafts, Minimum Weight Design ..........................................................................60

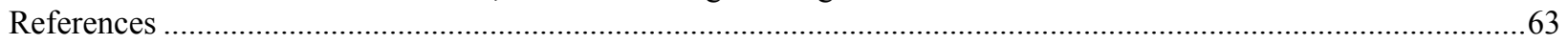





\title{
Materials Selection for Aerospace Systems
}

\author{
Steven M. Arnold \\ National Aeronautics and Space Administration \\ Glenn Research Center \\ Cleveland, Ohio 44135 \\ David Cebon and Mike Ashby \\ University of Cambridge \\ Cambridge CB2 1PZ United Kingdom
}

\section{Summary}

A systematic design-oriented, five-step approach to material selection is described: 1) establishing design requirements, 2) material screening, 3) ranking, 4) researching specific candidates and 5) applying specific cultural constraints to the selection process. At the core of this approach is the definition performance indices (i.e., particular combinations of material properties that embody the performance of a given component) in conjunction with material property charts. These material selection charts, which plot one property against another, are introduced and shown to provide a powerful graphical environment wherein one can apply and analyze quantitative selection criteria, such as those captured in performance indices, and make trade-offs between conflicting objectives. Finding a material with a high value of these indices maximizes the performance of the component. Two specific examples pertaining to aerospace (engine blades and pressure vessels) are examined, both at room temperature and elevated temperature (where time-dependent effects are important) to demonstrate the methodology. The discussion then turns to engineered/hybrid materials and how these can be effectively tailored to fill in holes in the material property space, so as to enable innovation and increases in performance as compared to monolithic materials. Finally, a brief discussion is presented on managing the data needed for materials selection, including collection, analysis, deployment, and maintenance issues.

\subsection{Introduction}

The importance of weight reduction in aerospace systems has been a major factor from the very beginning. Consequently, the use of new materials (e.g., dual alloy turbine disks and composite materials (ceramic, metallic and polymer based)) and new types of structural concepts, particularly the thin-walled type (sized primarily based on buckling) have dominated. Clearly, from a designer's perspective the primary function of a structure is to transmit forces through space with the minimum possible weight and cost to the customer. Typically the job of a designer is to balance a variety of functional requirements (i.e., types of loading conditions (tension, compression, bending, vibration, cyclic, etc.) with constraints (manufacturability, geometric limits, environmental aspects, maintainability, to name a few) so as to arrive at the "optimum" choice of structural concept and material selection for a given weight and/or cost (Figure 1).

This task can often be a daunting one for both the inexperienced as well as experience practitioner due to the wide range of choices available. Further, depending upon the engineer's background, for example a materials versus mechanics oriented professional, their answer to the question of designing for suitable deflection, for example, maybe quite different. The materials oriented person would typically think they need a material with high stiffness (i.e., Young's modulus $(E)$ ), whereas the structures oriented person would naturally think of high rigidity (e.g., EI, the product of Young's modulus and the moment of inertia $(I)$ given a beam in bending); the first being material property oriented and the other performance oriented. This diversity in perspective is precisely why a robust and systematic methodology for connecting material and application is required as will be presented and illustrated in this chapter. 


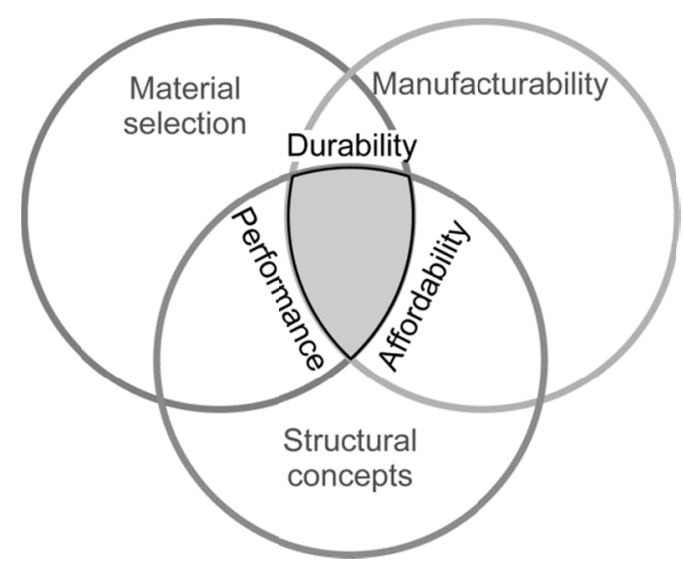

Figure 1.-Schematic indicating the intersection of material, manufacturability and structural concept which determines the engineering utility (sweet spot) of a given "system".

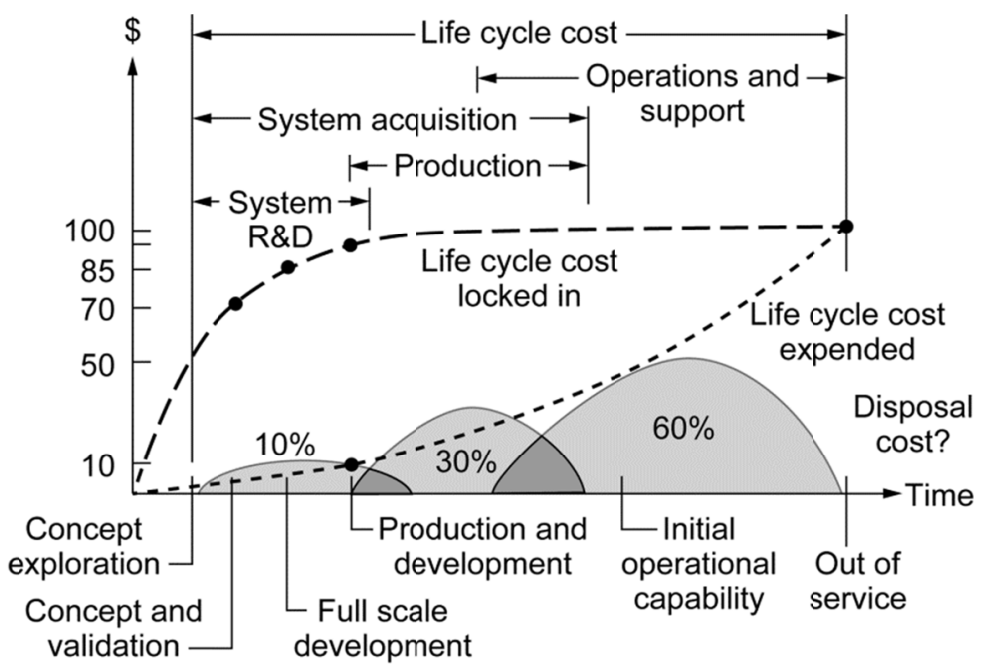

Figure 2.-Life cycle cost (Larson and Pranke, 1999).

Further, design is not a linear process as it involves multiple iterations, since the consequences of choices (both structural and material) made at the preliminary concept or embodiment stages may not become apparent until much later downstream when the details are examined more fully. Consequently, iteration (looping back to explore alternatives) is an essential part of the design process as is material selection which enters each stage of the design process. The importance of incorporating as much physics and understanding of the problem as early in the design process is dramatically illustrated in Figure 2, wherein it has been proposed that over 50 percent of the life cycle cost of a given system is locked in by the end of the preliminary design phase, with 85 percent by the end of the embodiment phase, and almost 100 percent by the time one goes to production, yet only 10 percent of the life cycle cost has been expended. This figure strongly suggests, once again, the need for a robust and systematic methodology for connecting material selection and application requirements as early in the process as possible to reduce the overall life cycle cost.

Clearly, material information is central to all aspects of engineering products. However, the nature of the data needed in the early stages differs greatly in its level of precision and breadth from that needed later on. At the concept-stage, the designer requires approximate property-values, but for the widest possible range of materials. All options are open: a polymer may be the best choice for one concept, a metal for another, even though the function is the same. The problem, at this stage, is not precision and 
detail; it is breadth and speed of access: how can the vast range of data be presented to give the designer the greatest freedom in considering alternatives?

At the embodiment stage the landscape has narrowed. Here we need data for a subset of materials, but at a higher level of precision and detail. These are found in the more specialized handbooks and software that deal with a single class or sub-class of materials - metals, or just aluminum alloys, for instance. The risk now is that of losing sight of the bigger spread of materials to which we must return if the details do not work out; it is easy to get trapped into a single line of thinking (or set of "connections") when other combinations of connections offer a better solution to the design problem.

The final stage of detailed design requires a still higher level of precision and detail, but for only one or a very few materials. Such information is best found in the data-sheets issued by the material producers themselves, and in detailed databases for restricted material classes. A given material (polyethylene, for instance) has a range of properties that derive from differences manufacturing by different producers make it. At the detailed design stage, a supplier must be identified, and the properties of his product must be used in the design calculations, given the slight properly differences observed in a material for different material producers. And sometimes even this is not good enough. If the component is a critical one (meaning that its failure could, in some sense or another, be disastrous) then it may be prudent to conduct in-house tests to measure the critical properties, using a sample of the material that will be used to make the product itself.

At the core of the material selection process is the inherent interaction between function, material, shape and process (see Figure 3). Function dictates the choice of both material and shape; and yet the selection of a material and process cannot be separated from the choice of shape. ${ }^{1}$ Since in order to manufacture a shape, the material is subjected to processes ${ }^{2}$ and these processes are influenced by the material's formability, machinability, weldability, heat-treatability, and so on. Also, process obviously interacts with shape - the process determines the shape, the size, the precision and, of course, the cost. And, of course, the processing route can dramatically change the properties of the material. These interactions are two-way: specification of shape restricts the choice of material and process; but equally the specification of process limits the materials you can use and the shapes they can take. The more sophisticated the design the greater the interactions and consequently, the tighter the specifications.

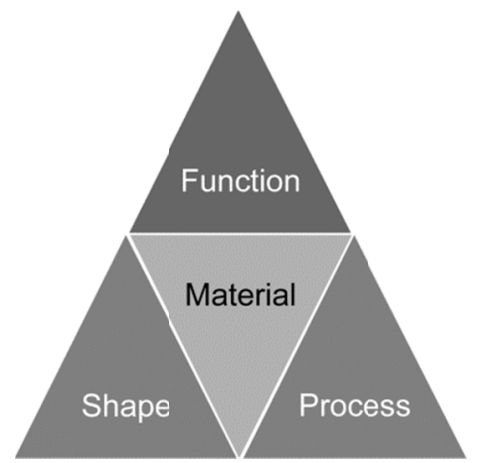

Figure 3.-At the core of material selection in mechanical design is the interaction between function, material, shape and process.

\footnotetext{
${ }^{1}$ The word "shape" is used here to include the external, macro-shape, and - when necessary — the internal, or micro-shape, as in a honeycomb or cellular structure.

${ }^{2}$ Here processes include: primary forming processes (like casting and forging), material removal processes (machining, drilling), finishing processes (such as polishing) and joining processes (e.g., welding).
} 


\subsection{A Systematic Approach to Materials Selection}

To 'select' means 'to choose'. But from what? Behind the concept of selection lies that of the permissible set of entities from which the choice is to be made. Within an engineering enterprise, the permissible set of materials will probably be the "preferred' list, specified by the "Materials Authority". However, for truly 'optimal' materials selection, the permissible set of entities must include all materials: all metals, all polymers, all ceramics and glasses, all composites. We refer to this as the 'Universe' of materials. If some of these materials are left out, the selection is no longer optimal over all materials but is only optimal over some subset of them. If, for example, the choice is limited to metals from the start, then the selection can only be optimal over the single family of materials, that of metals.

There is a second implication to the concept of selection. It is that all members of the permissible set must be regarded as candidates - they are, after all, viable choices - until, by a series of selection stages, they are shown to be otherwise. From this arise several key requirements of a data structure for the Selection database. The selection table must be comprehensive (includes all members of the permissible set). It should be structured - that is it must contain attributes that are universal (apply to all members of the permissible set of entities) and the attributes should be discriminating (have recognizably different values for different members of the permissible set). Similar considerations apply to any selection exercise (Cebon and Ashby 2000).

In the universe of materials, many attributes are universal and discriminating: density, bulk modulus and thermal conductivity are examples. Universal attributes can be used for screening and ranking, the initial

stage of any selection exercise. But if the values of one or more screening attributes are grossly inaccurate or missing, that material will be eliminated by default. It is important, therefore, that the database be complete having no holes or gaps in the records which would make a material fail a selection by default due to absence of data and be of high quality, meaning that the data in it can be trusted. This creates the need for data checking and estimation, which are tackled by methods described in Ashby (1998).

There are four main steps, which we here call translation, screening/rejection, ranking, and supporting information (research and organizational cultural constraints) see Figure 4. The steps can be likened to those in selecting a candidate for a job. The job is first analyzed (i.e., essential skills and required experience of the candidate identified; "translation") and advertised. Some of these are simple go/no go criteria like the requirement that the applicant "must have a valid driving license", or "a degree in materials science", eliminating anyone who does not ("screening"). Others imply a criterion of excellence, such as "typing speed and accuracy are priorities", or "preference will be given to candidates with a substantial publication list", implying that applicants will be ranked by these criteria ("ranking"). Finally references and interviews are sought for the top ranked candidates, building a file of supporting information (research and local cultural constraints) — an opportunity to probe deeply into character and potential.

\subsection{Methodology}

\subsubsection{Step 1: Translation}

How are the design requirements for a component (defining what it must do) translated into a prescription for a material? Any engineering component has one or more functions: to support a load, to contain a pressure, to transmit heat, and so forth. This must be achieved subject to constraints: that certain dimensions are fixed; that the component must carry the design loads or pressures without failure; that it insulates or conducts; that it can function in a certain range of temperature and in a given environment; and many more. In designing the component, the designer has an objective: to make it as cheap as possible, perhaps, or as light, or as safe, or perhaps some combination of these. Certain parameters can be adjusted to optimize the objective giving the designer the freedom to vary dimensions that have not been 


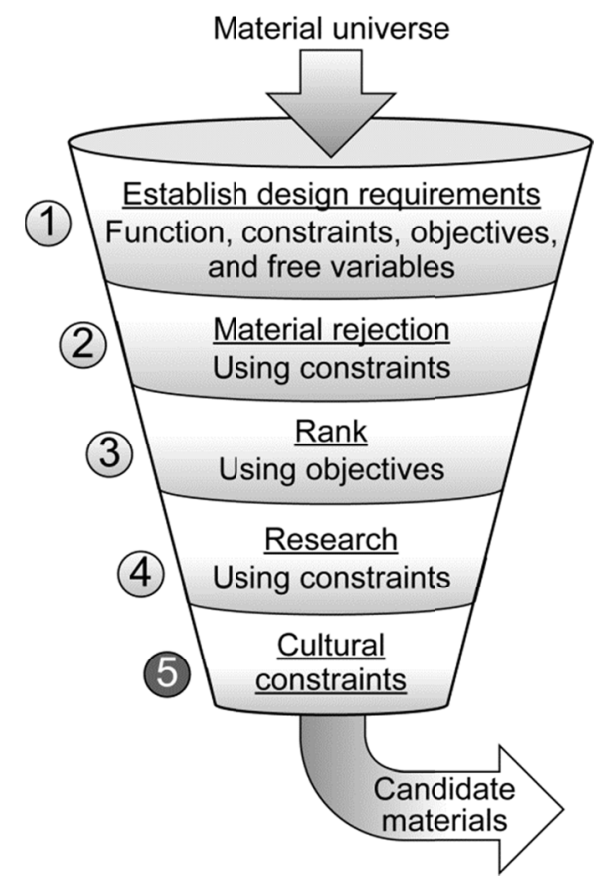

Figure 4.- Schematic illustrating a material selection strategy with the five specific steps being: Design requirements, material screening/rejection, ranking, research and organizational cultural constraints are shown.

constrained by design requirements and, most importantly, free to choose the material for the component. We refer to these as free variables. Function and constraints, objective and free variables (see Table 1) define the boundary conditions for selecting a material and - in the case of load-bearing components - $\mathrm{a}$ shape for its cross section. The first step in relating design requirements to material properties is a clear statement of function, constraints, objective, and free variables.

TABLE 1.-FUNCTION, CONSTRAINTS, OBJECTIVES AND FREE VARIABLES

\begin{tabular}{|l|l|}
\hline Function & What does component do? \\
\hline Constraints* & $\begin{array}{l}\text { What non-negotiable conditions must be met? } \\
\text { What negotiable but desirable conditions? }\end{array}$ \\
\hline Objective & What is to be maximized or minimized? \\
\hline Free variables & What parameters of the problem is the designer free to change? \\
\hline \\
"It is sometimes useful to distinguish between "hard" and "soft" constraints. Stiffness and strength might be \\
absolute requirements (hard constraints); cost might be negotiable (a soft constraint).
\end{tabular}

\subsubsection{Function}

Structural elements are components that perform a physical function (i.e., they carry loads, transmit heat, store energy, and so on) in short, they satisfy functional requirements. The functional requirements are specified by the design; for example a tie rod must carry a specified tensile load; a spring must provide a given restoring force or store a given energy; a heat exchanger must transmit heat at a given heat flux. Furthermore the loading on a given component/structure can generally be decomposed into some combination of axial tension or compression, bending and torsion; wherein almost always, one mode dominates. So common is this that the functional name given to a component often describes the way it is loaded: ties carry tensile loads; beams carry bending moments; shafts carry torques; and columns carry compressive axial loads. The words "tie", "beam", "shaft", and "column" each imply a function; such that many simple engineering functions can be described by single words or short phrases, saving the need to explain the function in detail. Table 2 itemizes some aerospace components and their associated simple idealization that can be extremely useful for material selection purposes. 
TABLE 2.-AEROSPACE APPLICATIONS/IDEALIZATIONS

\begin{tabular}{|c|c|c|c|}
\hline Application & Idealization & Loading & Constraints \\
\hline Truss framework & Tie & Tension & Strength \\
\hline Fuselages & Cylinder & $\begin{array}{l}\text { Compression } \\
\text { Tension } \\
\text { Bending }\end{array}$ & $\begin{array}{l}\text { Buckling } \\
\text { Strength } \\
\text { Deflection }\end{array}$ \\
\hline Shafts & Thin walled tube/Beam & $\begin{array}{l}\text { Torque } \\
\text { Rotation } \\
\text { Bending }\end{array}$ & $\begin{array}{l}\text { Bending } \\
\text { Shear } \\
\text { Vibration }\end{array}$ \\
\hline Combustion Chambers & $\begin{array}{l}\text { Thin walled Cylinder, } \\
\text { Internal pressure }\end{array}$ & $\begin{array}{l}\text { Pressure } \\
\text { Noise }\end{array}$ & $\begin{array}{l}\text { Thermal } \\
\text { Oxidation }\end{array}$ \\
\hline $\begin{array}{c}\text { Blades } \\
\text { (Fan, Compressor, } \\
\text { Turbine) }\end{array}$ & $\begin{array}{l}\text { Tie } \\
\text { Beam }\end{array}$ & $\begin{array}{c}\text { Bending } \\
\text { Tension } \\
\text { Fatigue } \\
\text { Thermal } \\
\text { Creep }\end{array}$ & $\begin{array}{l}\text { Deflection, Strength, Vibration, } \\
\text { Erosion, Temperature }\end{array}$ \\
\hline $\begin{array}{c}\text { Disks } \\
\text { (Compressor, Turbine) }\end{array}$ & Disk & $\begin{array}{l}\text { Rotation, Thermomechanical } \\
\text { Fatigue }\end{array}$ & $\begin{array}{l}\text { Strength, Ductility, Toughness, } \\
\text { Oxidation }\end{array}$ \\
\hline $\begin{array}{l}\text { Space Truss } \\
\text { Framework }\end{array}$ & Tie rod & Axial Loading & Strength, Buckling \\
\hline Nozzles & Thin walled Cylinder & $\begin{array}{l}\text { Pressure } \\
\text { Noise } \\
\text { Thermal }\end{array}$ & Strength, Vibration \\
\hline Wing & Plate & $\begin{array}{c}\text { Bending } \\
\text { Tension } \\
\text { Twist } \\
\text { Vibration } \\
\text { Fatigue }\end{array}$ & $\begin{array}{l}\text { Buckling, } \\
\text { Vibration, Strength } \\
\text { Deflection }\end{array}$ \\
\hline Cryogenic Tanks & Spherical Shell & $\begin{array}{l}\text { Internal Pressure } \\
\text { Thermal }\end{array}$ & $\begin{array}{c}\text { Strength, low temperature } \\
\text { Yield before break } \\
\text { Leak before break }\end{array}$ \\
\hline
\end{tabular}

\subsubsection{Constraints}

Constraints are design requirements that must be satisfied: for example, the minimum working temperature of a material must be $\leq-20^{\circ} \mathrm{C}$; the strength must be $\geq 400 \mathrm{MPa}$; the fracture toughness must be $\geq 15 \mathrm{MPa} \sqrt{\mathrm{m}}$, and so on. Constraints screen out unsuitable choices or enable rejection of specific materials for cause.

\subsubsection{Objectives}

Objectives are design criteria that must be maximized or minimized to optimize the performance of a component. Their function is to rank the materials and facilitate selection of the best candidates. For materials selection, the objectives can be used to generate 'material performance indices,' which are combinations of material properties that characterize performance in a given application (see Sec. 2.2). Typical examples are the specific stiffness of a material $E / \rho$, and the specific strength $\sigma_{f} / \rho$ ( $E$ is the Young's modulus, $\sigma_{f}$ is the failure strength and $\rho$ is the density). These particular indices can be used to select the optimum material for a light, stiff tie rod, or a light, strong tie rod, respectively. Many material performance indices have been derived and tabulated for standard design cases in mechanical, structural, thermo-mechanical, and electro-mechanical engineering (Ashby 2005).

\subsubsection{Free Variables}

Free variables are any parameters that are left open to the designer's free choice. Examples are: crosssectional area, length, thickness, material type, color, etc. 


\subsubsection{Step 2: Screening/Rejection}

Unbiased selection requires that all permissible materials are considered to be candidates until shown to be otherwise. Rejection eliminates candidates that cannot do the job at all because one or more of their attributes lies outside the limits set by the constraints. As examples, the requirement that "the component must function in boiling water," or that "the component must be transparent" imposes obvious limits on the attributes of maximum service temperature and optical transparency that successful candidates must meet. We refer to these as attribute limits. One should not be too hasty in applying attribute limits however, as it may be possible to engineer around them; for example, a component that gets too hot maybe cooled (or the geometry modified to enable use of the same material at lower stress, $E I$ versus $E$ ), or one that corrodes may be coated with a protective film. An aerospace specific case in point is the desire by many an engineer to impose a minimum limit on fracture toughness and strain to failure (e.g., $K_{\mathrm{IC}}>$ $15 \mathrm{MPa} / \mathrm{m}^{2}$ and $e_{f}>2$ percent) in order to ensure adequate tolerance to stress concentrations. This is most likely to be a rash step this early in the design process, as it would eliminate all polymers, ceramics and many composite materials from consideration. Since a more innovative designer may be able to put these materials to good use. Consequently, at this stage in the process the engineer needs to try to keep as many options open as possible.

\subsubsection{Step 3: Ranking}

Attribute limits do not, however, help with ordering the candidates that remain after the screening constraints have been applied. To do this we need optimization criteria. They are found in the material

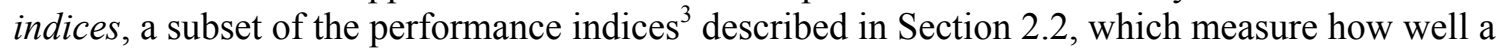
candidate can do the job. Performance is sometimes limited by a single property, sometimes by a combination of them. For example, the best materials for buoyancy are those with the lowest density, $\rho$; those best for thermal insulation the ones with the smallest values of the thermal conductivity, $\lambda$. Here maximizing or minimizing a single property maximizes performance. But as we shall see - the best materials for a light stiff tie-rod are those with the greatest value of the specific stiffness, $E / \rho$, where $E$ is Young's modulus. The best materials for a spring are those with the greatest value of $\sigma_{f}^{2} / E$ where $\sigma_{f}$ is the failure stress. The property or property-group that maximizes performance for a given design is called its material index. There are many such indices, each associated with maximizing some aspect of performance. These indices provide significant insight into the types of optimization strategies needed as well as selection guidelines for the given problem at hand.

To summarize: material rejection (or screening) isolates candidates that are capable of doing the job; ranking identifies those among them that can do the job best.

\subsubsection{Step 4: Research}

The outcome of Steps 1 through 3 produces a ranked short-list of candidates that meet the constraints and that maximizes or minimizes the criterion of excellence; whichever is required (this is why in Figure 4 we have used a funnel.

You could just choose the top-ranked candidate, but what bad secrets might it hide? What are its strengths and weaknesses? Does it have a good reputation? What, in a word, is its pedigree? To proceed further we seek a detailed profile of each candidate: it's supporting information (see Step 4 in Figure 4). Supporting information differs greatly from the structured property data used for screening. Typically, it is descriptive, graphical or pictorial: case studies or experience of previous uses of the material, details of its corrosion behavior in particular environments, information of availability and pricing, experience of its environmental impact. Such information is found in corporate documentation, handbooks, suppliers' data sheets, CD-based data sources and the world-wide web. Supporting information helps narrow the shortlist to a few final choices, allowing a definitive match to be made between design requirements and

\footnotetext{
${ }^{3}$ They provide criteria of excellence that allow ranking of materials by their ability to perform well in the given application.
} 
material attributes. Why are all these steps necessary? Without screening and ranking (material rejection), the candidate-pool can be enormous and the volume of supporting information overwhelming. Dipping into it, hoping to stumble on a good material, gets you nowhere. But once a small number of potential candidates has been identified by the screening-ranking steps, detailed supporting information can be sought for these few candidates, and the task becomes tractable.

\subsubsection{Step 5: Specific Cultural Constraints}

The final choice between competing candidates will, often, depend on local conditions: on in-house expertise or equipment, on the availability of local suppliers, and so forth. A systematic procedure cannot help here - the decision must instead be based on local/institutional knowledge. This does not mean that the result of the systematic procedure (describe above) is irrelevant. It is always important to know which material is best, even if, for local reasons (e.g., specific processing method for a possible material is to expensive), you decide not to use it.

\subsection{Material Performance Indices}

The screening and ranking process can be made quantitative by linking the technical (e.g., functional, geometric, material) and economic requirements of the design to the attribute profiles stored in a given database. The foundations of a robust and systematic ranking procedure are particular combinations of material properties that embody the performance of the component. These property combinations are called performance indices, as put forth by Ashby (2005). The performance, $P$, of a structural element is determined by three, typically independent, aspects: the functional requirements, $F$, the geometry, $G$, and the properties of the material, $M$, of which it is made. The performance $\mathrm{P}$ of the element can often be described by an equation of the form

$$
P=f(F, G, M)
$$

where $P$, the performance metric, describes some aspect of the performance of the component; (for example its mass, volume, cost, or life) and " $f($ )" means "a function of". Optimum design is the selection of the material and geometry that maximize or minimize $\mathrm{P}$, according to its functional requirements.

When this group of parameters can be assumed to be separable (that is, $M, F$ and $G$ are independent of each other), then the performance index is merely a product of three functions, $f_{1}, f_{2}$, and $f_{3}$;

$$
P=f_{1}(F) \cdot f_{2}(G) \cdot f_{3}(M)
$$

where the product $f_{1}(F) \cdot f_{2}(G)$ has been defined as the structural efficiency coefficient (and incorporates both functional requirements and geometry), and $f_{3}(M)$ is defined as the material efficiency coefficient. With this significant simplification, the overall performance index can be maximized or minimized by selecting a material to minimize $f_{3}(M)$, independent of the details of the design. This enables the optimal subset of materials to be identified without solving the complete design problem. While this is clearly a simplification of the full coupled design problem, it can provide a great deal of insight in the preliminary design stage of a project. This powerful and general method is simple, provided one is able to clearly identify, from the outset, the objective(s) (what you are trying to maximize or minimize), the constraints, and which parameters are specified and which are free.

When any component function is combined with specific constraints and objectives, a specific material index $\left(M_{p}=f_{3}(M)\right)$ is produced as illustrated in Figure 5. Therefore, it is possible to develop numerous material and structural indices that enable one to efficiently and accurately perform material selection for a variety of design functions (e.g., stiffness, strength, and vibration-limited designs, as well as damage-tolerant, electro-mechanical, thermal, and thermal-mechanical designs) on a number of fundamental structural components described in Table 2 (i.e., tie, beam, shaft, column, panel, cylinder/shell with internal pressure and rotating disks), see Appendix A and Ashby (2005) for additional 
details. The power of this approach is clearly illustrated by examining the differences in the resulting material index for a tie, beam and plate (see Figure 6) with a specified stiffness; that is $\frac{\rho}{E} ; \frac{\rho}{E^{1 / 2}} ; \frac{\rho}{E^{1 / 3}}$, respectively. Clearly, the only difference in the index is the exponent on Young's modulus where for a tie its one, a beam its $1 / 2$ and a plate is $1 / 3$. Consequently, the best materials for a light, stiff tie rod, beam or plate are those with the smallest values of $\frac{\rho}{E} ; \frac{\rho}{E^{1 / 2}} ; \frac{\rho}{E^{1 / 3}}$, respectively. The significance of this difference in exponents on the choice is best seen by creating a plot of Young's modulus versus density (i.e., a material property chart) as will be described in Section 2.3.

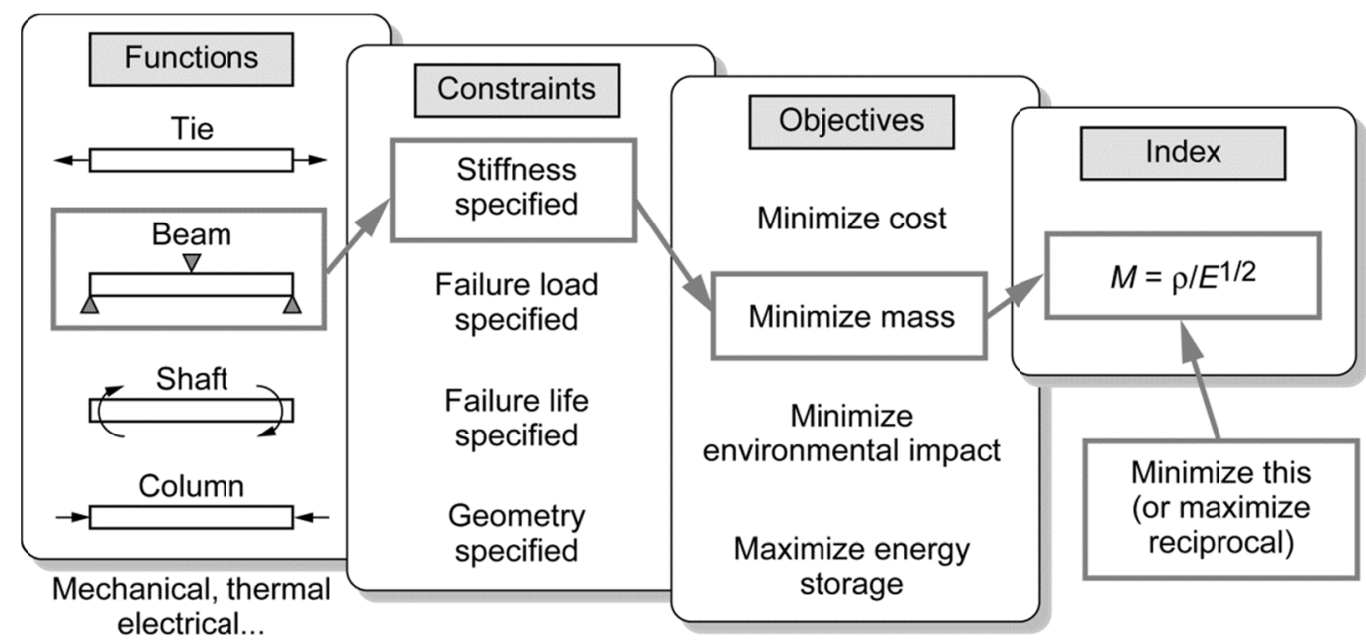

Figure 5.-The specification of function, objective, and constraint leads to a material index (Ashby 2005).
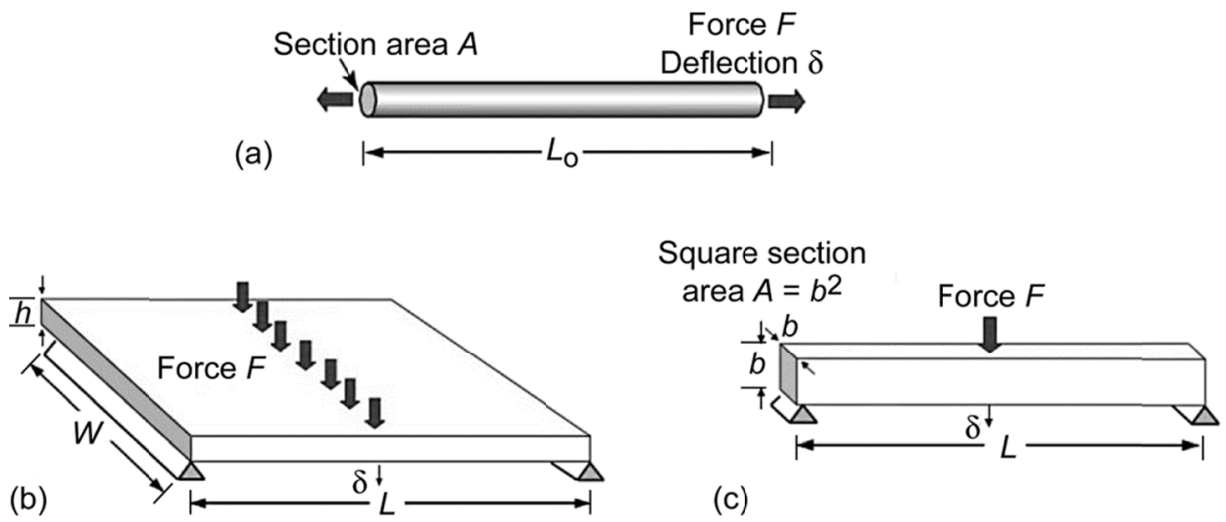

(c)

Figure 6.-(a) A tie with cross-section area $A$, loaded in tension. Its stiffness is $S=F / \delta$ where $F$ is the load and $\delta$ is the extension. (b) A panel loaded in bending. Its stiffness is $S=F / \delta$, where $F$ is the total load and $\delta$ is the bending deflection. (c) A beam of square section, loaded in bending. Its stiffness is $S=F / \delta$, where $F$ is the load and $\delta$ is the bending deflection. 


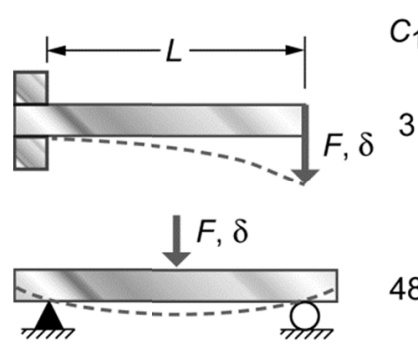

$F, \delta$

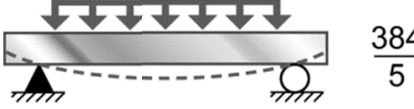

Figure 7.-Defines the influence of the end constraint the elastic flexural stiffness for beams and plates, see Table 3.

TABLE 3.-DESIGN REQUIREMENTS LIGHT STIFF: TIE, BEAM, PLATE.

\begin{tabular}{|c|c|c|c|}
\hline Function & Tie & $\begin{array}{c}\text { Beam } \\
(A=b \cdot b)\end{array}$ & $\begin{array}{c}\text { Plate } \\
(A=h \cdot W)\end{array}$ \\
\hline \multicolumn{4}{|l|}{ Constraint } \\
\hline Functional & $\begin{array}{l}\text { Tie must support axial } \\
\text { tensile load } F \text { without } \\
\text { deflecting too much; } \\
\left(S=F / \delta \geq A \cdot E / L_{o}\right)\end{array}$ & $\begin{array}{l}\text { Beam must support a bending load } \\
F \text { without deflecting too much, } \\
\text { meaning that the bending stiffness } \\
S \text { is specified }\left(S \geq C_{1} \cdot E \cdot I / L^{3}\right)\end{array}$ & $\begin{array}{l}\text { Panel must support a bending load } F \\
\text { without deflecting too much, i.e., } S \text { is } \\
\text { specified }\left(S \geq \mathrm{C}_{1} \cdot E \cdot I / L^{3}\right)\end{array}$ \\
\hline Geometric & Length Lo is specified & Length $\mathrm{L}$ is specified & Length $L$ and width $W$ are specified \\
\hline Objective & Minimize mass $(m=A \cdot L \cdot \rho)$ & Minimize mass $(m=A \cdot L \cdot \rho)$ & Minimize mass $(m=W \cdot h \cdot L \cdot \rho)$ \\
\hline Free Variables & \begin{tabular}{|l|} 
Cross section area, $A$ \\
Choice of material \\
\end{tabular} & $\begin{array}{l}\text { Cross section area, } A \\
\text { Choice of material } \\
\end{array}$ & $\begin{array}{l}\text { Panel thickness, } h \\
\text { Choice of material } \\
\end{array}$ \\
\hline $\begin{array}{l}\text { Performance } \\
\text { equation }\end{array}$ & $m \geq(S)\left(L^{2}\right)\left(\frac{\rho}{E}\right)$ & $m \geq\left(\frac{12 S}{C_{1} L}\right)^{1 / 2} \frac{12 S}{C_{1} L}\left(L^{3}\right)\left(\frac{\rho}{E^{1 / 2}}\right)$ & $m \geq\left(\frac{12 S}{C_{1} L}\right)^{1 / 3} \frac{12 S}{C_{1} W}\left(W L^{2}\right)\left(\frac{\rho}{E^{1 / 3}}\right)$ \\
\hline
\end{tabular}

Before continuing we want to introduced two types of applications that will be utilized throughout this chapter to demonstrate the various concepts discussed herein; these are those of blades be they in the fan (low temperature), compressor (mid temperature) or turbine (high temperature) sections of a jet engine (see Figure 8) and that of an internal pressure vessel (e.g., cryogenic tank, fuel lines or combustion chambers within a jet engine, see Figure 10). Here we will establish the indices that will be useful for material selection.

\subsubsection{Case Study 1a: Blades}

An important aeronautic application that one can utilize to illustrate the material selection process is that of fan blades, compressor blades or turbine blades in a gas turbine engine, as shown in Figure 8. The main functional distinction in the blades used in the different location is size, shape and temperature capacity. Figure 8(c) illustrates how a typical blade can be idealized as a cantilever beam subjected to a combination of axial tension (due to centrifugal loads), bending (due to pressure variations across the blade) and vibration loadings (due to the motion of the rotor and rapidly changing air flow field in the engine). 

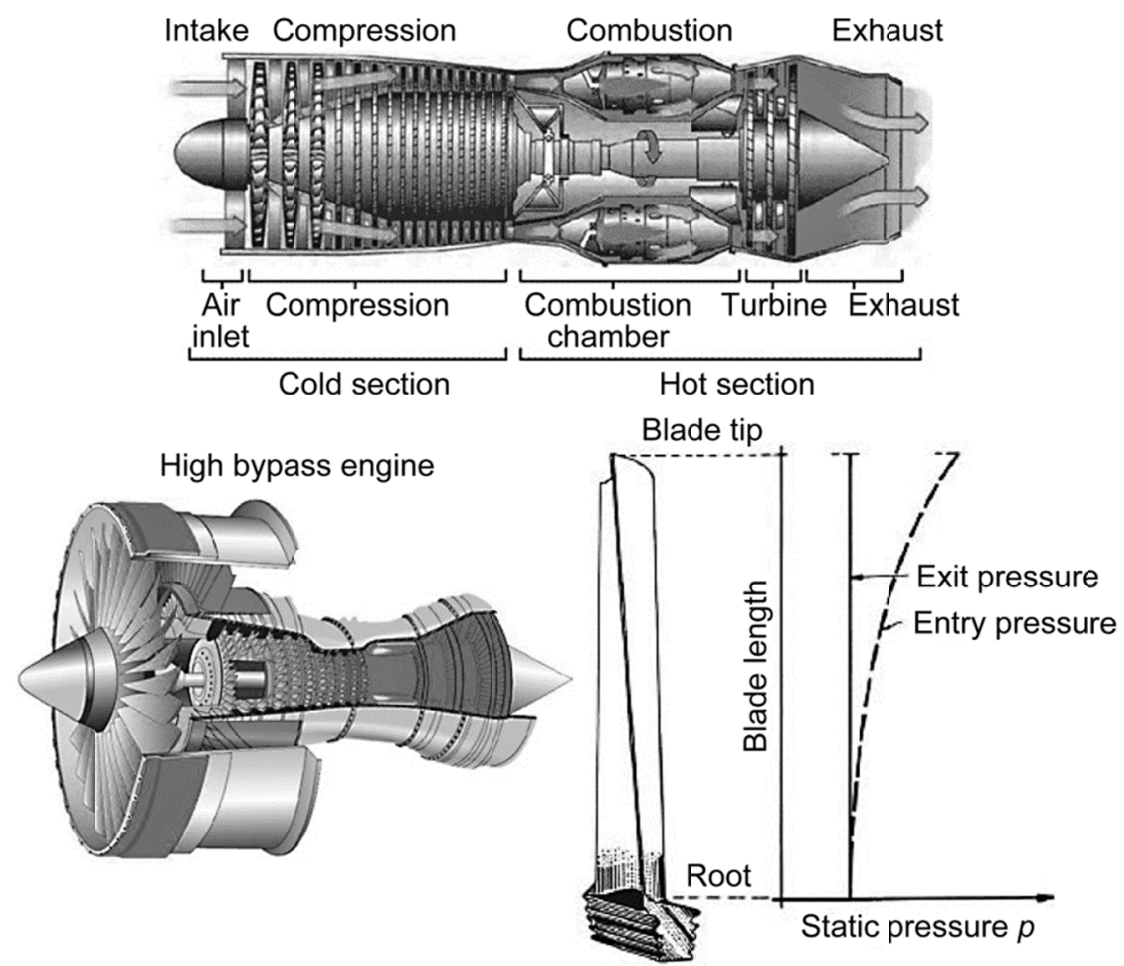

Figure 8.-Schematics of turbine jet engines (a) with and (b) without high by pass ratios, along with a typical blade response (c) due to engine operations..

The length $L$ and force $F$ are specified and are therefore fixed; the cross-section $A$, is free. We can reduce the mass by reducing the cross-section, but there is a constraint: the section-area A must be sufficient to carry the tensile load $F$, given a failure strength $\sigma_{f}$; thus requiring that

$$
A \geq \frac{F}{\sigma_{f}}
$$

Consequently, combining this constraint with the objective function we arrive at:

$$
m \geq(F)(L)\left(\frac{\rho}{\sigma_{f}}\right)
$$

Note the form of this result. The first bracket contains the specified load $F$. The second bracket contains the specified geometry (the length $L$ of the tie/beam) which together makeup the structural index previously discussed. The last bracket contains a specific relationship of material properties which were previously defined as the material index. The lightest beam that will carry $F$ safely then is that one made of the material with the smallest value of $\rho / \sigma_{f}$. We could define this as the material index of the problem, seeking a minimum, but it is more usual, when dealing with specific properties, to express them in a form for which a maximum is sought. We therefore invert the material properties in Eq. (4) and define the material index $M_{1}$, as

$$
M_{1} \geq\left(\frac{\sigma_{f}}{\rho}\right)
$$


Therefore, the lightest beam or tie-rod that will safely carry the load $F$ without failing is that with the largest value of this index, the "specific strength". A similar calculation for a light stiff tie (one for which the stiffness $S$ rather than the strength $\sigma_{f}$ is specified) leads to the previous index, given in Table 3 .

\subsubsection{Performance Index for Bending at Room Temperature}

Consider the case of a beam of section-area, $A$, length, $L$, subjected to bending, it must support a specified load $F$ without failing and be as light as possible, see Figure 6 . From strength of materials theory, the stress due to bending is

$$
\sigma_{\max }=\frac{M y}{I}=\frac{M}{Z}
$$

where $I$ is the moment of inertia, $y$ the distance from the neutral axis to outer edge of the beam, and $Z$ is the section modulus. Failure occurs than if the load exceeds the moment, i.e.,

$$
M=Z \sigma_{\max }=Z \sigma_{f}
$$

where again $\sigma_{f}$ is the stress at which failure of the material will occur. To enable the section shape to change for the same area of material, the section modulus $Z$ is replaced by $\phi_{B} Z_{o}$ where $Z_{o}$ is the section modulus for a square beam, i.e., $Z_{o}=\mathrm{A}^{3 / 2} / 6$, and $\phi_{B}$ is the shape efficiency factor. The maximum shape factor can be considered to be a material property and used profitably in the selection of materials. Note, solid equiaxed sections (circles, squares, hexagons, etc.) all have efficiency factors close to 1; whereas efficient shapes like thin-walled tubes or I-sections can have shape factors of 50 or more. The physical limit to $\phi_{B}$ is usually set by local buckling of the component.

As before in the case of the tie rod, the mass can be decreased by reducing the cross-section, but there is a constraint: the section-area $A$ must be sufficient to carry the bending stress, given a failure strength $\sigma_{j}$; thus requiring that

$$
A \geq\left(6 \frac{M}{\phi_{B} \sigma_{f}}\right)^{2 / 3}
$$

Finally, combining this constraint with the objective of minimum weight, $m=\rho L A$, one obtains the following expression:

$$
m \geq(6 M)^{2 / 3} L\left(\frac{\rho^{3 / 2}}{\phi_{B} \sigma_{f}}\right)^{2 / 3}
$$

Consequently, the best material and shape combination is that with the greatest value of the material index

$$
M_{2} \geq \frac{\left(\phi_{B} \sigma_{f}\right)^{2 / 3}}{\rho}
$$

\subsubsection{Performance Index for Vibration at Room Temperature}

There are two ways to mitigate vibration of a mechanical system: by ensuring that the input does not excite a natural frequency, or, if this is not possible, by ensuring that the system is sufficiently well damped to avoid excessive motion at resonance. Here we consider the first of these. In many cases, the need is to avoid 
exciting the lowest natural frequency of the system, and this can be achieved by ensuring that it occurs at high frequency, relative to the input.

Any undamped system vibrating at one of its natural frequencies can be reduced to the simple problem of a mass $m$ attached to a spring of stiffness $k$ - the restoring force per unit displacement. The natural frequency of such a system is

$$
f=\frac{1}{2 \pi} \sqrt{\frac{k}{m}}
$$

Different geometries require appropriate estimates of the effective stiffness, $k$, and mass, $m-$ often these can be estimated with sufficient accuracy by approximate modeling. Depending on the geometry of the beam and the end constraints, the higher natural frequencies of rods and beams can be simple multiples of the lowest. Figure 9 shows the lowest natural frequencies of the flexural modes of uniform beams or plates of length $L$ with various end constraints. The spring stiffness $k$ is equivalent to the stiffness $S$ in Table 3 for beam/plate bending, so the natural frequencies can be written:

$$
f=\frac{C_{2}}{2 \pi} \sqrt{\frac{E I}{m_{o} L^{4}}}
$$

where $C_{2}$ (given in Figure 9) depends on the end constraints and $m_{o}$ is the mass of the beam per unit length. The mass per unit length is just the area times the density, $A \rho$, so the natural frequency becomes

$$
f=\frac{C_{2}}{2 \pi} \sqrt{\frac{A}{12 L^{4}}} \sqrt{\frac{E \emptyset_{B}}{\rho}}
$$

where $I=\phi_{B} I_{o}$ has been utilized to enable the most efficient shape to be considered. Thus, frequencies scale as $M_{3}=\sqrt{E \emptyset_{B} / \rho}$ when all dimensions are specified or when the stiffness is specified

$$
f=\frac{C_{2}}{2 \pi}\left(\frac{S}{12 L^{5}}\right)^{1 / 2} \sqrt{\frac{E \phi_{B}}{\rho}}
$$

the frequencies scale with $\frac{\sqrt{E \Phi_{B}}}{\rho}$.
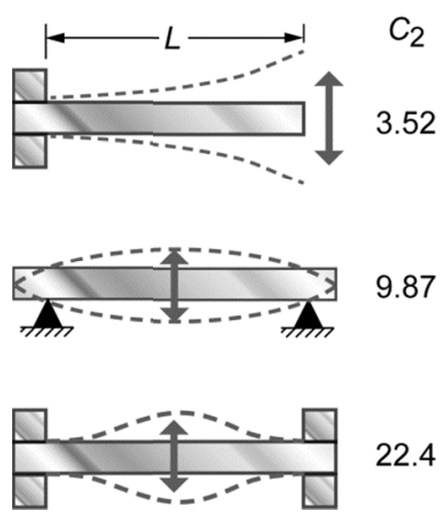

Figure 9.-The natural vibration modes of beams clamped in different ways. 


\subsubsection{Case Study 2a: Pressure Vessels}

Multiple applications/structures can be classified as cylindrical or spherical in nature, particularly in the case of space structures. Often these structures are internally pressurized as well, for example the feed lines on rocket engines, composite overwrap pressure vessels, cryogenic fuel tanks, and expendable/reusable launch vehicles, as shown in Figure 10. Consequently, in this case study, performance indices pertinent to cylindrical/spherical pressure vessels will be identified.

In the case of cryogenic storage tanks, multiple design configurations can be, and have been, envisioned from a single tank with insulation to hybrid tanks with either insulating materials or pure vacuum in between walls or various combinations thereof. The overall objective of the designs is to have a safe, lightweight, thermally-efficient cryogenic storage system. Some important tank system parameters relative to flight durations are presented in Table 4. The materials, tank structural configurations, and insulation system options are numerous and interdependent.

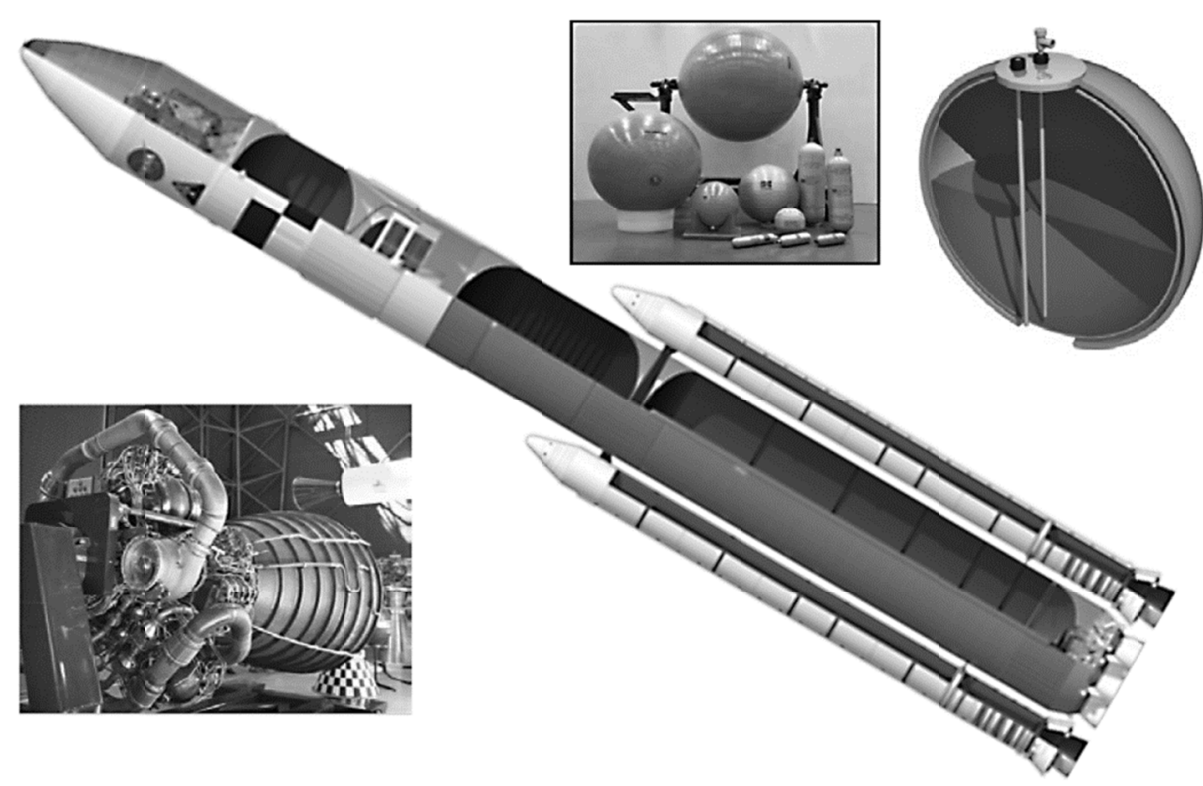

Figure 10.-Various space structures/components/vessels; a) Space Shuttle Main Engine, SSME, b) schematic of Ares $V$ heavy lift system, c) composite over wrap pressure vessels, d) double walled cryogenic storage tank. .

TABLE 4.-IMPORTANT TANK SYSTEM PARAMETERS

RELATIVE TO FLIGHT DURATION

[Listed in order of importance.]

\begin{tabular}{|l|l|}
\hline & Mass density \\
Short flight & Strength and toughness \\
duration & Coefficient of thermal expansion \\
& Stiffness \\
& Thermal diffusivity \\
& Thermal conductivity \\
\hline & Mass density \\
& Thermal conductivity \\
Long flight & Strength and toughness \\
duration & Coefficient of thermal expansion \\
& Stiffness \\
& Thermal diffusivity \\
\hline
\end{tabular}


The key material indices applicable for both thermal and mechanical issues of interest in the case of cryogenic tanks are shown in Table 5. Clearly it is desirable to use materials that possess high strength, high fracture toughness, and high stiffness, as well as low density and low permeation to liquid and gaseous hydrogen; however, no single material provides all these attributes simultaneously.

Consequently, material performance indices associated with these properties, such as those given in Table 5 , must be used to identify the best material candidates for hybrid tank wall construction. Among these parameters, strength and density tend to dominate the design criteria.

TABLE 5.-PERFORMANCE INDICES FOR THERMAL AND MECHANICAL COMPONENTS OF CRYOGENIC STORAGE TANK

\begin{tabular}{|l|c|}
\hline \multicolumn{1}{|c|}{ Function and constraints } & $\begin{array}{c}\text { Performance index, } \\
\text { maximize }\end{array}$ \\
\hline \multicolumn{2}{|c|}{ Thermal } \\
\hline Minimum heat flux at steady state, fixed thickness & $1 / k$ \\
Minimum temperature rise in specified time, fixed thickness & $1 / \mathrm{a}$ \\
Maximum energy stored for given temperature rise and time & $k / \alpha^{1 / 2}$ \\
Minimum thermal distortion & $k / \alpha$ \\
\hline \multicolumn{2}{|c|}{ Mechanical } \\
\hline Strength-limiting design with minimum mass \\
Damage-tolerant design with minimum mass \\
Deformation-limiting design with minimum mass \\
$k=$ thermal conductivity \\
$a=$ thermal diffusivity $\left(k / \rho C_{p}\right)$ \\
$\rho=$ mass density \\
$C_{p}=$ specific heat \\
$\alpha=$ coefficient of thermal expansion \\
$\sigma_{f}=$ strength \\
$K_{\mathrm{I} c}=$ mode I fracture toughness \\
$E=$ Young's modulus \\
Time, $t=w^{2} / 2 a$ with $w=$ wall thickness.
\end{tabular}

In the case of thin-walled spherical pressure vessels of radius $R$, the stress in the wall is given by

$$
\sigma=\frac{P R}{2 t}
$$

And the mass of the thin-walled spherical tank is given by

$$
m=4 \pi R^{2} t \rho
$$

From fracture mechanics we know that a crack will propagate by fast fracture when the stress intensity factor, which is a combination of the applied far field stress, $\sigma$, and crack length, $2 c$, reaches the fracture toughness of the material, $K_{\mathrm{Ic}}$. This condition can be expressed by the following relation:

$$
K_{\mathrm{I} c}=Y \sigma \sqrt{\pi c}
$$

where $Y$ is a parameter that takes on various values depending upon the changes in crack geometries and loading conditions (see Broek (1984) and Anderson (1995)).

Consequently the internal pressure at which the working stress of the tank is below the critical stress that would cause a crack to propagate can be obtained by rearranging Eqs. (15) and (17) and substituting the results:

$$
P \leq \frac{2 t}{R}\left(\frac{K_{\mathrm{I} c}}{Y \sqrt{\pi c}}\right)
$$


Clearly, the largest pressure (for a given $R, t$ and $c$ ) is obtained for the material with the largest fracture toughness since the pressure in Eq. (18) is proportional to $K_{\mathrm{Ic}}$. Such a design, however, is not fail-safe, so additional conditions have been traditionally introduced to provide a greater level of safety. These are known as "yield-before-break" and "leak-before-break".

Yield-before-break requires that the stress to cause fracture be greater than that to yield the material, thus providing a state of detectable deformation prior to fracture. This condition is expressed as:

$$
C_{\max } \leq \frac{1}{\pi Y^{2}}\left(\frac{K_{\mathrm{I} c}}{\sigma_{y}}\right)^{2}
$$

where the stress in Eq. (17) has been replaced by the yield stress, $\sigma_{y}$, of the material. Consequently, the tolerable crack size, and thus integrity of the pressure vessel, is maximized by maximizing the following material index:

$$
M_{4}=\frac{K_{\mathrm{I} c}}{\sigma_{y}}
$$

Leak-before-break, typically utilized for large pressure vessels, requires that a stable crack be just large enough to penetrate both the inner and outer surfaces of the vessel (i.e. without fast facture) so that the leak caused by the presence of the crack can be detected. This condition is obtained by requiring that the unstable crack size exceeds the thickness (i.e., $2 c>t$ ) and that the wall thickness, $t$, contain the pressure, $P$, without yielding. This condition leads to the following:

$$
P \leq \frac{4}{\pi R Y^{2}}\left(\frac{{K_{\mathrm{Ic}}}^{2}}{\sigma_{y}}\right)
$$

Consequently, the pressure is carried most safely when the material index

$$
M_{5}=\frac{K_{\mathrm{I} c}^{2}}{\sigma_{y}}
$$

is the largest possible.

Both of these material performance indices, $M_{4}$ and $M_{5}$, can be maximized by choosing materials with low yield stresses, however, that could be problematic since the thickness and therefore the mass of the tank is inversely related to the yield stress, see Eqs. (15) and (16). Therefore for aerospace applications, which are typically weight critical, this demands that $\sigma_{y} / \rho$ be as large as possible since

$$
m \geq \frac{2 \pi R^{3} P}{\sigma_{y} / \rho}
$$

These indices will be used latter to down select materials for use with lightweight pressure vessels.

\subsection{Material Property Charts}

Material property charts enable the condensing of a large body of information into a compact but accessible form. They reveal correlations between material properties that aid in checking and estimating data; and in conjunction with performance indices, constitute the backbone for tackling real design problems. They provide a convenient way of mapping out the areas of 'property space' occupied by each material class, and the sub-areas occupied by individual materials and provide a mechanism for surveying design-limiting properties (be it a single value or a combination of properties). 
Utilizing the performance indices discussed in the previous section, enables the engineer to choose the chart axes so that function specific information can be displayed. For example, a chart of Young's modulus $(E)$ verses density $(\rho)$, see Figure 11, not only guides the best choice of material for the stiffness limited design of a tie rod, beam or a plate, (see Appendix A) but also shows the longitudinal wave velocity $(E / \rho)^{1 / 2}$ and design for vibration. Similarly a plot of fracture toughness $K_{\mathrm{IC}}$ against modulus $E$ shows the critical strain energy release rate (toughness) $G_{I C}$; a diagram of thermal conductivity $(\kappa)$ verses diffusivity $(a)$ also gives the volume specific heat $\rho C_{v}$; tensile strength $\left(\sigma_{f}\right)$ verses Young's modulus $(E)$ shows the elastic energy-storing capacity, $\sigma_{f}^{2} / E$, to name a few.

The most striking feature of the charts, as pointed out by Ashby (2005) is the way in which members of a material class cluster together, despite the wide range in various properties. For example, the modulus and density of metals (denoted by dark gray contour labeled Metals) in Figure 11, occupy a field that is distinct from that of polymers (denoted as lighter gray), or that of ceramics (lightest gray ellipse), or that of composites (hashed ellipse). The same is true of strength, toughness, thermal conductivity and the rest. Even though the fields sometimes overlap, they always have a characteristic place within the whole picture, due to the physical make up of the various materials. All charts have one thing in common, that some areas within the given material space are not populated. Some of these areas are inaccessible for fundamental reasons that relate to fundamental physics: the size and packing of atoms and the nature of the forces that bind their atoms together. But other areas are empty even though, in principle, they are accessible and if accessed would enable novel design possibilities. It is precisely this clustering, in combination with the material (or more generally the performance) indices that enable the rejection and ranking of various materials with respect to structural function.

Material property charts have numerous applications. One is the checking and validation of data, another concerns the development of, and identification of uses for, new materials which can fill in empty regions, see Section 3.2. But most important of all, the charts form the basis for the previously presented procedure for materials selection.

On a log-log plot, a contour with a constant value of a material index plots as a straight line. For example, the performance index for a light-stiff plate is given by (Appendix A):

$$
M_{6}=E^{1 / 3} / \rho
$$

Taking logs of both sides:

$$
\log \left(M_{6}\right)=\frac{1}{3} \log (E)-\log (\rho)
$$

or

$$
\log (E)=3 \log (\rho)+3 \log \left(M_{6}\right)
$$

Consequently each line in the family of straight parallel lines of slope 3, on a plot of $\log (E)$ verses $\log (\rho)$, corresponds to a fixed value of $M_{6}$. All materials that lie on a line of constant $E^{1 / 3} / \rho$ perform equally well as a light, stiff panel, while those above the line perform better (are lighter for a specified stiffness) than those below the line.

Examining Figure 11 it can be seen that Mg-alloys, Al-alloys, Ti-alloys, steels and $\mathrm{W}$-alloys all fall near a line with the same value of $E / \rho$ (the index for displacement limited tie rod subjected to tensile loading, see the heavy solid line). This raises the question: Why do we use aluminum in the manufacture of airplanes and not steel? This is immediately obvious when one takes into account the appropriate material index for plates/shells subjected to bending, i.e., $E^{1 / 3} / \rho$, see Appendix A. This is plotted as a dashed line of slope 3 , passing through the aluminum bubble on Figure 11. It can be seen that aluminum has a much higher value of $E^{1 / 3} / \rho$ than steel and therefore has superior performance for a light, stiff plate. Additional attribute limits (e.g., horizontal or vertical lines) can also be added to narrow the associated search window (e.g., $E>10 \mathrm{GPa}$ or $\rho>2 \mathrm{Mg} / \mathrm{m}^{2}$ ), thereby producing a short list of candidate materials. Material property charts will be utilized in the next section for two case studies to illustrate the utility of these charts. 


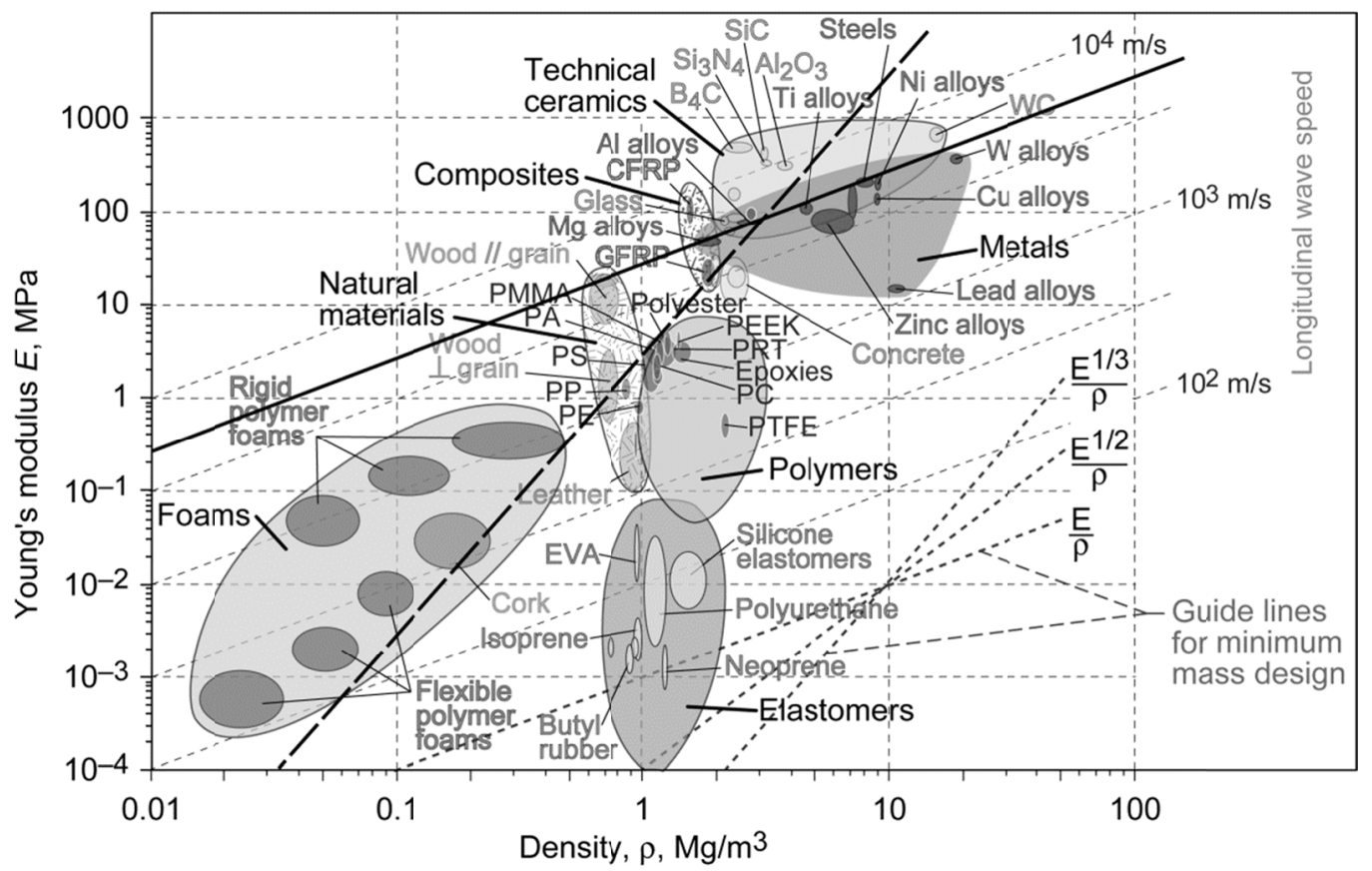

Figure 11.-Modulus versus density property chart.

\subsection{Material Choices for Case Studies}

\subsubsection{Case Study 1b: Blades}

Returning to our first case study related to jet engine blades (be they fan, compressor or turbine) one can quickly identify the various materials that will be best in the case of resisting bending loads. As indicated in Eq. (10) the appropriate material index is

$$
M_{2} \geq{\frac{\left(\phi_{B} \sigma_{f}\right)^{2 / 3}}{\rho}}^{2 / 3}
$$

for temperatures wherein time-dependent behavior can be ignored. This index can also be utilized to indicate which material would be useful for each region of the engine if plotted against maximum service temperature, see Figure 12. For example, the fan section of jet engine experiences temperatures up to $290{ }^{\circ} \mathrm{C}$, with the compressor section experiencing temperatures up to $700^{\circ} \mathrm{C}$, and the turbine experiencing $1600^{\circ} \mathrm{C}$ or less. Since the actual material index, $M_{2}$, is plotted as the ordinate in Figure 12, a horizontal line becomes our selection guideline. Therefore, considering the bending strength alone, it becomes immediately obvious, which materials could be the best choice for low mass blades. For fan blades, Al, Ti, PMCs; for compressor blades, Ti-6-4, Ti-6-2-4-6, B/Al, beryllium; and for turbine blades Inconel 718, Waspaloy, and $\mathrm{SiC} / \mathrm{SiC}$. Note that beryllium would be eliminated for toxicity reasons rather mechanical performance. (This elimination would occur in the research stage of the selection process in Figure 4). These are but a few of our choices (depending upon the required value of the material index) that have been substantiated over the years through direct experience.

It is also clear from Figure 12 that if the choice is limited, apriori, to metals, then as temperature increases (as the application region moves toward the rear of engine) the material performance index must be lowered. This indicates that the mass of higher temperature blades must be greater than lower temperature blades, for a similar duty. However, if the design space is opened-up to include non-metals (particularly ceramics) the index can be maintained (in fact, doubled from 10 to 20) even at elevated temperatures. It is evident then why significant investment is being placed upon the development of composite alternatives to enable significantly lighter weight components for elevated temperatures. 


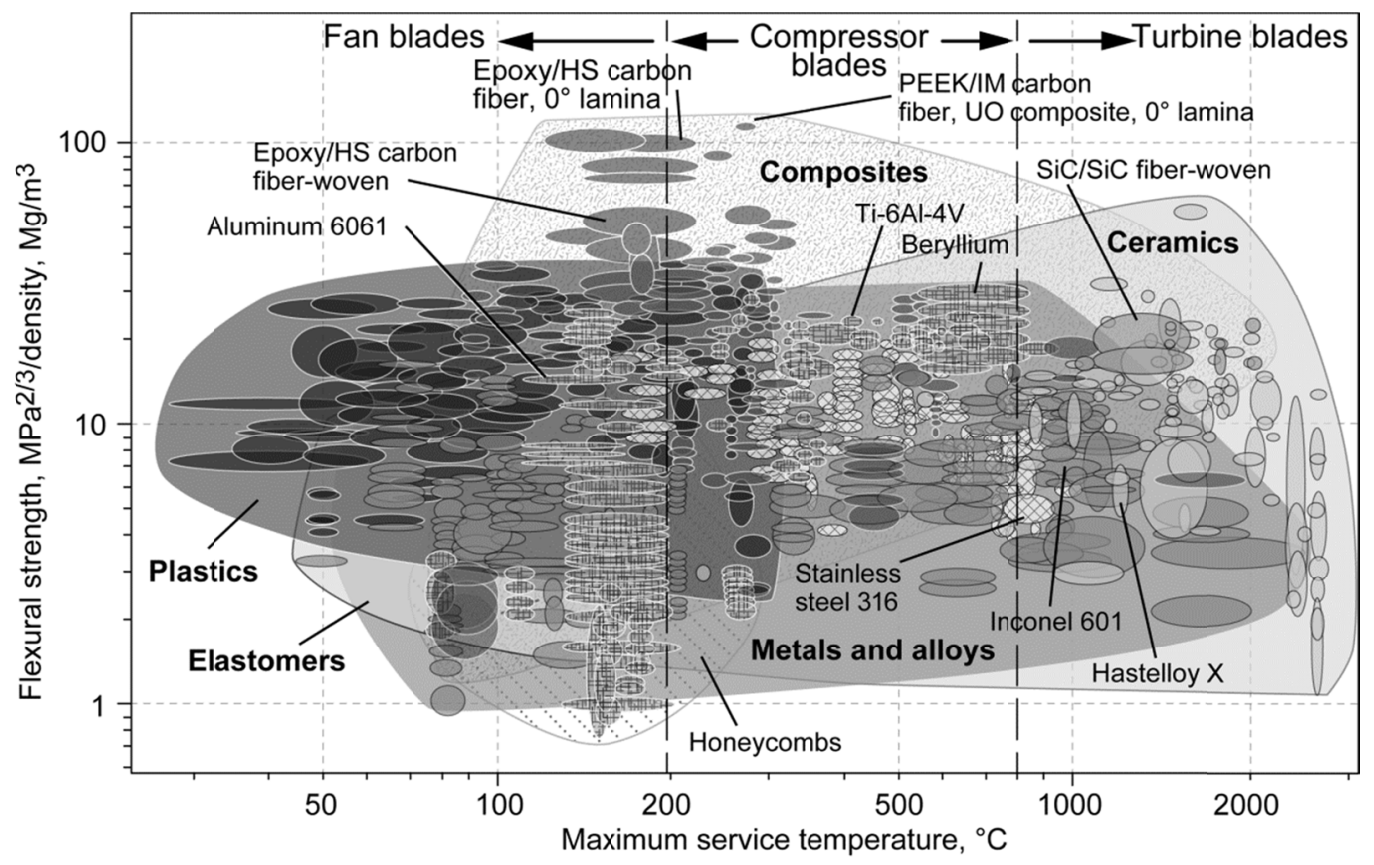

Figure 12.-Flexural strength versus maximum service temperature.

Bending stress is but one type of loading required to be sustained by a given blade design (albeit fan, compressor or turbine), the others being axial tension (due to centrifugal loads) and vibrational loadings (due to rotational motion and fluctuating gas flows through the engine). As shown previously, to minimize mass (or weight) of a given blade requires that a material with a high specific strength $\left(\sigma_{f} / \rho\right)$ in tension be selected and a high value of $E^{1 / 2} / \rho$ to maximize its fundamental vibrational frequency. Note any weight savings in blades has a multiplying effect on other components such as significant reduction in compressor and turbine disks as well as shaft loads.

To assist in making the trade between several constraints the software package 'CES Selector' from Granta Design can be utilized (Granta, 2011). This software enables engineers to depict graphically the various material indices and overlay them to arrive at a subset of candidate materials that can be investigated further. For a discussion on how to deal with multiple constraints and objectives the reader is referred to Chapter 9 of Ashby (2005).

Figure 13 shows the subset of materials after specifying values for the three material indexes given tensile loading, bending, and vibration. The values assumed were: $M_{1}=\left(\frac{\sigma_{f}}{\rho}\right) \geq 60, \quad M_{2}=\frac{\left(\phi_{B} \sigma_{f}\right)^{2 / 3}}{\rho} \geq 10$, and $M_{3}=E \phi_{B} / \rho \geq 10,000$. Note that $\phi_{B}=1$ in both $M_{2}$ and $M_{3}$. Figure 13(a) shows the subset of materials when each index is treated independently, while Figure 13(b) shows the corresponding results when interaction between indexes are accounted for, that is if a given material is eliminated due to failure to meet anyone criterion then it is removed in all three property chart spaces whether or not it fails in that particular space or not. Comparing Figure 13(a) to (b) it is immediately obvious that by considering all loading criteria at once (i.e., Figure 13(b)) leads to a significantly smaller subset of workable material systems for the various temperature ranges or blade types. This assumes the value of the material index (requirement) would be the same in all three temperature regimes. It is interesting to note that Ti-6-4, Ti-6-2-46 , Inconel 718, and Waspoloy are equivalent with respect to specific stiffness but titaniums are significantly better in both bending and specific strength thus substantiating their use in fan and compressor blade applications. A key factor yet to be considered is inelastic effects that come into play at elevated temperatures; this will be briefly considered in Section 3.0 Advanced Selection. 
(a) Independent
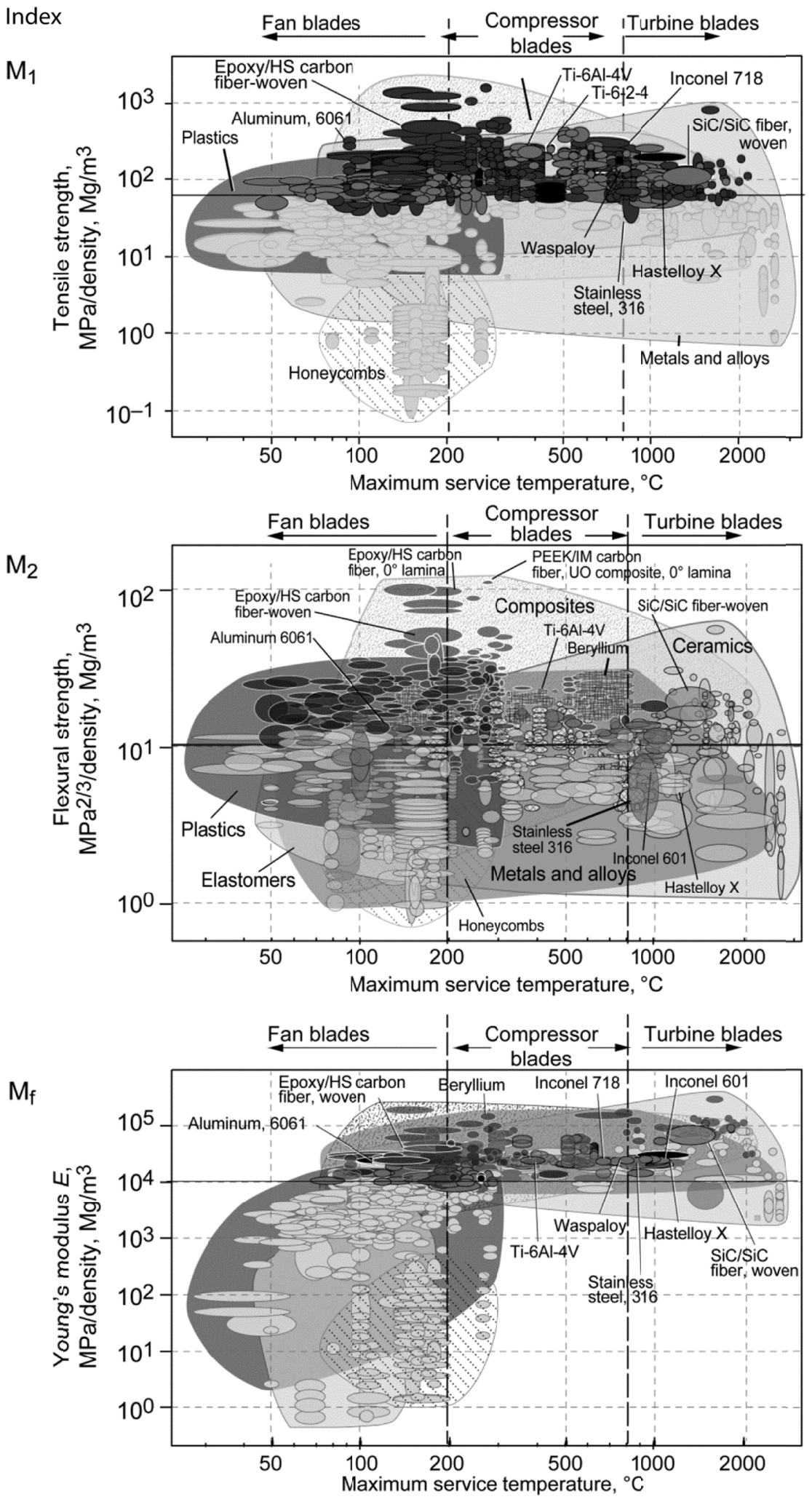

Figure 13.- Illustration of the interaction between three material indices for a blade subjected to tension, bending and vibration. (a) Independent; and (b) Interacting constraints. 
(b) Interacting constraints
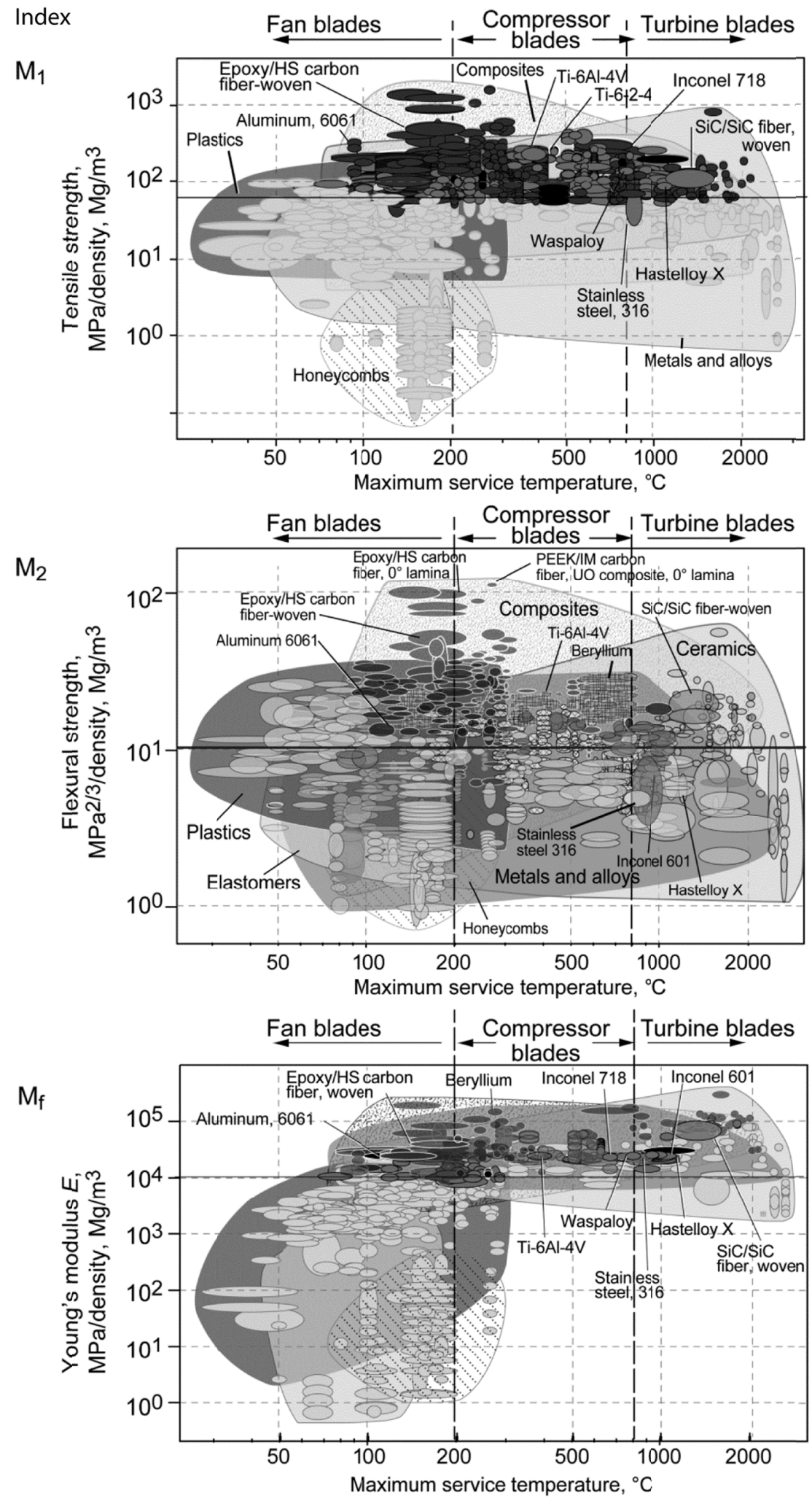

Figure 13.-Concluded. 


\subsubsection{Case Study 2b: Pressure Vessels}

The storage of liquid hydrogen in a lightweight tank provides significant challenges. The low density of the hydrogen fuel results in the need for a larger volume storage vessel relative to other fuels. Mechanical tank loads are derived from 1) the difference in pressure within the tank and the ambient conditions, 2) fuel weight, 3) vehicle acceleration loads, 4) fuel slosh due to aircraft maneuvers, and 5) the weight of the tank system and its supports. Fuel slosh is bound to be encountered as the aircraft maneuvers or as it encounters air turbulence during the flight. Furthermore, the internal tank pressure has to be maintained at a constant absolute pressure in order to maintain the hydrogen in a liquid state. The tank weight increases with increasing operating pressure. Typically, gaseous hydrogen is used as the pressurant for liquid hydrogen. Two important criteria for tank wall design include material selection and wall architecture, which are not mutually exclusive. Many options are available and their advantages and disadvantages are discussed in Mital et al. (2006) where guidelines are provided for choosing an optimum system. Here the discussion will be limited to selection of the tank wall material, based upon mechanical loading alone to illustrate the selection process.

Clearly it is desirable to use materials that possess high strength, high fracture toughness, and high stiffness, as well as low density and low permeation to liquid and gaseous hydrogen; however, no single material provides all these attributes simultaneously. Consequently, once again material performance indices, associated with the functional requirements, such as those given in Table 5, must be used to identify the best material candidates for tank wall construction. Among the material parameters, strength and density tend to dominate the design criteria as the mass of the tank is inversely related to specific strength (see Eq. (23)). Figure 14 shows strength versus mass density for various engineering materials. In this case, materials in the upper left corner are preferable. Composite materials exhibit high specific strength relative to metals and are well suited to aerospace applications: continuous fiber reinforced polymer (CFRP) composites provide the highest strength yet lightest choice. However, the use of continuous fiber reinforced composite materials most likely will involve higher initial manufacturing costs and their permeability to hydrogen is a potential complication. As per Figure 14, the materials that have the sufficient strength and acceptably low densities are PMCs, CMCs and metallic materials. Ceramic materials offer high specific strength, but due to their low fracture toughness (see Figure 15), are not viable for a tank wall material. A potential lower cost alternative to CFRP may be discontinuous reinforced metallic composites (DRX), specifically discontinuous reinforced aluminum (DRA) as described by Miracle (2001). DRAs are essentially isotropic and can be manufactured using less expensive techniques such as casting. The DRX materials have the added benefit of extremely low (if not negligible) hydrogen gas permeability issues typically associated with PMC systems. However, during a detailed study, Arnold et al. (2007) showed that minimum gage thickness requirements kept DRA materials from outperforming PMC materials for this application.

Two key material performance indices that are generally applicable to the design of high pressure vessels but may also be applicable to low pressure cryogenic storage tanks where described previously. These indices are 'yield-before break', $M_{4}=K_{\mathrm{Ic}} / \sigma_{f}$, and the 'leak-before-break', $M_{5}=K_{\mathrm{Ic}}{ }^{2} / \sigma_{f}$ and are illustrated in Figure 15. Utilizing the first index ensures that the stress required to propagate a critical flaw is greater than that to yield the material and the second criterion, ensures that the maximum pressure carried will result in a stable crack that will just enable a leak to occur prior to catastrophic failure. Figure 16 once again clearly illustrates the difference between treating material indices as independent quantities (a) versus considering the interaction of the material indices during the selection process (b); the latter resulting in a reduction in potential material candidates. In Figure 16 only a subset (aerospace materials) of the 'Material Universe' database available within CES Selector is examined for illustrative purposes. Here we see that if the assumed values of the material indices are $M_{1}=\left(\frac{\sigma_{f}}{\rho}\right) \geq 20$ and $M_{5}=\frac{K_{I_{c}}{ }^{2}}{\sigma_{y}} \geq 10$ only a finite set of viable materials; for example Ti, PMCs remain. 


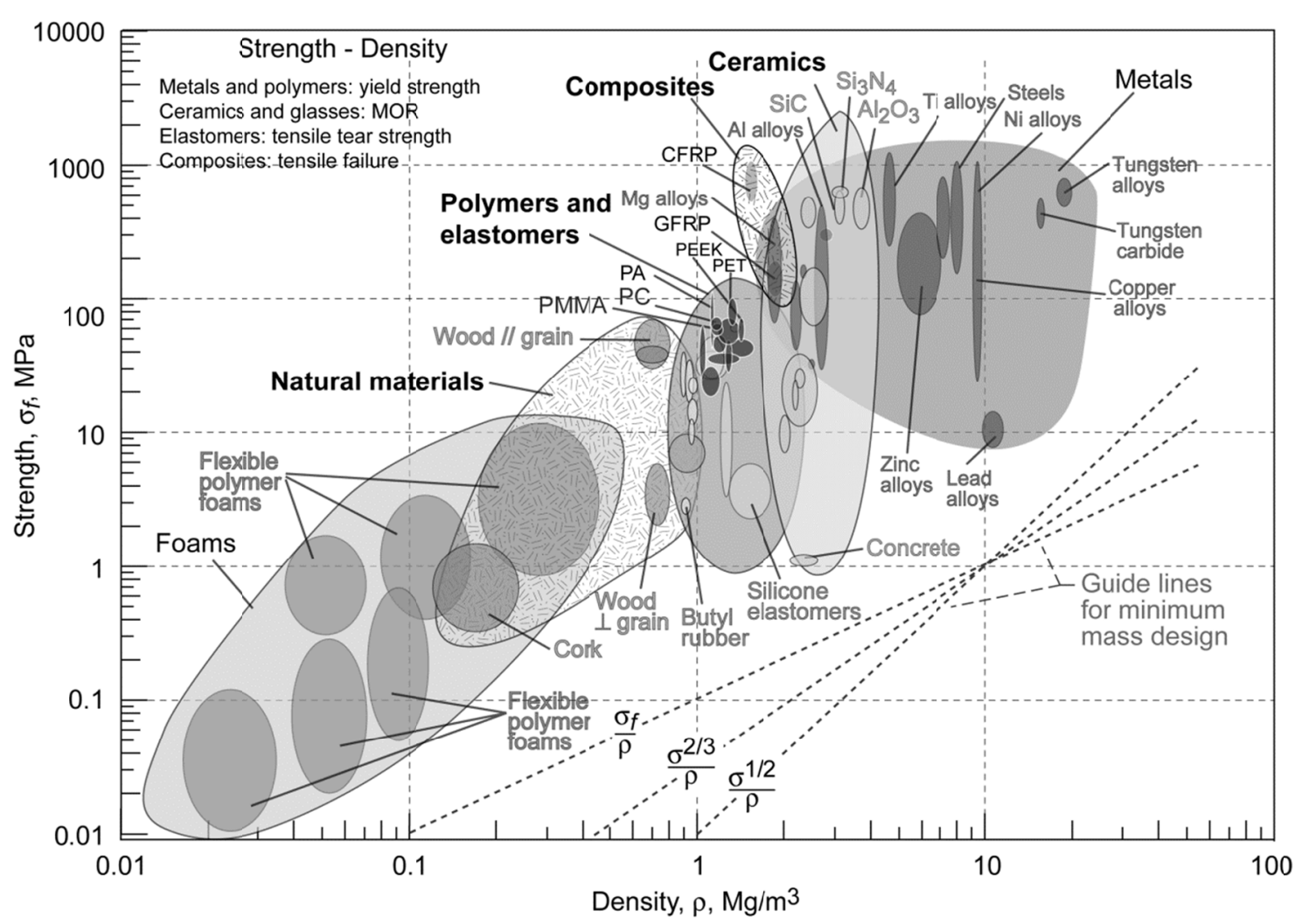

Figure 14.- Strength versus mass density for various engineering materials as per Ashby (2005).

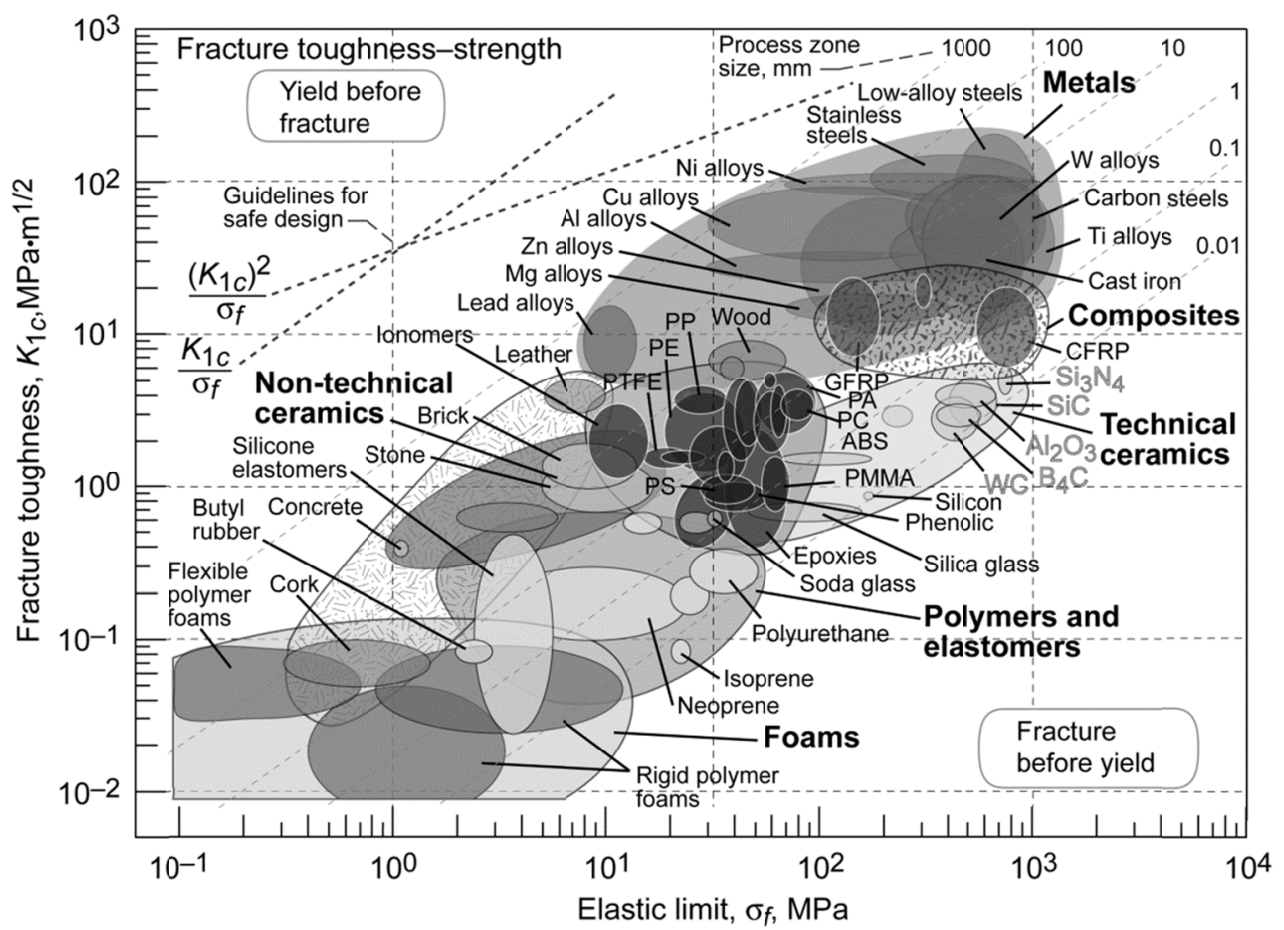

Figure 15.-Fracture toughness versus elastic limit. 

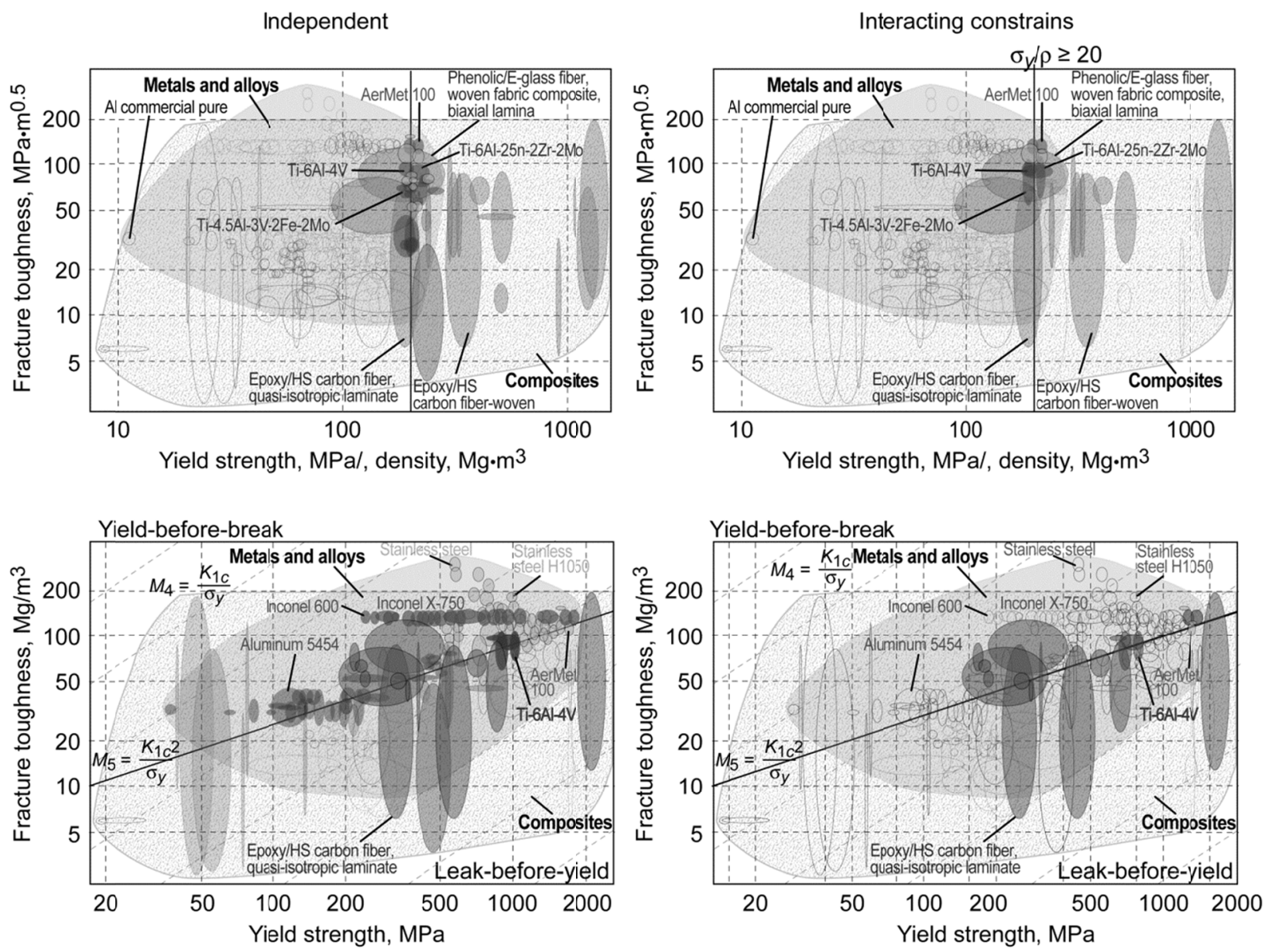

Figure 16.--lllustrates the impact of allowing interaction of material indices for a pressurized vessels.

(a) Independent; and (b) Interacting constraints.

\subsection{Advanced Selection}

\subsection{Materials for High Temperature Applications}

The behavior of real materials to thermal and mechanical stimuli can vary greatly depending upon the magnitude and multiaxiality of loading and the magnitude of the homologous temperature $\left(T_{H}=T / T_{m}\right)$; that is the ratio of applied temperature (measured on an absolute scale, e.g., Kelvin K) to that of the melting point of a given material. For example at room temperature material response is typically timeindependent and either reversible (i.e., linear elastic) or irreversible (inelastic), depending upon whether or not the yield stress of the material has been exceeded. Alternatively, when $T_{H}>0.25$ time-dependent behavior, both reversible and irreversible, can be commonly observed as illustrated schematically in Figure 17, wherein i) strain rate sensitive, ii) creep, iii) relaxation, iv) thermal recovery, v) dynamic recovery and vi) creep/plasticity interaction response behavior are all shown. Other complex time and path dependent behavior such as cyclic ratcheting, creep/fatigue interaction, thermal mechanical fatigue are also often times observed depending upon the magnitude and type of loading (e.g., thermal or mechanical) being applied, see Lemaitre and Chaboche (1990). Note in the case of Ni based superalloys this ratio is significantly higher $\left(T_{H} \geq 0.6\right.$ to 0.9$)$, see Chester et al. (1987)) 
A prerequisite for meaningful assessment of component durability and life, and consequently design of structural components, is the ability to accurately predict the stress and strains occurring within a loaded structure, composed of a given material. As constitutive material models (be they simple or complex) provide the required mathematical link between stress and strain, this necessitates the development and characterization of an appropriate constitutive model for any material before that material can be certified for use by a designer. Thus constitutive models with varying levels of idealizations have been proposed and utilized, each with its own shortcomings/limitations.

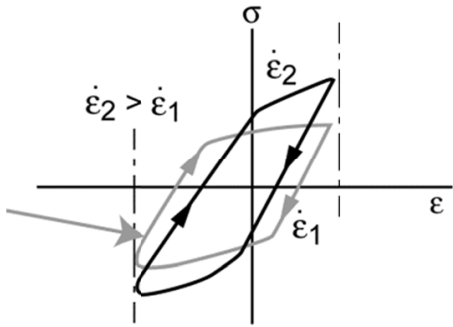

Strain-rate sensitivity
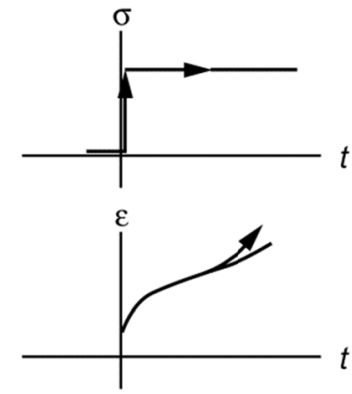

Creep
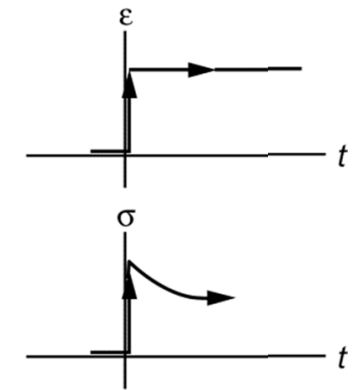

Relaxation

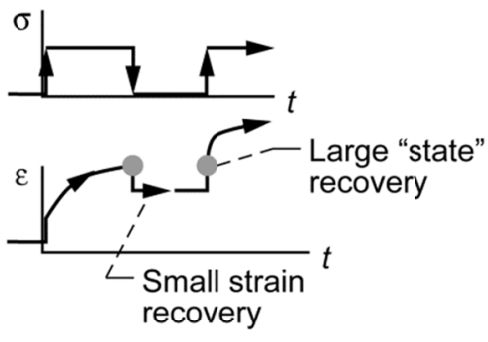

Thermal recovery

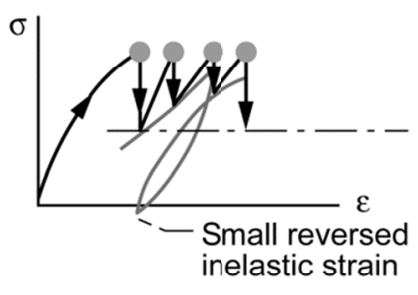

Dynamic recovery

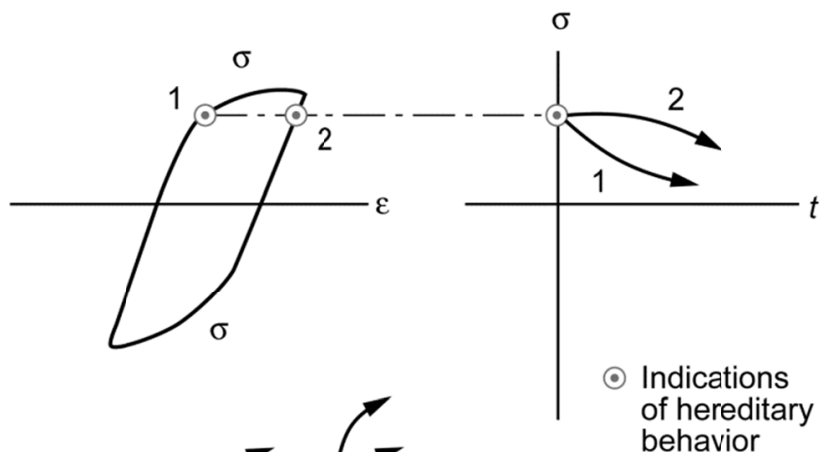

behavior

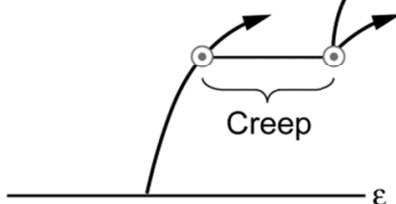

Creep-plasticity interactions

Figure 17.-Schematics showing representative hereditary material behavior at elevated temperature. 
The most well-known and widely used constitutive relation/model is the generalized Hooke's law

$$
\sigma_{i j}=C_{i j k l} e_{k l}
$$

which describes multiaxial time-independent, linear (proportional) reversible material behavior. Up to now we have only utilized uniaxial Hooke's law: $\sigma=E e$. Extension into the irreversible regime is accomplished by assuming an additive decomposition of the total strain tensor, $\varepsilon_{i j}$,

$$
\varepsilon_{i j}=e_{i j}+\varepsilon_{i j}^{I}+\varepsilon_{i j}^{t h}
$$

into three components, that is a reversible mechanical, $e_{i j}$, (i.e., elastic/viscoelastic); an irreversible, $\varepsilon_{i j}^{I}$, (i.e., inelastic or viscoplastic); and a reversible thermal strain, $\varepsilon_{i j}^{\text {th }}$ component.

Equation (26) can also be rearranged...

$$
e_{i j}=\varepsilon_{i j}-\varepsilon_{i j}^{I}-\varepsilon_{i j}^{t h}
$$

Substituting expression (27) into Eq. (25) gives a stress strain relation that incorporates irreversible strains as well as reversible ones, that is:

$$
\sigma_{i j}=C_{i j k l}\left(\varepsilon_{i j}-\varepsilon_{i j}^{I}-\varepsilon_{i j}^{t h}\right)
$$

Numerous models describing the evolution of the inelastic strain have been proposed in the literature. Table 6 contains a few representative examples with a brief description of their required material parameters.

The well known Norton-Bailey creep model (Skrzypek and Hetnarski, 2000) and its multiaxial generalization proposed by Odqvist (1936) followed by a coupled fully-associative unified viscoelastoplastic model has been formulated (Arnold and Saleeb (1994) and Saleeb et al. (2001)) with sufficient generality to permit systematic introduction of multiple mechanisms for both viscoelastic (timedependent reversible) and viscoplastic (time-dependent irreversible) response components. This general, multi-mechanism, hereditary deformation model has been shown to accurately represent a wide spectrum of material response under different loading conditions for the case of titanium alloys (Saleeb and Arnold (2001) and Arnold et al. (2001 and 2004). Examples include 1) rate-dependent (effective) material tangent stiffness during initial loading or any subsequent reversed loading, 2) pure transient response (e.g., in creep or relaxation) within the reversibility region, 3) an elastic behavior upon stress reversal, irrespective of the load level, as well as, 4) other response features common to 'unified viscoplastic' formulations (e.g., rate-sensitivity, creep-plasticity interaction, thermal recovery, etc.). The following generalized anisotropic material behavior constitutive model results; see Table 6 for definition of the associated flow and evolutionary laws:

$$
\dot{\sigma}=E\left(\dot{\varepsilon}-\dot{\varepsilon}^{I}\right)+\dot{q}
$$

All of this is said to emphasize that although for mathematical convenience materials are often classified into specific idealized groups (e.g., linear elastic, plastic, viscoelastic, and viscoplastic), nothing can compel real materials, however, to behave according to these idealized models. And typically, when dealing with actual complex material behavior as represented in Figure 17, it is not sufficient to describe this behavior with simple single parameter relationships or point wise values (e.g., $E, v, \sigma_{y}, H$, etc.) which have worked so nicely for material selection at low homologous temperatures (e.g., typically at room temperature) where such complex path dependent behavior is suppressed. 
TABLE 6.-EXAMPLES OF VARIOUS CONSTITUTIVE MODELS AND THEIR REQUIRED MATERIAL PARAMETERS

\begin{tabular}{|c|c|c|c|}
\hline Model & $\begin{array}{c}\text { Idealized } \\
\text { material } \\
\text { behavior }\end{array}$ & Mathematical representation & $\begin{array}{l}\text { Required isotropic } \\
\text { material parameters }\end{array}$ \\
\hline $\begin{array}{l}\text { Ramberg- } \\
\text { Osgood } \\
(1943)\end{array}$ & $\begin{array}{l}\text { Elastic } \\
\text { Plastic }\end{array}$ & $\varepsilon^{I}=H\left(\frac{\sigma}{\sigma_{y}}\right)^{n}$ & $\sigma_{y}, H, n$ \\
\hline $\begin{array}{c}\text { Norton- } \\
\text { Bailey } \\
\text { [Skrzypek } \\
\text { and Hetnarski } \\
(2000)]\end{array}$ & $\begin{array}{l}\text { Uniaxial } \\
\text { Creep }\end{array}$ & $\dot{\varepsilon}^{I}=A \sigma^{n}$ & $A, n$ \\
\hline $\begin{array}{c}\text { Odqvist } \\
(1936)\end{array}$ & $\begin{array}{l}\text { Multiaxial } \\
\text { Creep }\end{array}$ & $\begin{array}{l}\dot{\varepsilon}_{i j}^{I}=B J_{2}^{\prime}{ }^{m} S_{i j} \\
\text { where } \quad m=1 / 2(n-1) \text { and } B=1 / 2\left(3^{(n+1) / 2}\right) A \\
J_{2}^{\prime}=1 / 2 S_{i j} S_{i j} \quad \text { with } S_{i j}=\sigma_{i j}-1 / 3 \sigma_{k k} \delta_{i j}\end{array}$ & $A, n$ \\
\hline $\begin{array}{c}\text { Arnold et al. } \\
(1994,2004) ; \\
\text { Saleeb et al. } \\
\text { (2001); } \\
\text { Saleeb and } \\
\text { Arnold } \\
(2004)\end{array}$ & $\begin{array}{l}\text { Visco- } \\
\text { elastoplastic }\end{array}$ & 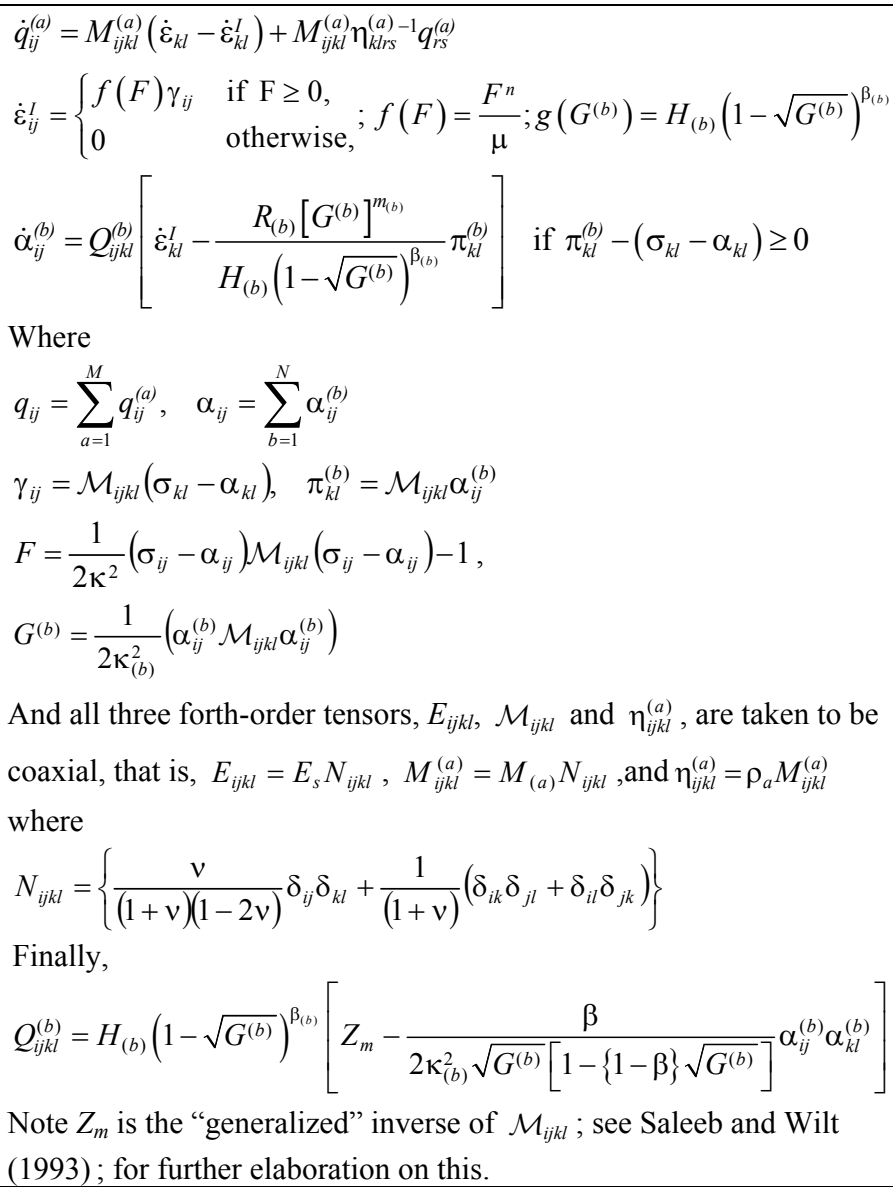 & $\begin{array}{c}2+2 M \text { reversible } \\
\text { constants: } \\
E_{s}, M_{(a)}, v, \rho_{(a)} \\
\text { and } \\
3+5 N \text { irreversible } \\
\text { constants } \\
\kappa, n, \mu \\
H_{(b)}, R_{(b)}, m_{(b)}, \kappa_{(b)}, \\
\qquad \beta_{(b)} \\
\text { where } N \text { defines the } \\
\text { number of } \\
\text { viscoplastic } \\
\text { mechanisms and } M \\
\text { the number of } \\
\text { viscoelastic }\end{array}$ \\
\hline
\end{tabular}

So what should we do when the application operates at elevated temperatures - throw up our hands and just select materials based on linear elastic behavior? Not necessarily as there are simplified (albeit less accurate) approaches for high-temperature performance that allow some inelastic (e.g., creep) behavior to be accounted for and therefore influence the material selection process. Four such approaches are: 1) maximum service temperature (as in Sec. 2.4), 2) allowable stress, 3) design for creep, and 4) deformation mechanism maps. In this section, a brief description of the maximum service temperature and allowable stress approaches will be discussed. This will be followed by a more detailed description of 
how to account for creep behavior in the material selection process. It is strongly suggested, however, that a rigorous nonlinear analysis, with a proper constitutive model, e.g., the unified viscoplastic GVIPS model (Arnold et al., 1994, 2004; Saleeb et al., 2001, 2004), be conducted for the top material candidates to verify the validity/suitability of the chosen material for a given design application.

\subsubsection{Maximum and Minimum Service Temperature}

The simplest measures of tolerance to temperature are the maximum and minimum service temperatures, $T_{\max }$ and $T_{\min }$. The former tells us the highest temperature at which the material can reasonably be used without oxidation, chemical change or excessive deflection or 'creep' becoming a problem (the continuous use temperature, or CUT, is a similar measure). The latter is the temperature below which the material becomes brittle or otherwise unsafe to use. These are empirical, with no universally accepted definitions; therefore caution should be used to fully understand the underlying assumptions and implications. For example, the minimum service temperature for carbon steels is the ductile-to-brittle-transition temperature - a temperature below which the fracture toughness falls steeply. For elastomers it is about $0.8 T_{g}$, where $T_{g}$ is the glass temperature. Below $T_{g}$ elastomers cease to be rubbery and become hard and brittle. Examining Figure 18 wherein strength versus maximum temperature is plotted, it is apparent that polymers and low melting metals like the alloys of zinc, magnesium and aluminum offer useful strength at room temperature but by $300{ }^{\circ} \mathrm{C}$ they cease to be useful (as inelastic/softening behavior is exhibited) -indeed, few polymers have useful strength above $135^{\circ} \mathrm{C}$. Titanium alloys and low-alloy steels can have useful strength up to $600{ }^{\circ} \mathrm{C}$; above this temperature highalloy stainless steels and more complex superalloys based on nickel, iron and cobalt are needed. The highest temperatures require refractory metals like tungsten or technical ceramics such as silicon carbide $(\mathrm{SiC})$ or alumina $\left(\mathrm{Al}_{2} \mathrm{O}_{3}\right)$.

In Figure 12, the flexure strength versus maximum service temperature was utilized to identify potential candidate materials for three types of gas turbine engine blades: fan blades $T<300{ }^{\circ} \mathrm{C}$; compressor blades, $T<700{ }^{\circ} \mathrm{C}$; and turbine blades that operate above $700{ }^{\circ} \mathrm{C}$. In case study $1 \mathrm{~b}$, Ti-6-4 was identified as a potential fan or compressor blade material whose maximum service temperature was given a range of approximately 350 to $420^{\circ} \mathrm{C}$, see Figure 13 . However, in a recent study (see Arnold et al. 2009) the complete time-dependent and rate-dependent temperature regimes for this material were experimentally mapped out. Results demonstrated that this maximum service temperature is too aggressive and should really be limited to $300{ }^{\circ} \mathrm{C}$, since only below this temperature can it be assumed that no rate-dependence and only a minor amount of time-dependence are present, see Figure 19. In Figure 19 the deformation response of Ti-6-4 over a wide range of temperatures is documented. Here, the variation of the moduli and experimentally determined threshold stress, $\kappa$, (that stress which truly delineates between the reversible and irreversible strain regimes) are plotted as a function of temperature (see Arnold et al. 2001). The modulus $E_{S}$ represents the "infinitely slow" modulus, i.e., the elastic modulus of the material if it was loaded at an infinitely slow strain rate, whereas the modulus $\mathrm{E}_{\mathrm{D}}$ represents the "dynamic modulus", which is the modulus of the material if it is loaded "infinitely fast" (e.g., very high, $\geq 1 \times 10^{-3}$ ) rate (i.e., all time dependence is locked into this modulus). As can be seen in Figure 19, at elevated temperatures there is a significant difference between the two modulus values, indicating that even in the so-called "elastic" range, there is significant time-dependence (reflected as rate dependent apparent moduli). Below a temperature of about $300^{\circ} \mathrm{C}$, the two moduli are approximately equal; indicating the response of the Ti-6-4 material is rate-independent but not necessarily timeindependent. Above $300{ }^{\circ} \mathrm{C}$, the response is rate-dependent and time-dependent even below the threshold stress. To appreciate the practical significance of this fact, the operating temperatures typically encountere in aircraft engines are also noted below the horizontal axis in Figure 19, as well as the occasional, higher-temperature regime encountered during over-temp maneuvers. Clearly, even when one is within the typical engine design range and expecting the material response to be reversible, or "elastic", the material behavior (at least in the case of Ti-6-4) would in fact be rate-dependent and would generate an additional strain of $\sigma * / E_{s}$ over time, where $\sigma^{*}$ is the current applied stress that is less than or equal to 
the threshold stress $\kappa$ denoted by the square symbol line. Consequently, at temperatures greater than $300{ }^{\circ} \mathrm{C}$ and stresses below $\kappa$, if classical elasticity methods were used in the design, then this rate dependence, i.e., viscoelastic response, would not be captured. Furthermore, at stresses above $\kappa$, the material response is viscoplastic due to the rate-and-time-dependence, and similarly using the classical methods of plasticity in analysis and design, would also not be accurate.

Figure 19 further indicates that the value of the threshold stress, $\kappa$, decreases significantly as a function of temperature. More importantly, Figure 19 demonstrates that at elevated temperatures the threshold stress $(\kappa)$ is significantly below the traditional "proportional limit" or apparent "yield stress" of the material (obtained at a total strain rate of $0.001 / \mathrm{sec}$ ) indicated by the dashed line (and x symbols). However, if one obtains the proportional limit from tensile test conducted at $1.0 \times 10^{-6} / \mathrm{sec}$ strain rate the values would correspond very closely to those of the threshold stress. This comparison then leads to the conclusion that irreversible material behavior can take place at stress levels well below those considered using traditional methods for the analysis of metals. If classical design methods were used, the material response below the "proportional limit" would be assumed to be fully reversible, and only the response after the proportional limit would be assumed to be irreversible. However, as is shown in the figure, that assumption could lead to significant inaccuracies in the predictions of the material response.

All of this is said to reinforce the fact that although simplifications can be made to aid the material selection/rejection process it remains extremely important, when dealing with material behavior at elevated temperatures, that significant care be taken to fully understand the various candidate materials that one will be suggesting at the end of any selection process.

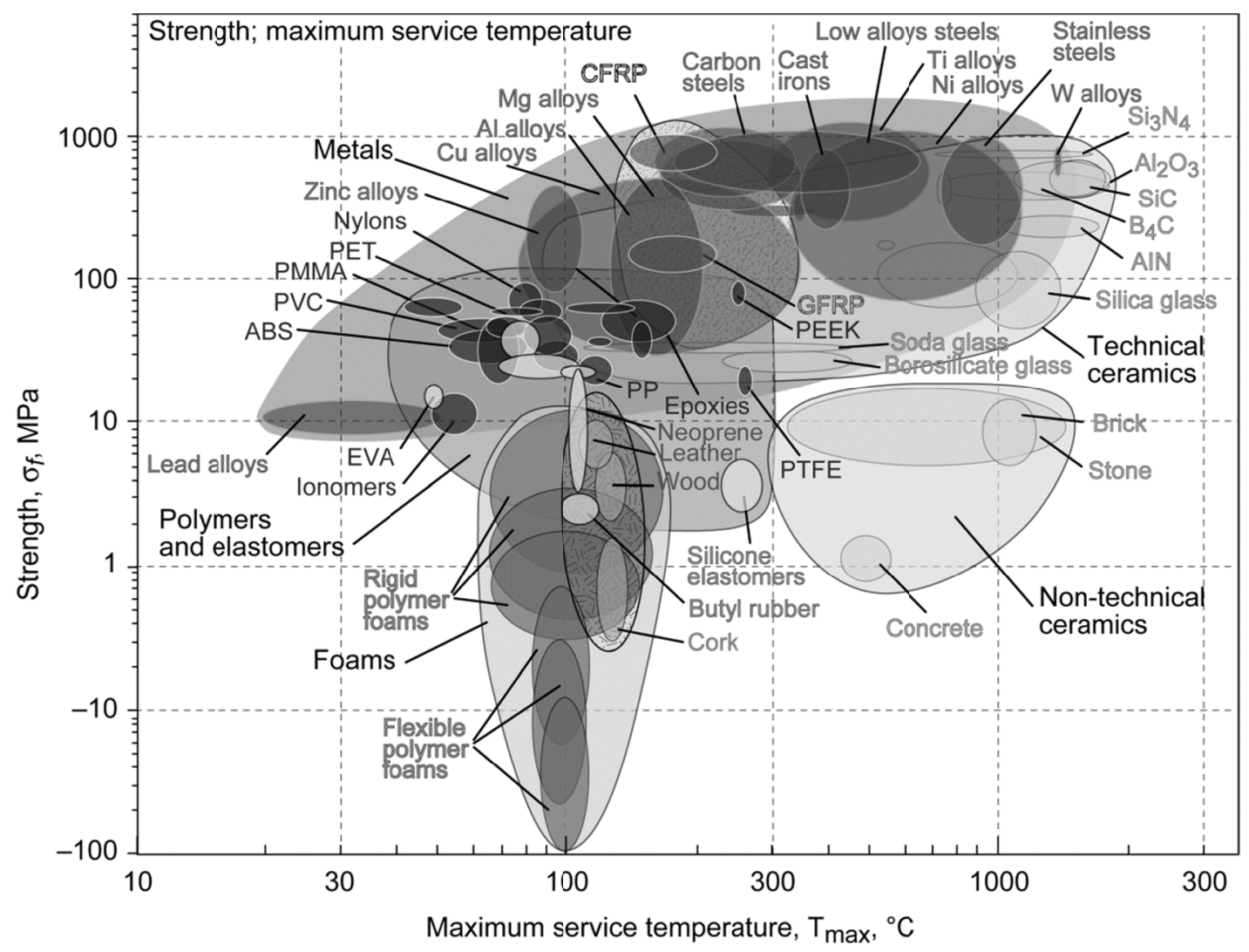

Figure 18.-A chart showing the strength (elastic limit) versus maximum service temperature of the material. 


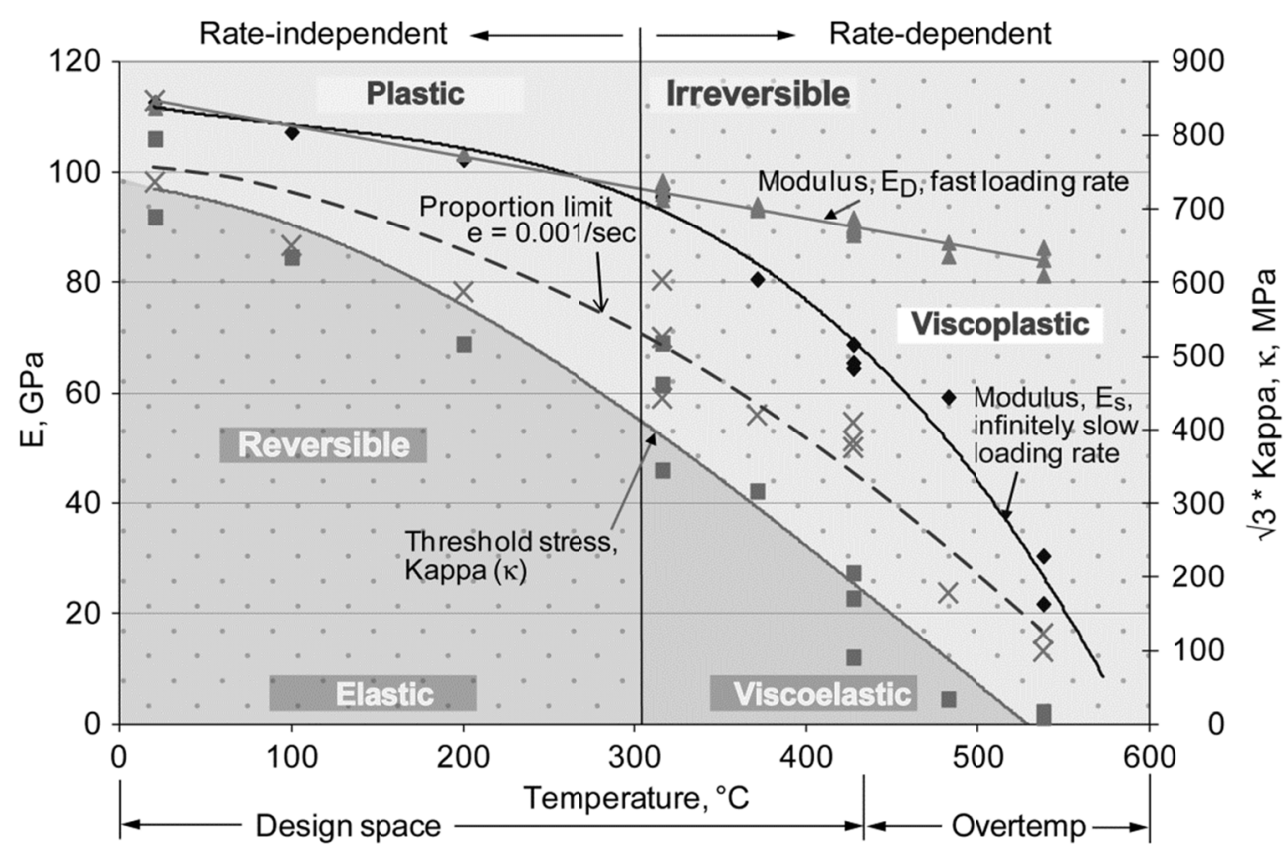

Figure 19.-Variation of modulus and threshold stress, $\kappa$, as a function of temperature for Ti-6-4 material.

\subsection{Design for Creep}

How are materials chosen to avoid failure by creep at high temperatures (Figure 20)? Traditionally material selection has been based largely upon experience. Polymers can be used at room temperature, but - with only a few exceptions - not above $100^{\circ} \mathrm{C}$. The most creep resistant of aluminum alloys are good to about $200{ }^{\circ} \mathrm{C}$; titanium alloys to $600{ }^{\circ} \mathrm{C}$; stainless steels to $850{ }^{\circ} \mathrm{C}$ and so on. But optimal selection requires much more than this. The choice depends not only on material properties, but on the mode of loading (tension, bending, torsion, internal pressure), on the failure criterion (excessive deflection, fracture, relaxation of stress, buckling, etc.) and on the optimization objective (minimizing weight, or cost, or maximizing life). A designer, not himself a specialist on creep, has no easy way to identify the subset of materials best suited to his needs, or to predict the ways in which a change in the design might influence the choice.

In design against creep, one seeks the material and the shape which will carry the design loads without failure, for the design life at the design temperature. The meaning of "failure" depends on the application. We distinguish four types of failure, illustrated in Figure 20.

a. Displacement-limited applications, in which precise dimensions or small clearances must be maintained (as in the disks and blades of turbines), when design is based on creep rates $\dot{\varepsilon}$ or displacement rates $\dot{\delta}$.

b. Rupture-limited applications, in which dimensional tolerance is relatively unimportant, but fracture must be avoided (as in pressure-piping), when design is based on time-to-failure $t_{f}$.

c. Stress-relaxation-limited applications in which an initial tension relaxes with time (as in the pretensioning of cables or bolts) when design is based on a characteristic relaxation time $t_{r}$.

d. Buckling-limited applications, in which slender columns or panels carry compressive loads (as in the upper wing skin of an aircraft, or an externally-pressurized tube), when design is based on critical time-to-instability $t_{b}$. 
(a)

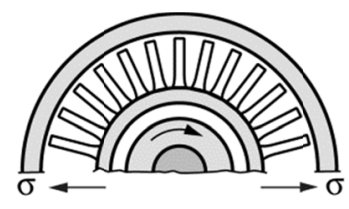

(b)

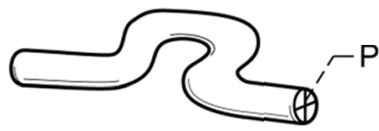

(c)

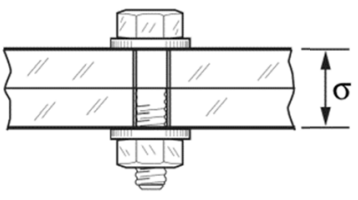

(d)

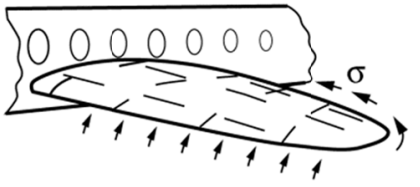

Figure 20.-Creep is important in four classes of design: (a) displacement-limited; (b) failure limited, (c) relaxation-limited, (d) buckling limited.

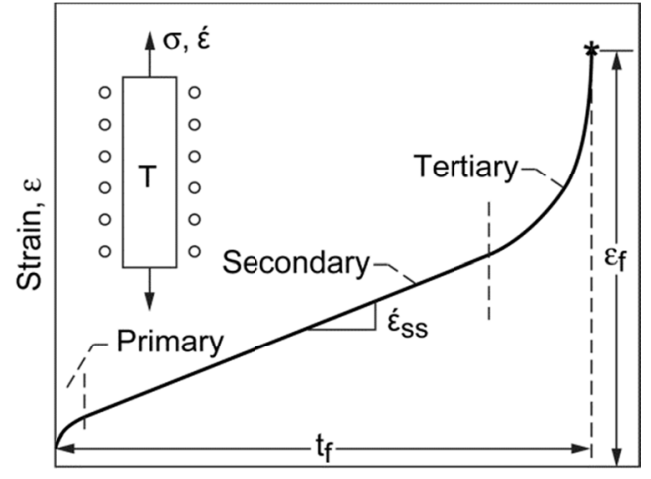

Time, $t$

Figure 21.-A typical creep curve showing the tensile strain $\varepsilon$ plotted against time $t$. It shows primary, secondary and tertiary stages, and the quantities $\varepsilon_{s s}, \varepsilon_{f}, t_{f}$.

To tackle any of these situations constitutive equation, as previously discussed, are required which relate the strain-rate $\dot{\varepsilon}$ or time-to-failure $t_{f}$ for a material to the stress $\sigma$ and temperature $T$ to which it is exposed.

\subsubsection{Constitutive Equation for Creep Deflection}

When a material is loaded at constant stress and homologous temperature $T_{H}$, above approximately 0.25 , it typically will experience creep, as schematically depicted in Figure 21. Creep response typically involves a primary extension stage, followed by a steady-state creep stage, and ends with an accelerating tertiary stage. The important parameters are marked: the steady state creep rate $\dot{\varepsilon}_{s s}$, the time to fracture, $t_{f}$, and the creep ductility, $\varepsilon_{f}$.

The characteristics of the curve and the way it changes with temperature and stress are described mathematically by a constitutive equation (Finnie and Heller, 1959; Hult, 1966; Penny and Marriott, 
1971; Gittus, 1975; Frost and Ashby, 1982; Evans and Wilshire, 1985). Many constitutive equations for creep-rate have been suggested, some purely empirical, some science-based; most are a mix of the two. Those most widely used in engineering design when deflection is important, relate the steady-state strainrate $\dot{\varepsilon}_{s s}$ to the tensile stress $\sigma$ and the temperature $T$ thus:

$$
\dot{\varepsilon}_{s s}=A f(\sigma) \exp -\left(\frac{Q}{R T}\right)
$$

where $A$ is a kinetic constant, $Q$ an activation energy, $R$ the gas constant and $f(\sigma)$ means " a function of stress $\sigma$ ". The function $f(\sigma)$ can be approximated, over restricted ranges of stress, by the Norton-Bailey power law given in Table 6 and slightly rewritten here:

$$
\dot{\varepsilon}_{s s}=A\left(\frac{\sigma}{\sigma_{o}}\right)^{n} \exp -\frac{Q}{R T}=\dot{\varepsilon}_{o}\left(\frac{\sigma}{\sigma_{o}}\right)^{n},
$$

where the constant $A$, the activation energy $Q$, the exponent $n$ and the characteristic strength constant $\sigma_{o}$ are material properties. Considerable experience has accumulated in the use of Norton's Law, which has the appeal that it allows analytical solutions to a wide range of engineering problems (see, for instance, Finnie and Heller, 1959; Hult, 1966; Penny and Marriott, 1971). For this reason we shall use it here even though, from a scientific point of view, it lacks a completely respectable pedigree. Nor is it capable of accounting for creep/plasticity effects that more sophisticated unified viscoplastic models were developed to handle.

\subsubsection{Constitutive Equation for Creep Fracture}

When fracture rather than deflection is design-limiting, creep is characterized instead by the time to fracture, $t_{f}$. It, too, can be described by a constitutive equation with features like those of Eq. (31). Here, again, a power law gives an adequate description over a restricted range of $\sigma$ and $T$ :

$$
t_{f}=B\left(\frac{\sigma}{\sigma_{f}}\right)^{-q} \exp \left(\frac{Q_{f}}{R T}\right)=t_{f 0}\left(\frac{\sigma}{\sigma_{f}}\right)^{-q},
$$

With its own values of kinetic constants $B$, activation energy $Q_{f}$, exponent $q$ and characteristic strength $\sigma_{f}$.

\subsubsection{Constitutive Equation for Relaxation}

Relaxation requires a constitutive equation which combines creep (inelastic) and elastic response when total strain rate is held constant at zero. Consequently, from Eq. (29), and assuming tension it takes the form:

$$
\dot{\sigma}=-E \dot{\varepsilon}_{s s}^{I},
$$

where $E$ is Young's modulus, $\dot{\varepsilon}_{s s}$ is given by Eq. (31) and $\dot{\sigma}$ is the rate of change of stress with time. It is important to realize however that although the form of the inelastic strain is the same as Eq. (33) the material constants take on completely different values since the relaxation spectrum is typically significantly shorter than that of steady state creep. For the bending of a beam (as in Figure 22) the equation becomes instead

$$
\frac{\dot{F}}{S}=\dot{\delta}_{c},
$$

where $\dot{F}$ is the rate of change of force $F, S$ is the bending stiffness and $\dot{\delta}_{c}$ is the creep deflection rate of the beam. Similar expressions describe torsion and compression. 
(a)

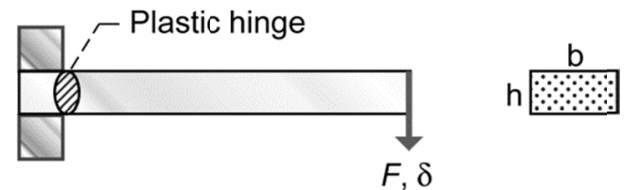

(b)

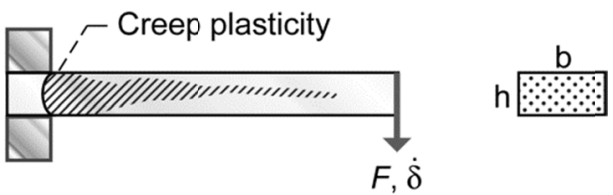

(c)

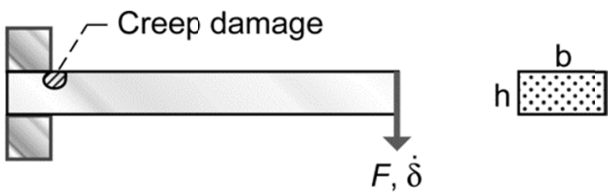

Figure 22.-A cantilever beam loaded with an end load $F$. (a) At room temperature a plastic hinge forms where the bending moment is highest. (b) At high temperature, creep plasticity is distributed. (c) Creep fracture starts where the local tensile stress is highest.

\subsubsection{Material Selection in the Creep Regime}

The objective here is to derive indices which parallel those used for room temperature design (Ashby, 1992), but now tailored for design when creep takes place. The immediate difficulty is that the 'strength' is now no longer a fixed material property, but depends on temperature and on the strain-rate. The treatment below is kept as brief as possible. Fuller details can be found elsewhere (e.g., Abel and Ashby, 1994).

\subsubsection{Deflection-Limited Design}

Consider first the simple case of a tensile member — a tie rod — of minimum weight, designed to carry a load $F$ for a life time, $t$, without deflecting more than $\delta$ at a temperature $T$. If the tie has length $L$, the steady strain-rate must not exceed

$$
\dot{\varepsilon}=\frac{\delta}{L t}
$$

Inserting this into the constitutive Eq. (32) for tensile creep and inverting gives

$$
\sigma=\frac{F}{A}=\sigma_{0}\left(\frac{\delta}{\dot{\varepsilon}_{0} L t}\right)^{1 / n},
$$

The objective is to minimize the mass of the tie. Solving for A and substituting this into the equation $m=\mathrm{A} L \rho$ for the mass gives

$$
m=\frac{L \rho F}{\sigma_{D}},
$$

with 


$$
\sigma_{D}=\sigma_{0}\left(\frac{\delta}{\dot{\varepsilon}_{0} L t}\right)^{1 / n}
$$

Thus the lightest tie which meets the constraints of $F, T, t$ and $\sigma$ is that made of the material with the largest value of

$$
M_{6}=\left(\frac{\sigma_{D}}{\rho}\right) \text {, }
$$

This has the same form as the previous elastic material index for a tie rod

$$
M_{1}=\frac{\sigma_{y}}{\rho} \text {, }
$$

with $\sigma_{y}$ replaced by $\sigma_{D}$, defined above. Consequently it contains both temperature and time.

The analysis of beams, shafts, pressure vessels (and the like) is a little more complex, but follows the same pattern. Consider, as an illustration, the cantilever beam of Figure 22(b) carrying a load $F$, but now at a temperature such that it creeps. The objective, as before, is to make the beam as light as possible; the constraints (again as before) are that its length $L$ and the proportions, of its cross-section are fixed, and that it must support the load $F$ for a time $t$ at temperature $T$ without deflecting more than $\delta$. The design specification constrains the deflection rate, $\dot{\varepsilon}$ : it must not exceed $\delta / t$. The deflection rate $\dot{\varepsilon}$ for a cantilever beam with end load $F$, creeping according to the constitutive Eq. (32) is

$$
\dot{\varepsilon}=\frac{2}{(n+2)}=\dot{\varepsilon}_{0} L^{2}\left\{\frac{4 F L}{\sigma_{0}}\left(\frac{2 n+1}{2 n}\right) \frac{1}{b h^{\frac{2 n+1}{n}}}\right\}^{n},
$$

See Appendix B for complete derivation. Eliminating $b$ and $h$ between the equations $m=A L \rho$ and (40), using $b=\alpha h$ and $A=\alpha h^{2}$ gives

$$
m=\rho L^{\frac{3 n+3}{3 n+1}} \alpha^{\frac{n+1}{3 n+1}}\left(\left(\frac{2 n+1}{2 n}\right) \cdot \frac{4 F L}{\sigma_{D}}\right)^{\frac{2 n}{3 n+1}}
$$

with $\sigma_{D}$, which we call the design strength, given by

$$
\sigma_{D}=\sigma_{0}\left(\frac{n+2}{2} \frac{\dot{\delta}}{L \dot{\varepsilon}_{0}}\right)^{\frac{1}{n}},
$$

Equation (41) looks messy, but it is not as bad as it seems. For example the fully-plastic limit can be found by setting $n=\infty$, thereby simplifying Eq. (41) to

$$
m=\rho L \alpha^{1 / 3}\left\{\frac{4 F L}{\sigma_{D}}\right\}^{2 / 3},
$$


which is identical with the mass of the plastic beam $m=\rho L \alpha^{1 / 3}\left\{\frac{4 F L}{\sigma_{y}}\right\}^{2 / 3}$ if $\sigma_{D}$ is replaced by $\sigma_{y}$. The design strength in creep, then, plays the same role as the yield strength in room-temperature plasticity. In fact, Eq. (43) is a good approximation to the more complex result of Eq. (41) over the entire range of values of the exponent $n(3<n<20)$ normally encountered in metals and alloys. Inspection shows that the mass is minimized by maximizing the index $M_{2}$ given earlier $M_{2}=\frac{\sigma_{y}^{2 / 3}}{\rho}$ with $\sigma_{y}$ replaced by $\sigma_{D}$ (remember that $\sigma_{D}$ contains temperature and deflection-rate).

A parallel calculation for a panel (flat plate in bending) gives an equation $M_{7}=\frac{\sigma_{y}^{2 / 3}}{\rho}$ again with $\sigma_{y}$ replaced by $\sigma_{D}$, appropriately defined. Similar expressions are derived for torsion and for internal pressure (Appendix B). Selection with the objective of minimizing cost rather than weight lead to identical results with $\rho$ replaced by $C_{m} \rho$, where $C_{m}$ is the material cost per $\mathrm{kg}$; and the objective of minimizing energy content is achieved by replacing this by $q_{m} \rho$, where $q_{m}$ is the energy content per $\mathrm{kg}$.

\subsubsection{Fracture-Limited Design}

Consider next an application in which fracture, not deflection-rate, is design-limiting (Figure 20(b)). For a bending beam the largest stresses appear - and creep-fracture starts - in the outer fibers at the place where the bending moment $M$ is greatest (Figure 22(c)). The time $t$ to the onset of failure of the cantilever, using the constitutive relation of Eq. (32), is

$$
t=t_{f o}\left(\frac{2 q+1}{2 q} \cdot \frac{4 F L}{\sigma_{f o} b h^{2}}\right)^{q},
$$

Writing $b=\alpha h$, solving for the area $A=b h$ and substituting in $m=A L \rho$ gives

$$
m=\rho L \alpha^{1 / 3}\left(\left(\frac{2 q+1}{2 q}\right) \frac{4 F L}{\sigma_{D}}\right)^{2 / 3},
$$

with the design strength

$$
\sigma_{D}=\sigma_{f o}\left(\frac{t_{f o}}{t}\right)^{\frac{1}{q}}
$$

The parallel with deflection-limited design is obvious; and once again the result reduces to that for full plasticity in the limit $q=\infty$. The mass is minimized, as before, by maximizing the index of equation $M_{7}=\frac{\sigma_{y}{ }^{2 / 3}}{\rho}$ with $\sigma_{y}$ replaced by this new, fracture-related $\sigma_{D}$ which depends on design life, $t$, and on

temperature, $T$. Analogous calculations for ties and panels give equations $M_{1}=\frac{\sigma_{y}}{\rho}$ and $M_{3}=\frac{\sigma_{y} / 3}{\rho} \longrightarrow$ only the definition of $\sigma_{D}$ is different. Similar expressions describe torsion and internal pressure (Appendix B.1), and are modified for cost or energy content by replacing $\rho$ by $C_{m} \rho$ or $q_{m} \rho$ as before.

\subsubsection{Relaxation-Limited Design}

A tensile cable, or a bolt, that is pretensioned to provide a bearing or clamping force $F$ at an elevated temperature, relaxes with time by creep. The calculation is a standard one; elastic strain $\sigma / E$ is replaced over time by creep. The total change in strain in the cable or bolt is zero, since its ends are fixed. The governing equation for the stress in the component was given earlier as Eq. (33). Integrating this with the boundary condition $\sigma=\sigma_{i}$ at $t=0$, gives 


$$
\left(\frac{\sigma_{o}}{\sigma}\right)^{n-1}-\left(\frac{\sigma_{o}}{\sigma_{i}}\right)^{n-1}=(n-1) \frac{E \dot{\varepsilon}_{0} t}{\sigma_{0}},
$$

where $\sigma_{i}$ is the stress to which the cable or bolt was originally tightened, and $\sigma$ is the stress to which it has relaxed in time $t$. In this case a constraint is specified by defining a characteristic relaxation time, $t_{r}$, as the time required for the stress to relax to a specified fraction of its initial value. Inverting Eq. (47) gives:

$$
t_{r}=\left[1-\left(\frac{\sigma}{\sigma_{i}}\right)^{n-1}\right] \frac{\sigma_{o}{ }^{n}}{(n-1) E \dot{\varepsilon}_{0} \sigma^{n-1}},
$$

Clearly the quantity in the square bracket can be thought of as merely a scaling factor, consequently the result is independent of the choice of $\sigma / \sigma_{i}$. For illustrative purposes the ratio $\sigma / \sigma_{i}$ is taken to be 0.5 and for $n>3$ the term in square brackets is then close to unity; thus for simplicity it shall be neglected. The design specifies the minimum bearing or clamping load $F$. Writing $\sigma=F / A$ and substituting for $A$ in equation $m=A L \rho$, gives the mass of the cable or bolt which will safely provide a clamping load greater than $F$ for a life $t_{r}$;

$$
m=\frac{L \rho F}{\sigma_{D}},
$$

with

$$
\sigma_{D}=\sigma_{o}\left(\frac{\sigma_{o}}{(n-1) E \dot{\varepsilon}_{0} t_{r}}\right)^{\frac{1}{n-1}}
$$

The mass is minimized by selecting the material with the greatest value of $\sigma_{D} / \rho$, that is, the material index is once more that of equation $M_{1}=\frac{\sigma_{y}}{\rho}$ replaced by this new $\sigma_{D}$.

Springs, too, relax their tension with time. Most are loaded in bending, when the constitutive behavior is that of Eq. (34). Taking a beam of length $L$ as an example, we write, for the stiffness $S$ :

$$
S=\frac{C_{2} E I}{L^{3}},
$$

where $I$ is the second moment of its area and $C_{2}$ is a constant. Integrating with the boundary conditions $F$ $=F_{i}$ at $t=0$ gives a result with the form of Eq. (47). Proceeding as before, we find for the minimum weight design of a leaf spring (or any spring loaded in bending), which must not relax its restoring force in time $t_{r}$ at temperature $T$, the index $M_{7}$ is $M_{7}=\frac{\sigma_{y}{ }^{2 / 3}}{\rho}$, with $\sigma_{D}$ (when $n>3$ ) given by

$$
\sigma_{D} \approx \sigma_{o}\left(\frac{\sigma_{o}}{E \dot{\varepsilon}_{o} t_{r}}\right)^{\frac{1}{n-1}},
$$

Abel and Ashby (1994) list results for other modes of loading. Similar calculations for ties and panels give equations $M_{1}=\frac{\sigma_{y}}{\rho}$ and $M_{8}=\frac{\sigma_{y}{ }^{1 / 3}}{\rho}$ again—only the definition of $\sigma_{D}$ is different. The earlier adaptations to cost or energy apply here as well. 


\subsubsection{The Selection Procedure}

Expressions for the indices $M$ and the associated design strengths $\sigma_{D}$ are summarized in Appendix 0 to B.3. The close parallel between these results and those for room temperature plasticity (equations $M_{1}=\frac{\sigma_{y}}{\rho}, M_{7}=\frac{\sigma_{y}{ }^{2 / 3}}{\rho}$ and $\left.M_{8}=\frac{\sigma_{y}{ }^{1 / 3}}{\rho}\right)$ suggests a selection procedure. The design temperature $T$ and acceptable deflection-rate $\dot{\delta}$ or life, $t$, or relaxation time $t_{r}$ are identified. Using this information, values for the appropriate $\sigma_{D}$ are calculated from a database of creep properties for materials (it is necessary to capture the value of $\sigma_{D}$ at the value $\sigma_{y}$ to allow for the change of deformation mechanism to yielding at low temperatures). These are used to construct a chart of $\log \left(\sigma_{D}\right)$ against $\log (\rho)$. This is the creepequivalent of Figure 14, but is specific to the particular temperature, deflection-rate or life required by the design since these appear in the definition of $\sigma_{D}$. The indices $M_{1}, M_{7}$ and $M_{8}$ can be plotted onto it, allowing optimum selection for each application.

This is best understood through examples. Those of the next section are deliberately simplified to avoid unnecessary digression. The method remains the same when the complexity is restored.

\subsubsection{Case Study}

The example below illustrates the selection of materials for structures loaded at elevated temperatures, and which are limited by deflection. Components limited by fracture or by stress relaxation can be handled in a similar manner. Remember many other considerations enter the selection of materials for high-temperature use as well; for example resistance to oxidation, to thermal shock, and so on. Here we consider the selection for the initial short-list of candidates, of which these additional considerations would then be investigated.

\subsubsection{Case Study 1c: Fan and Turbine Blades for Gas Turbines}

A rotating blade of an aircraft turbine is self-loaded (Figure 20(a) and Figure 23); the centrifugal force caused by its own mass is much larger than that exerted by the gases which propel it. Adiabatic compression of the intake air can heat the compressor-fan blade to $400{ }^{\circ} \mathrm{C}$ or more. The dominant mode of steady loading, therefore, is tensile, and proportional (for fixed blade proportions) to the density of the blade material. It could, then, be anticipated that the appropriate index is that for tensile loading, $M_{1}$ of equation $M_{1}=\frac{\sigma_{y}}{\rho}$, with the design strength for tensile loading, $\sigma_{D}$, replacing $\sigma_{y}$, see Eq. (38).

More detailed analyses add complexity, but confirm this result (Able and Ashby, 1994). The turbine blade is loaded in the same way, but is hotter: designers would like to go to $1000{ }^{\circ} \mathrm{C}$. The task is to select materials to maximize the safe angular velocity of the compressor or turbine blade, designed to operate for a life t of $1000 \mathrm{hr}$ without extending by more than $\delta$, which is required to be 1.0 percent of its length, for each of these temperatures, and at the same time to minimize the weight.

The profile and section are determined by the blade design — neither is free. The mass is minimized by minimizing

$$
M_{9}=\frac{1}{\rho}
$$

Figure 24 through Figure 26 show $\sigma_{D}$ creep strength, calculated for 400,1000 , and $1500^{\circ} \mathrm{C}$, respectively, with a value of $\frac{\dot{\delta}}{L}$ and $T$ corresponding to the design specification, plotted against density, $\rho$. Selection lines plotting the appropriate indices are shown and the corresponding potential material selections are listed in Table 7 through Table 9. The sweet spot (desired location) for material selection being the upper left hand corner of the figures. 


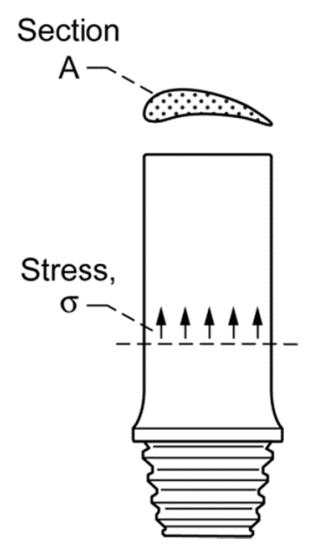

Figure 23.-A schematic of a turbine blade

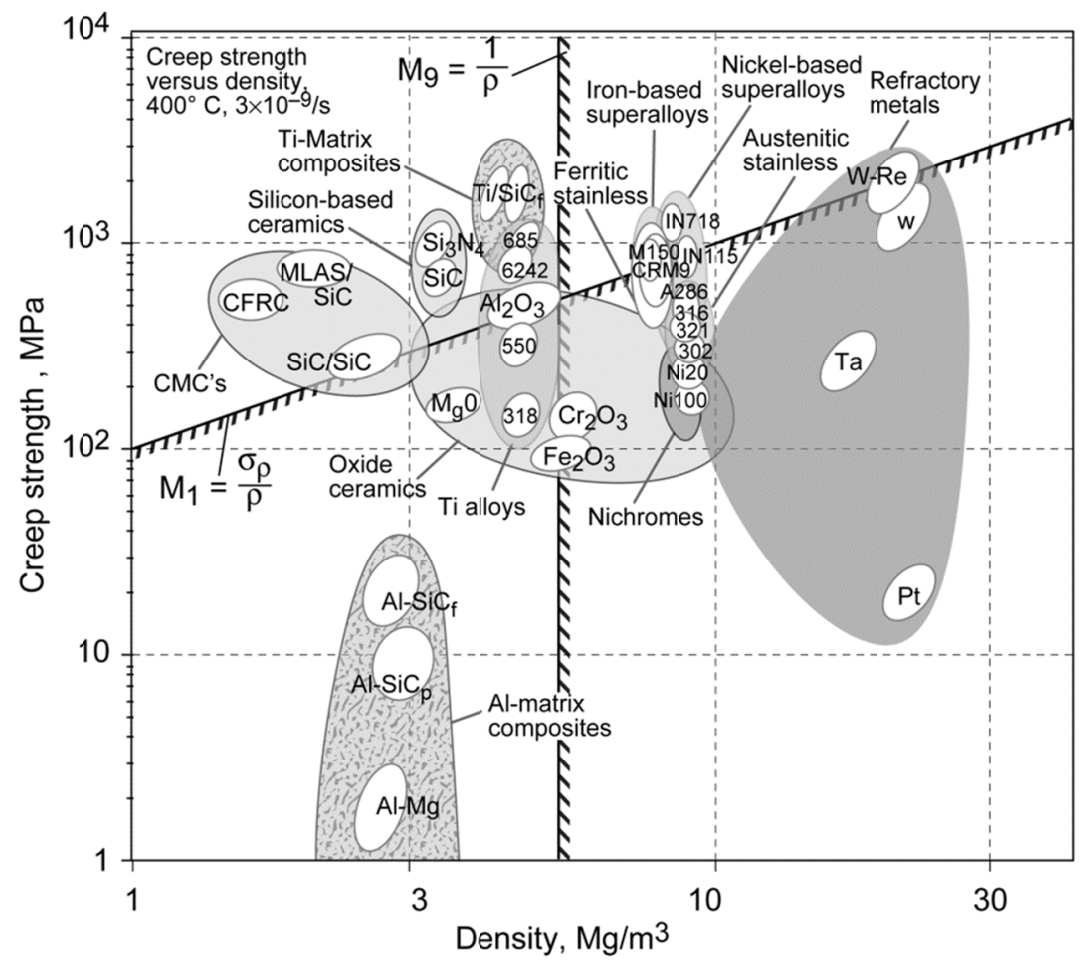

Figure 24.-A selection chart for deflection limited design at $400{ }^{\circ} \mathrm{C}$ for a life of $1000 \mathrm{hr}$. 


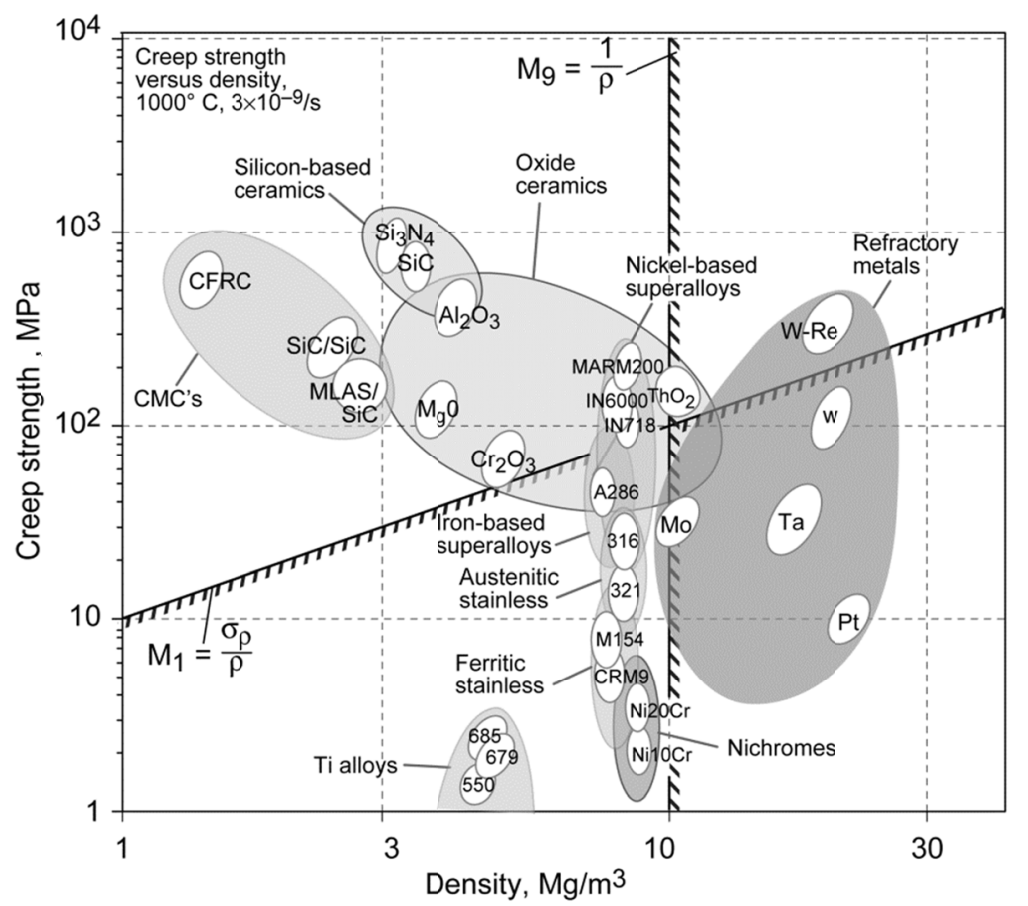

Figure 25.-A selection chart for deflection limited design at $1000{ }^{\circ} \mathrm{C}$ for a life of $1000 \mathrm{hr}$

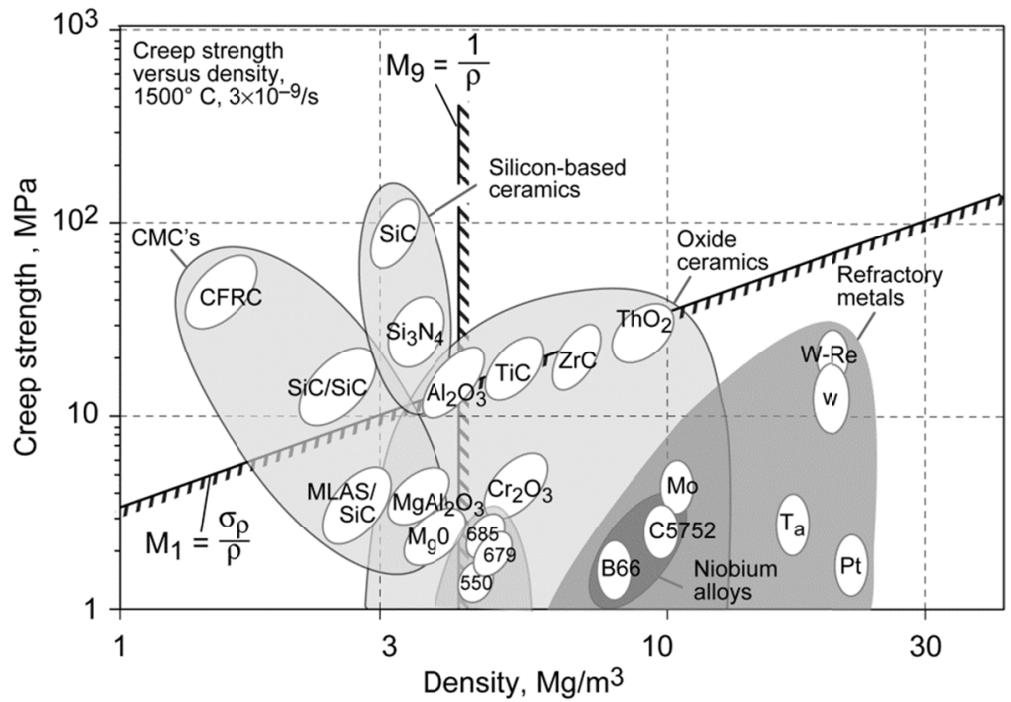

Figure 26. - A selection chart for deflection limited design at $1500{ }^{\circ} \mathrm{C}$ for a life of $1000 \mathrm{hr}$.

TABLE 7.-CANDIDATE MATERIALS FOR DEFLECTION LIMITED BLADE DESIGN AT $400{ }^{\circ} \mathrm{C}$ FOR A LIFE OF $1000 \mathrm{hr}$

\begin{tabular}{|l|l|}
\hline \multicolumn{1}{|c|}{ Material } & \multicolumn{1}{c|}{ Comment } \\
\hline Ti-matrix composites (Ti/Si/C $\mathrm{C}_{\mathrm{f}}$ ) & The ultimate in performance, but very expensive \\
\hline Ti alloys (e.g., Ti 685, 6242) & High creep strength and low density makes these the best choice \\
\hline Ni-based superalloys (e.g., IN738) & Excellent creep strength, but both indices $M_{1}$ and $M_{4}$ inferior to Ti alloys \\
\hline Iron based superalloys, stainless steels & Less good than nickel-based alloys, but cheaper \\
\hline Ceramics and CMC's & Excellent values of $M_{1}$ and $M_{4}$ but brittleness is a problem \\
\hline
\end{tabular}


TABLE 8.-CANDIDATE MATERIALS FOR DEFLECTION

LIMITED BLADE DESIGN AT $1000^{\circ} \mathrm{C}$ FOR A LIFE OF $1000 \mathrm{hr}$

\begin{tabular}{|l|l|}
\hline \multicolumn{1}{|c|}{ Material } & \multicolumn{1}{c|}{ Comment } \\
\hline Ni-based superalloys & Among metallic alloys, these have the highest values of $M_{1}$ but heavy \\
\hline Refractory metals & W-Re alloys offer high $M_{1}$ but very heavy \\
\hline Oxide ceramics and silicon-based ceramics, CMS's & Large weight saving possible if design can accommodate brittleness \\
\hline
\end{tabular}

TABLE 9.-CANDIDATE MATERIALS FOR DEFLECTION

LIMITED BLADE DESIGN AT $1500^{\circ} \mathrm{C}$ FOR A LIFE OF $1000 \mathrm{hr}$

\begin{tabular}{|l|l|}
\hline \multicolumn{1}{|c|}{ Material } & \multicolumn{1}{c|}{ Comment } \\
\hline Oxide and silicon-based ceramics $(\mathrm{SiC}, \mathrm{Al} 203)$ & Offer high values of $M_{1}$ and $M_{4}$ but design must accommodate brittleness \\
\hline Refractory metals & Tungsten - rhenium creep resistant, but heavy \\
\hline Ceramic composites (SiC-SiC; carbon-carbon) & $\begin{array}{l}\text { Potential for gains in performance, but brittleness and chemical stability } \\
\text { require attention }\end{array}$ \\
\hline
\end{tabular}

\subsection{Engineered Materials}

Engineered or 'hybrid' materials are combinations of two or more materials, or of materials and space, assembled in such a way as to have attributes not offered by any one material alone (Figure 27).

Particulate and fiber reinforced composites are examples of one type of hybrid, but there are many others: sandwich structures, lattice structures, segmented structures and more. Hybrids and composites differ from bulk materials in providing an opportunity to tailor the properties of the 'material' to the application - in effect designing the material, while designing the component. This requires the ability to synthesize properties of candidate hybrid materials during the design process. This in turn requires the engineer to choose the components of the hybrid, their configuration and their relative fraction. The new variables expand the design space, allowing the creation of new "materials" with specific property profiles. Consequently, one can view these new "materials" as mini-structures since internal to the

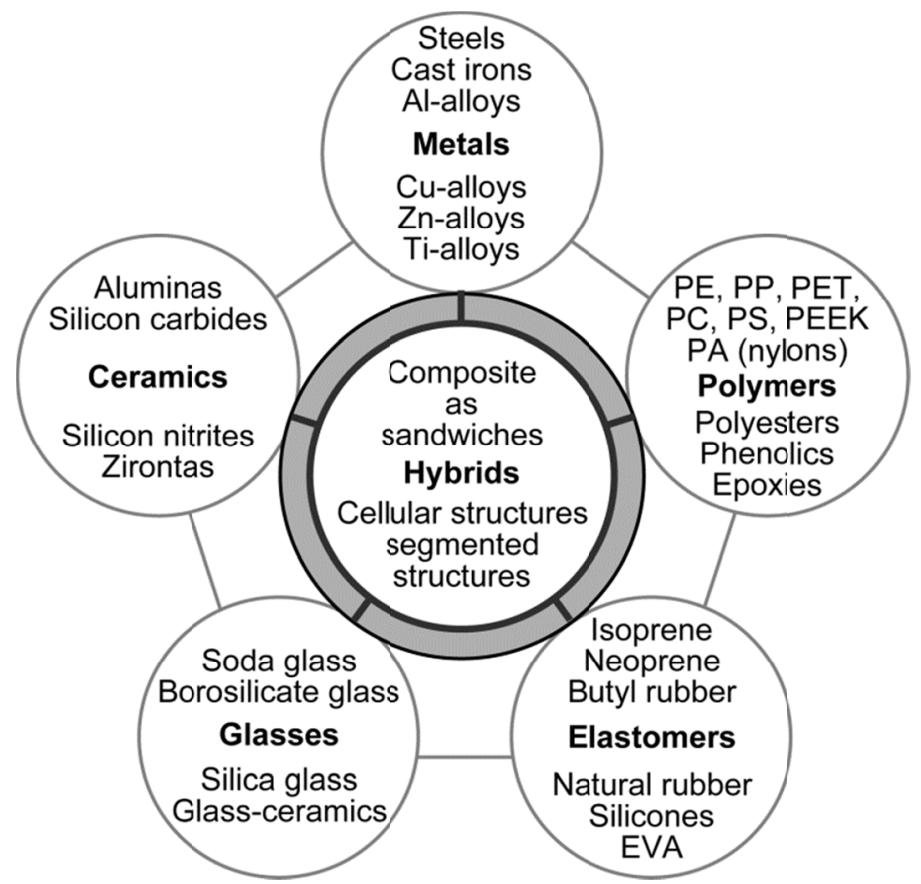

Figure 27.-Hybrid materials combine the properties of two (or more) monolithic materials, or of one material and space. They include fibrous and particulate composites, foams and lattices, sandwiches and almost all natural materials. 
material the individual constituents will redistribute the local stress and strain fields to carry the globally applied fields most effectively.

But how is one to compare a hybrid - a sandwich structure for example - with monolithic materials such as polycarbonate or titanium? To do this we must think of the sandwich not only as a hybrid with faces of one material bonded to a core of another, but as a "material" in its own right, with its own set of effective properties; it is these that allow the comparison.

The approach adopted here is one of breadth rather than precision. The aim is to assemble methods to allow the properties of alternative hybrids to be scanned and compared with those of monolithic materials, seeking those that best meet a given set of design requirements. Once materials and configuration have been chosen, standard methods - optimization routines, finite-element analyses - can be used to refine them. But what the standard methods are not good at is the quick scan of alternative combinations. That is where the approximate methods discussed here pay off.

The broad classes of hybrid can be considered in this way:

- Cellular structures are combinations of material and space giving precise control of density, stiffness, strength and thermal conductivity.

- Sandwich structures have outer faces of one material supported by a core of another, usually a low density material - a configuration that can offer a flexural stiffness per unit weight that is greater than that offered by either component alone.

- Composites combine two solid components, one, the reinforcement, contained in the other, the matrix.

- Coated materials enable the surface properties of the bulk material to be enhanced by addition of a thin surface layer.

Continuum and micro-mechanical models can be used to estimate the equivalent properties of each configuration. These can then be plotted on material selection charts, which become comparison-tools for exploring unique combinations of configuration and material. Some examples follow later.

\subsubsection{Holes in Material-Property Space}

As previously described, material properties can be "mapped" as material property charts of which Figure 28 is an example (for an up-to-date survey see Ashby et al. 2010). All the charts have one thing in common: parts of them are populated with materials but other parts are not. Some parts of the holes are inaccessible for fundamental reasons that relate to the size of atoms and the nature of the forces that bind them together. But others are empty even though, in principle, they could be filled.

\subsubsection{Criteria of Excellence}

Is anything to be gained by developing materials (or material-combinations) that lie in these holes? To answer this a criteria of excellence is needed to assess the merit of any given hybrid. These are provided by the material indices, described above. If a possible hybrid has a value of any one of these that exceed those of existing materials, it achieves our goal.

The axes of Figure 28 are Young's modulus, $E$, and density $\rho$. The property-combinations $E / \rho, E^{1 / 2} / \rho$ and $E^{1 / 3} / \rho$ are measures of the excellence or material indices for selecting materials for light, stiff structures. A grid of lines of one index $-E / \rho$ - is plotted on the figure. The arrow lies normal to the index lines. If the filled areas can be expanded in the direction of the arrow (i.e., to greater values of $E / \rho$ ) the materials so created will enable lighter, stiffer structures to be made. The arrow thus defines a vector for material development.

One approach to filling holes - the long-established one - is that of developing new metal alloys, new polymer chemistries and new compositions of glass and ceramic so as to create monolithic materials that expand the populated areas of the property charts. But developing new materials can be expensive and 


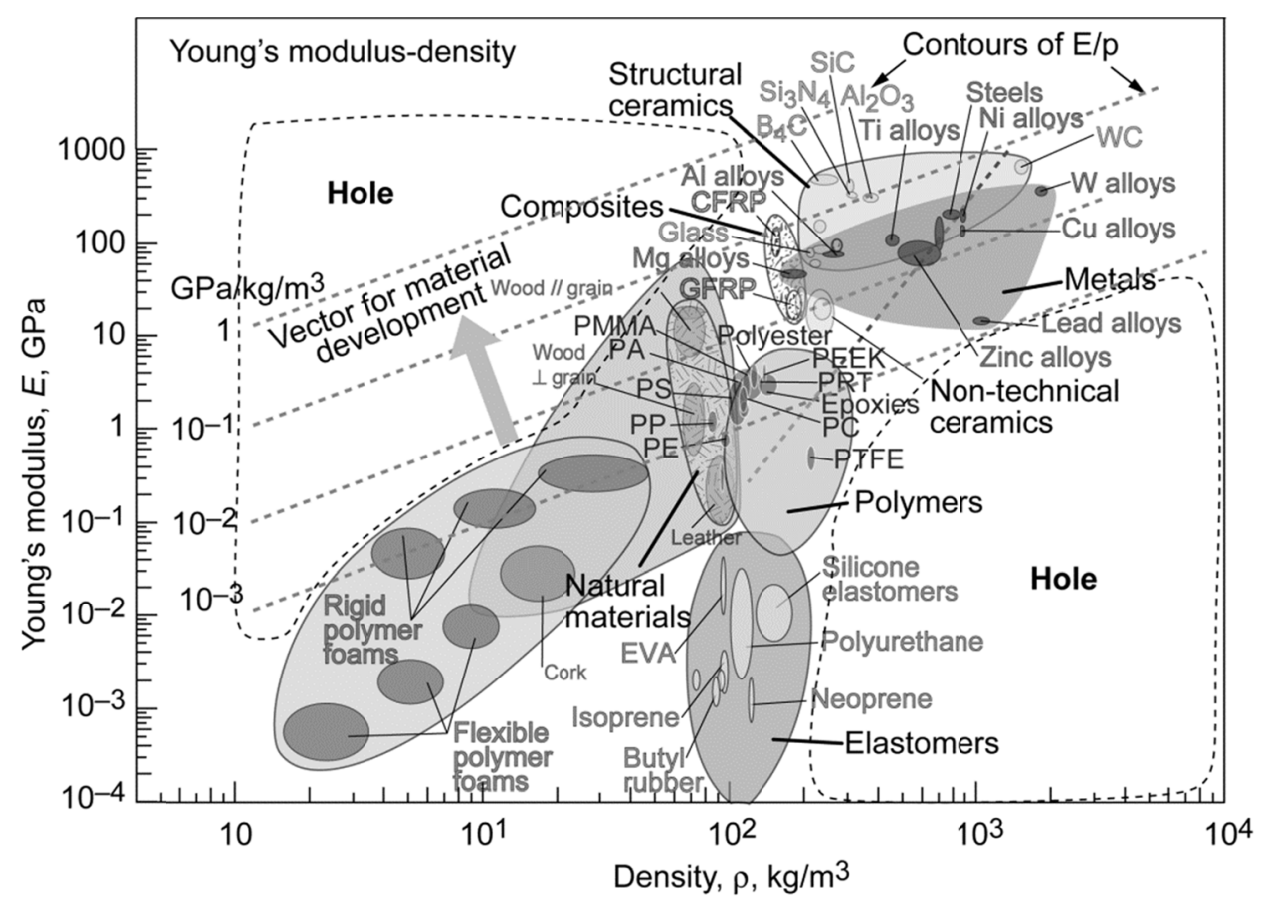

Figure 28.-A material property chart showing modulus-density space, with contours of specific modulus, E/p. Part of the space is occupied by materials, part it empty (the "holes"). Material development that extended the occupied territory in the direction of the arrow (the "vector for material development") allows components with greater stiffness-to-weight than is at present possible.

uncertain, and the gains tend to be incremental rather than step-like. An alternative is to combine two or more existing materials so as to allow a superposition of their properties - in short, to create hybrids. The great success of carbon and glass-fiber reinforced composites at one extreme, and of foamed materials at another (hybrids of material and space) in filling previously empty areas of the material property charts is encouragement to explore ways in which such hybrids can be designed.

When is a hybrid a "material"? There is a certain duality about the way in which hybrids are thought about and discussed. Some, like filled polymers, composites or wood are treated as materials in their own right, each characterized by its own set of macroscopic material properties. Others - like galvanized steelare seen as one material (steel) to which a coating of a second (zinc) has been applied, even though it could be regarded as a new material with the strength of steel but the surface properties of zinc. Sandwich panels illustrate the duality, sometimes viewed as two sheets of face-material separated by a core material, and sometimes - to allow comparison with monolithic materials - as a "material" with their own density, axial and flexural stiffness and strength, thermal conductivity, expansion coefficient, etc. To call any one of these a "material" and characterize it as such is a useful shorthand, allowing designers to use existing methods when designing with them. But if we are to design the hybrid itself, we must deconstruct it, and think of it as a combination of materials (or of material and space) in a chosen configuration.

\subsubsection{Synthesizing the Properties of Cellular Structures: Foams and Lattices}

This section provides an example of the synthesizing properties of foams and cellular structures. Some simple mathematical models for synthesizing homogenized properties of these materials are discussed first. This is followed by a numerical example. The principal sources of the following models are: Gibson and Ashby (1997) and Ashby et al. (2000). For a similar discussion of other classes of hybrids: composites and sandwich panels see Ashby et al. (2010). 

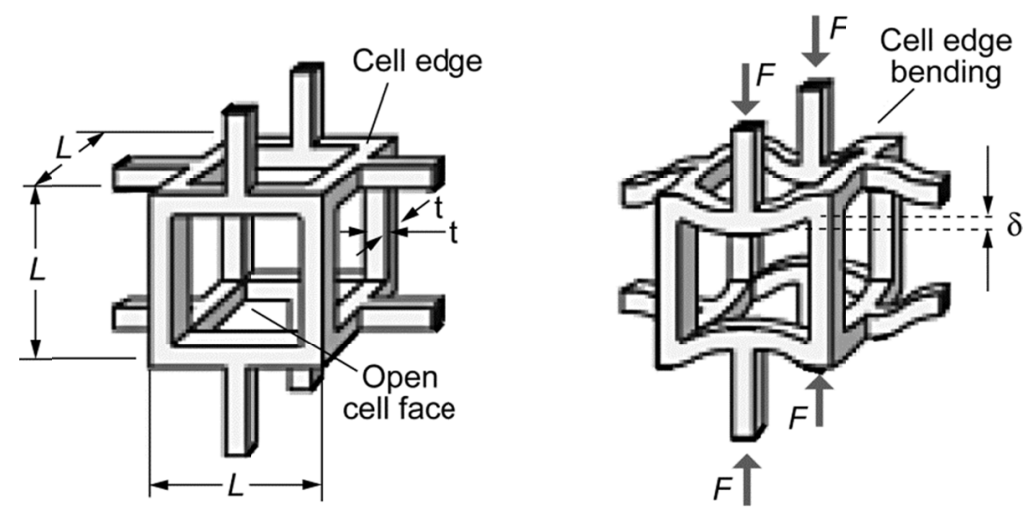

Figure 29.-A cell in a low density foam. When the foam is loaded, the cell edges bend, giving a low-modulus structure.
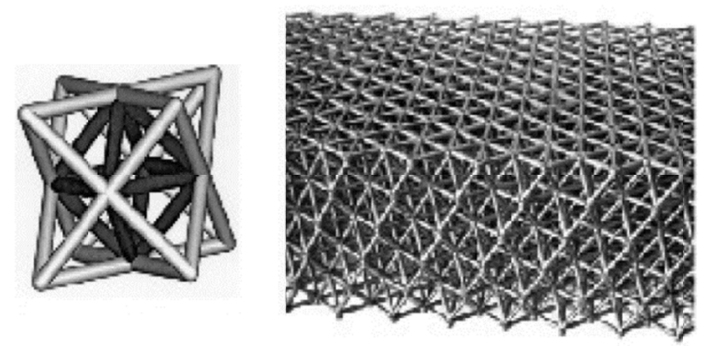

Figure 30.-A micro-truss structure and its unit cell. The cell edges stretch when the structure is loaded, making it stiffer and stronger than a foam of the same density.

Cellular structures - foams and lattices - are hybrids of a solid and a gas. The properties of the gas might at first sight seem irrelevant, but this is not so. The thermal conductivity of low-density foams of the sort used for insulation is determined by the conductivity of the gas contained in its pores; and the dielectric properties, and even the compressibility, can depend on the gas properties. There are two distinct species of cellular solid. The first, typified by foams, are bending-dominated structures; the second, typified by triangulated lattice structures, are stretch dominated - a distinction explained more fully below.

Foams are cellular solids made by expanding polymers, metals, ceramics or glasses with a foaming agent - a generic term for one of many ways of introducing gas, much as yeast does in bread-making. Figure 29 shows an idealized cell of a low-density foam. It consists of solid cell walls or edges surrounding a void space containing a gas or fluid. Foams have the characteristic that, when loaded, the cell walls bend. Lattice-structures (Figure 30) are configured to suppress bending, so the cell edges have to stretch instead.

\subsubsection{Density}

Cellular solids are characterized by their relative density, which for the structure shown here (with $t<<L)$ is

$$
\frac{\tilde{\rho}}{\rho_{s}}=C_{1}\left(\frac{t}{L}\right)^{2}
$$

where $\widetilde{\rho}$ is the density of the foam, $\rho_{s}$ is the density of the solid of which it is made, $L$ is the cell size, $t$ is the thickness of the cell edges and $C_{1}$ is a constant, approximately equal to 1 . 


\subsubsection{Mechanical Properties}

In Figure 31 the compressive stress-strain curve of a cellular solid is depicted. The material is linear elastic, with modulus $\widetilde{E}$ up to its elastic limit, at which point the cell edges yield, buckle or fracture. The foam continues to collapse at a nearly constant stress (the "plateau stress", $\widetilde{\sigma}_{p l}$ ) until opposite sides of the cells impinge (the "densification strain" $\widetilde{\varepsilon}_{d}$ ), when the stress rises rapidly. The mechanical properties are calculated in the ways developed below.

Elastic Moduli of Bending-Dominated Foams: A remote compressive stress $\sigma$ exerts a force $F \propto \sigma L_{2}$ on the cell edges, causing them to bend and leading to a bending deflection $\delta$, as shown in Figure 29. For the open-celled structure shown in the figure, the bending deflection scales as

$$
\delta \propto \frac{F L^{3}}{E_{s} I}
$$

where $E_{s}$ is the modulus of the solid of which the foam is made and $I=\frac{t^{4}}{12}$ is the second moment of area of the cell edge of square cross section, $t^{2}$. The compressive strain suffered by the cell as a whole is then $\varepsilon$ $=2 \delta / L$. Assembling these results gives the modulus $\widetilde{E}=\sigma / \varepsilon$ of the foam as

$$
\widetilde{E}=C_{2}\left(\frac{\widetilde{\rho}}{\rho_{s}}\right)^{2} E_{s} \quad \text { (bending-dominated behavior) }
$$

Since $\widetilde{E}=E_{s}$ when $\widetilde{\rho}=\rho_{s}$, we expect the constant of proportionality $C_{2}$ to be close to unity-a speculation confirmed both by experiment. Numerical simulation gives $C_{1}=0.7$, the value used in the examples below. The quadratic dependence means that a small decrease in relative density causes a large drop in modulus. When the cells are equiaxed in shape, the foam properties are isotropic with shear modulus, bulk modulus and Poisson's ratio via

$$
\widetilde{G}=\frac{3}{8} \widetilde{E} \quad \widetilde{K}=\widetilde{E} \quad \nu=\frac{1}{3}
$$

Elastic Moduli of Stretch-Dominated Lattices: The structure shown in Figure 30, is fully triangulated. This means that the cell edges must stretch when the structure is loaded elastically. On average one third of its edges carry tension when the structure is loaded in simple tension, regardless of the loading direction. Thus

$$
\widetilde{E}=C_{3}\left(\frac{\widetilde{\rho}}{\rho_{s}}\right) E_{s} \quad \text { (stretch-dominated behavior) }
$$

with $C_{3}=1 / 3$. The modulus is linear, not quadratic, in density giving a structure that is stiffer than a foam of the same density. The structure of Figure 32 is almost isotropic, so we again approximate the shear modulus, bulk modulus and Poisson's ratio by Eq. (57).

\subsubsection{Yield Strength, Flexural Strength and Compressive Strength}

Strength of bending-dominated foams. When the structure of Figure 29 is loaded beyond the elastic limit, its cell walls may yield, buckle elastically or fracture as shown in Figure 32. Consider yielding first (Figure 32(a)). Cell edges yield when the force exerted on them exceeds their fully plastic moment. 


$$
M_{f}=\frac{\sigma_{y, s} t^{3}}{4}
$$

where $\sigma_{y, s}$ is the yield strength of the solid of which the foam is made. This moment is related to the remote stress by $M \propto F L \propto \sigma L^{3}$. Assembling these results gives the compressive failure strength when yield dominates, $\widetilde{\sigma}_{c}$

$$
\tilde{\sigma}_{c}=C_{4}\left(\frac{\tilde{\rho}}{\rho_{s}}\right)^{3 / 2} \sigma_{y, s} \quad \text { (yield of foams) }
$$

where the constant of proportionality, $C_{4} \approx 0.3$, has been established both by experiment and by numerical computation.

Elastomeric foams collapse not by yielding but by elastic bucking; brittle foams by cell-wall fracture (Figure 32(b) and (c)). As with plastic collapse, simple scaling laws describe this behavior well. Collapse by buckling occurs when the stress exceeds

$$
\tilde{\sigma}_{c} \approx 0.05\left(\frac{\tilde{\rho}}{\rho_{s}}\right)^{2} E_{s} \quad \text { (buckling of foams) }
$$

We identify the compressive strength $\widetilde{\sigma}_{c}$ with the lesser of Eqs. (60) or (61). We further set the yield strength $\tilde{\sigma}_{y}$ the flexural strength $\widetilde{\sigma}_{\text {flex }}$ equal to $\widetilde{\sigma}_{c}$.

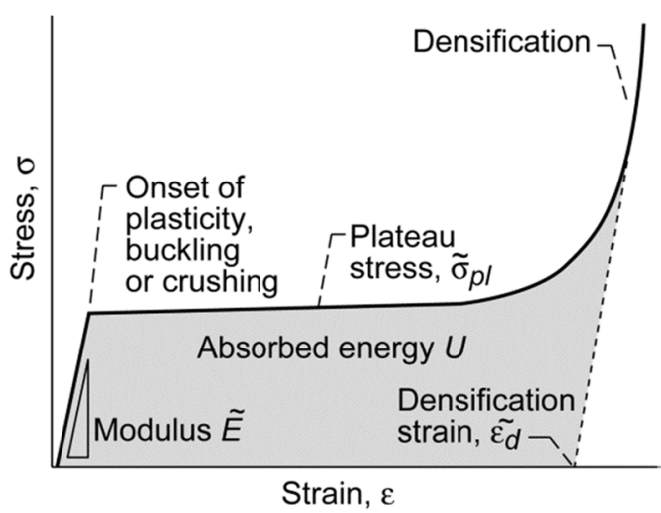

Figure 31.-The modulus is determined by cell edge bending or stretching. The plateau stress is determined by buckling, plastic bending or fracturing of the cell walls. 
(a)

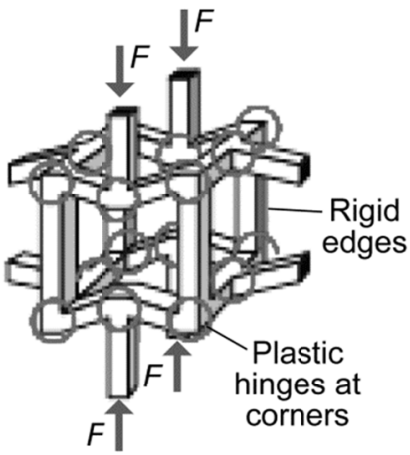

(b)

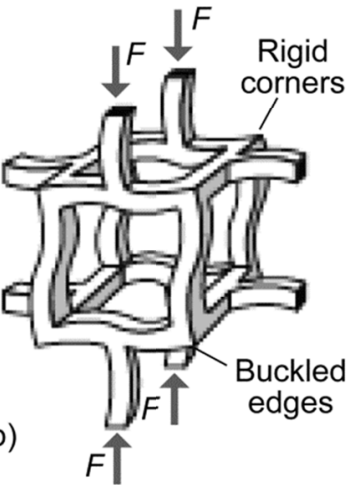

(c)

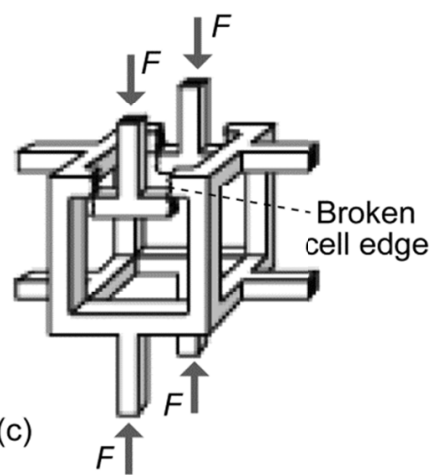

Figure 32.-Collapse of foams. (a) When a foam made of a plastic materials loaded beyond its elastic limit, the cell edges bend plastically. (b) An elastomeric foam, by contrast, collapses by the elastic buckling of its cell edges. (c) A brittle foam collapses by the successive fracturing of cell edges.

Strength of stretch-dominated lattices: Collapse occurs when the cell edges yield, giving the collapse stress

$$
\tilde{\sigma}_{c} \approx \frac{1}{3}\left(\frac{\tilde{\rho}}{\rho_{s}}\right) \sigma_{y, s} \quad \text { (yield of lattices) }
$$

This is an upper bound since it assumes that the struts yield in tension or compression when the structure is loaded. If the struts are slender, they may buckle before they yield. They do so at the stress

$$
\widetilde{\sigma}_{c} \approx 0.2\left(\frac{\tilde{\rho}}{\rho_{s}}\right)^{2} E_{s}
$$

We identify the compressive strength $\widetilde{\sigma}_{c}$ with the lesser of Eqs. (62) and (63). We further identify the yield strength $\widetilde{\sigma}_{y}$, the flexural strength $\widetilde{\sigma}_{\text {flex }}$ with $\widetilde{\sigma}_{c}$.

\subsubsection{Fracture Toughness}

Fracture toughness of bending-dominated foams: Foams that contain long crack-like flaws compared to the cell size $\ell$ fail by fast fracture, meaning that the crack propagates unstably, if the stress intensity factor exceeds the critical value $\widetilde{K}_{\text {Ic }}$, which is the lesser of 


$$
\widetilde{K}_{\mathrm{I} c}=0.5\left(\frac{\ell}{a}\right)^{1 / 2}\left(\frac{\tilde{\rho}}{\rho_{s}}\right)^{3 / 2} K_{\mathrm{I} c, s} \text { and } K_{\mathrm{I} c, s}
$$

Here $a$ is the intrinsic flaw size of the cell edge material, $K_{\mathrm{I} c, s}$ is its fracture toughness and $\sigma_{t s, s}$ is its tensile strength; wherein typically $\ell / a \approx 10$.

This behavior is not confined to open-cell foams. Most closed-cell foams also follow these scaling laws. At first sight, this is an unexpected result because the cell faces must carry membrane stresses when the foam is loaded, and these should lead to a linear dependence of both stiffness and strength on relative density. The explanation lies in the fact that the cell faces are very thin; they buckle or rupture at stresses so low that their contribution to stiffness and strength is small, leaving the cell edges to carry most of the load.

Fracture toughness of stretch-dominated lattices: Lattices that contain long crack-like flaws compared to the cell size $\ell$ fail by fast fracture if the stress intensity factor exceeds the critical value $\widetilde{K}_{\text {Ic }}$, which is the lesser of

$$
\widetilde{K}_{\mathrm{I} c}=0.5\left(\frac{\ell}{a}\right)^{1 / 2}\left(\frac{\widetilde{\rho}}{\rho_{s}}\right) K_{\mathrm{I} c, s} \quad \text { and } \quad K_{\mathrm{I} c, s}
$$

$\ell / a$ is the ratio of the cell size of the foam to the flaw size in the material — again typically having a value of approximately 10 .

\subsubsection{Thermal Properties}

Specific heat and thermal expansion: The specific heat $\widetilde{C}_{p}$ of foams and lattices (units: J/kg.K) and the expansion coefficient $\widetilde{\alpha}$ (units $\mathrm{K}^{-1}$ ) are the same as those of the solid of which they are made.

Thermal conductivity: The cells in most cellular structures are sufficiently small that convection of the gas within them is completely suppressed. The thermal conductivity of the foam is then the sum of that conducted thought the cell walls and that through the still air (or other gas) they contain. To an adequate approximation

$$
\tilde{\lambda}=\frac{1}{3}\left(\left(\frac{\widetilde{\rho}}{\rho_{s}}\right)+2\left(\frac{\tilde{\rho}}{\rho_{s}}\right)^{3 / 2}\right) \lambda_{s}+\left(1-\left(\frac{\widetilde{\rho}}{\rho_{s}}\right)\right) \lambda_{g}
$$

where $\lambda_{s}$ is the conductivity of the solid and $\lambda_{g}$ that of the gas (for dry air it is $0.025 \mathrm{~W} / \mathrm{m} . \mathrm{K}$ ). The term associated with the gas is important: blowing agents for foams intended for thermal insulation are chosen to have a low value of $\lambda_{g}$.

\subsubsection{Electrical Properties}

Resistivity: The electrical resistivity, $\widetilde{\rho}_{\text {elec }}$ of foam is given by

$$
\tilde{\rho}_{\text {elec }}=\frac{3}{\left(\left(\frac{\tilde{\rho}}{\rho_{s}}\right)+2\left(\frac{\tilde{\rho}}{\rho_{s}}\right)^{3 / 2}\right.} \rho_{\text {elec }, s}
$$

Dielectric properties: Insulating foams are attractive for their low dielectric constant, $\widetilde{\varepsilon}_{r}$, falling towards 1 (the value for air or vacuum) as the relative density decreases: 


$$
\widetilde{\varepsilon}_{r}=1+\left(\varepsilon_{r, s}-1\right)\left(\frac{\widetilde{\rho}}{\rho_{s}}\right)
$$

where $\varepsilon_{r, s}$ is the dielectric constant of the solid of which the foam is made. The dielectric loss tangent is independent of foam density and just equal to that of the solid of which the foam is made.

\subsubsection{Example: Aluminum Metal Matrix Composite (MMC) Foams and Lattices}

The starting point is aluminum $20 \% \mathrm{SiC}(\mathrm{p}),{ }^{4}$ a mix that is the basis of one of the Cymat range of metal foams. The properties of two hybrids are compared a "Foam" and an "Octet lattice", that generates two sets of new records. They appear on the Modulus-Density chart of Figure 33 as lines of white and gray circles, respectively. The starting material, $\mathrm{Al} 20 \% \mathrm{SiC}(\mathrm{p})$, is identified at the upper right. The modeled foams, plotted white, are labeled with their relative densities in parentheses. Measured data for real aluminum-SiC(p) foams (shown as black ellipse in Fig. 33) are also labeled, underlined, with relative densities in parentheses, allowing a comparison. Note that the lattices, plotted in gray, lie at higher values of modulus for the same density. At a relative density of 3.5\% (0.035) the lattice is predicted to be ten times stiffer than foam of that density.

In Figure 34 many other engineering materials have been added. The lattice structures out-perform all of them, expanding the populated area of the chart. So an AlSiC(p) lattice provides one possible way to find a material with superior modulus/density performance than conventional materials. Further examples can be found in Ashby et al. (2010).

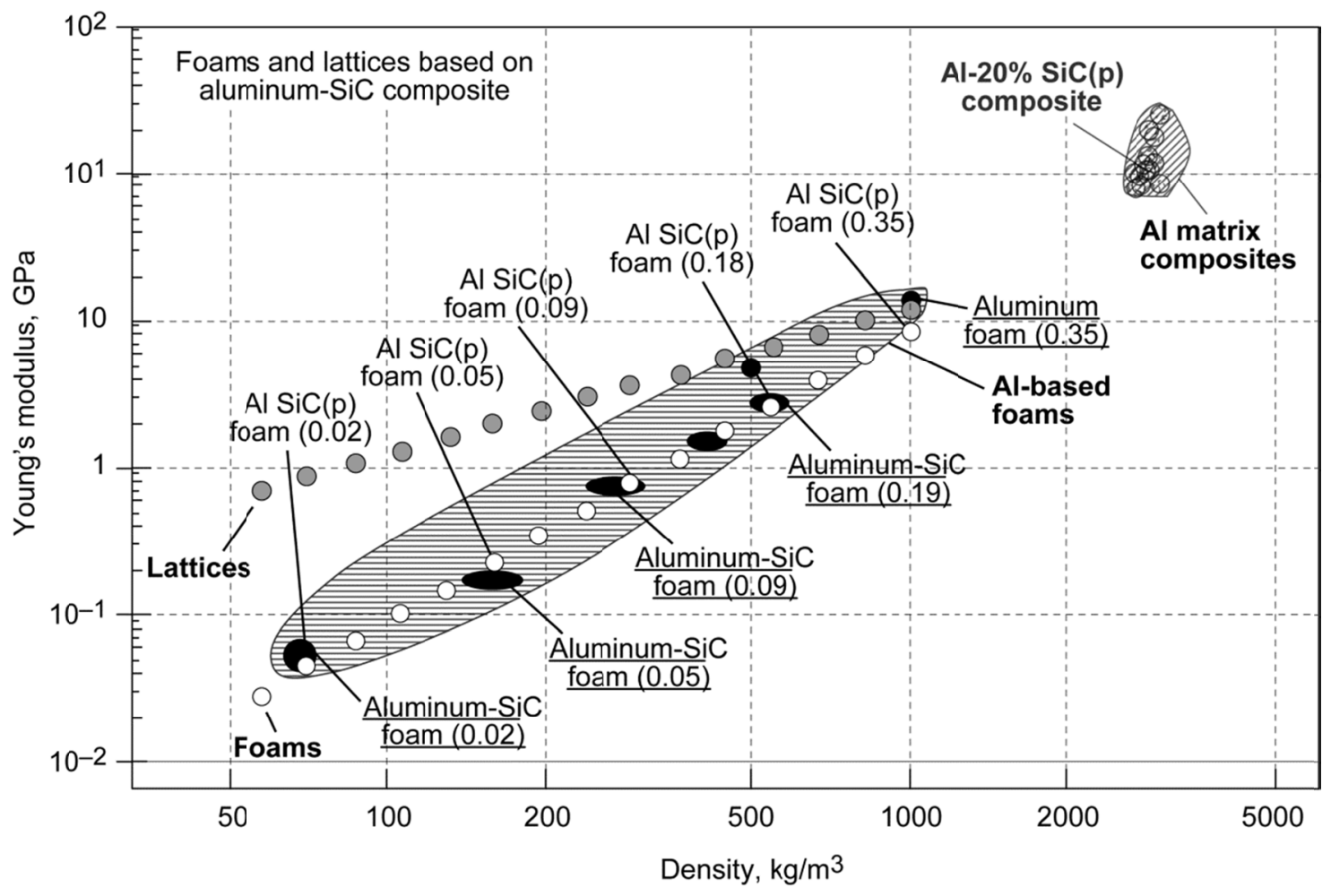

Figure 33.-The input window of the synthesizer, set for Cellular structures - Octet lattice. The chart shows some of the output. The starting material, Al $20 \% \mathrm{SiC}(\mathrm{p})$ appears at the upper right. The line of white ellipses show the modulus and density of foams made from Al-SiC $(p)$. They should be compared with the measured values for real aluminum $\mathrm{SiC}(\mathrm{p})$ foams, shown in black with underlined labels. The relative densities are listed in brackets. The modulus and density of lattices made of the same material are shown in gray for comparison. Chart generated by the CES Hybrid Synthesizer, (Ashby et al., 2010). 


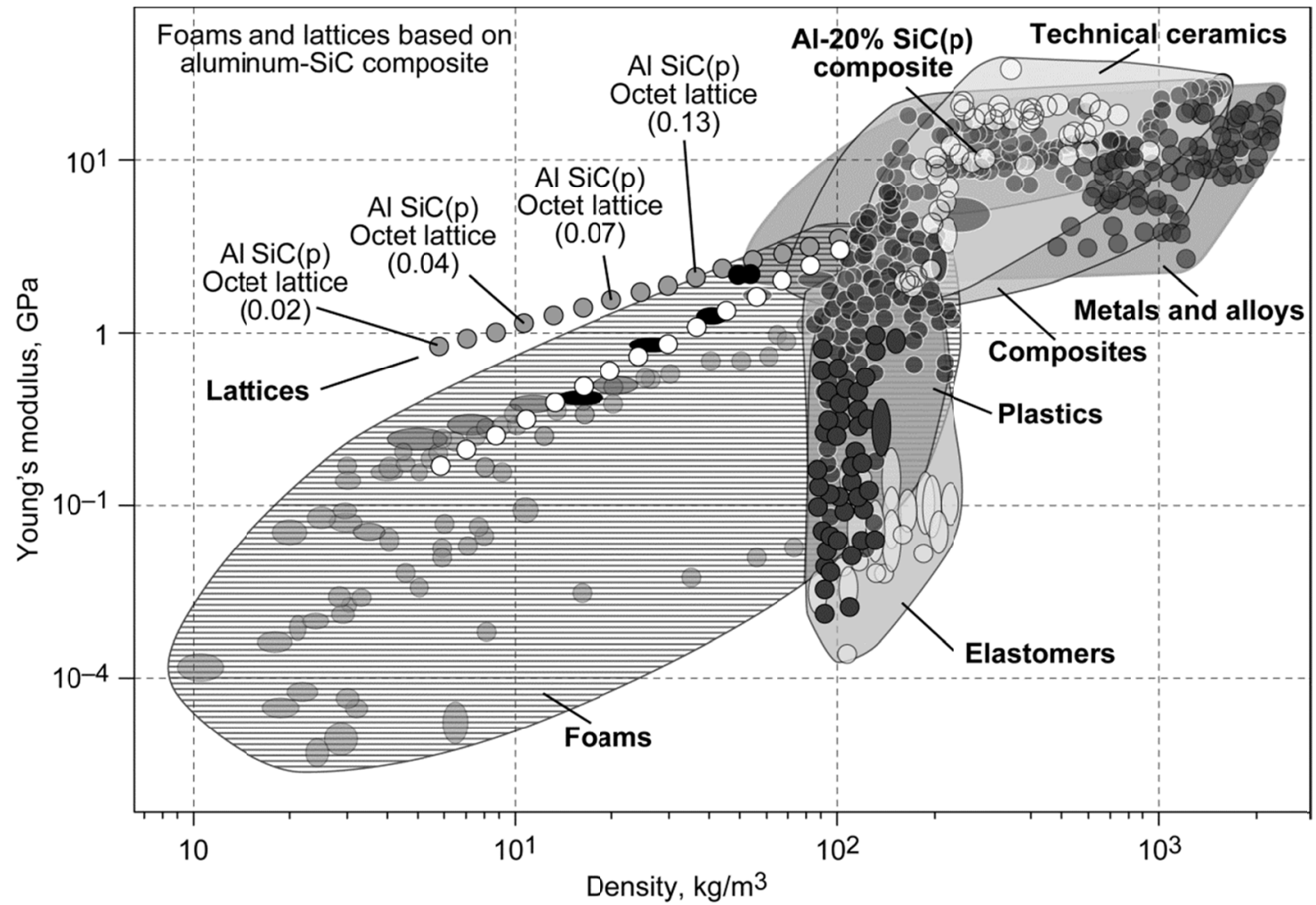

Figure 34.-The moduli of Al-SiC lattices compared to those of the other materials of engineering. The lattices lie outside the currently populated areas of the chart. Numbers in brackets are relative densities. Chart generated by the CES Hybrid Synthesizer, (Ashby et al., 2010).

\subsubsection{The CES Hybrid Synthesizer}

The approach described has been implemented in the CES Selector (2011), as a scoping tool that allows fast exploration of hybrid structures (see Ashby et al., 2010). It presents approximate analyses of the properties that might be achieved by forming a single material into a cellular structure or by combining two materials to form a sandwich or a composite. The purpose of the tool is to encourage innovation by allowing estimated property-profiles for virtual novel hybrids to be explored and compared with the property-profiles of established engineering materials.

If a suitable innovative material can be found in this way, the next steps are more detailed analyses, e.g., using finite element methods, followed by manufacturing, testing and qualifying the new material.

\subsection{Data Issues}

To accomplish the material selection processes described above, the quantity and quality of the material information is central to all aspects of the process and most importantly to the final engineering products. The needs for materials information change throughout the lifecycle of an engineering component see Table 10. Likewise, the informatics infrastructure required to handle the potentially massive amounts of material data should not be overlooked nor underestimated.

Early in the design process, the 'conceptual design' phase, information is needed for all possible materials, but at a relatively low level of precision, since the objective at this stage is to select a small subset of materials that can optimally perform the function of the component with acceptable cost and environmental impact. 'Typical' values of the engineering properties and environmental impact data are best suited to this task. Narrowing this subset to one or two preferred candidates requires encyclopedic data sources that can inform the designer of a wide range of (often unquantifiable) characteristics of the 
material. This 'supporting information' includes details of corrosion, heat treatment, environmental impact and joining characteristics, as well as previous in-house experience in using the material. As the design of the component is finalized, detailed stress analyses and lifing calculations are needed, which in turn require very precise 'allowable' design values of the properties of a single material.

TABLE 10.-MATERIAL INFORMATION NEEDS THROUGH A PRODUCT LIFE CYCLE

\begin{tabular}{|l|l|l|}
\hline Product life phase & \multicolumn{1}{|c|}{ Materials information } & \multicolumn{1}{c|}{ Engineering operation } \\
\hline Design & $\begin{array}{l}\text { Selection data (typical props) } \\
\text { Supporting information } \\
\text { Environmental impact information } \\
\text { Design 'allowables' } \\
\text { Specific constitutive and failure } \\
\text { models for detailed design }\end{array}$ & $\begin{array}{l}\text { Materials selection } \\
\text { Environmental analysis } \\
\text { Life cycle assessment } \\
\text { Design calculations } \\
\text { Stress analysis } \\
\text { Lifing, simulation }\end{array}$ \\
\hline Manufacture & Processing data & $\begin{array}{l}\text { Process modeling, } \\
\text { Manufacturing simulation }\end{array}$ \\
\hline In-service & Durability information & $\begin{array}{l}\text { Maintenance } \\
\text { Predict remaining life } \\
\text { Investigate failures }\end{array}$ \\
\hline End of life & $\begin{array}{l}\text { Environmental impact information } \\
\text { Hazardous materials regulations } \\
\text { Recycling information }\end{array}$ & End of life policy implementation \\
\hline
\end{tabular}

Next the component must be manufactured, which has its own data requirements for information about the processing characteristics of the raw material - the viscosity when molten, the strength at high temperature, the hardness, toughness, etc. Then when the component is in service, there is a need for material data for maintenance purposes (e.g., for manufacturing spare parts), for predicting the remaininglife and for investigating service failures when they arise. Finally, at the end of life, the component may be recycled or disposed-of in some other way, therefore requiring knowledge of the environmental characteristics of the material — for example information about toxicity or degradation in landfill and associated legislative requirements - can be essential.

All this is to make the point that having a multifaceted, "complete" material data source in a well organized, easily retrievable, information management system is a critically important and often unappreciated aspect of the entire engineering process. The value of a given database depends on its precision and its completeness, or in other words on its quality. Consequently, numerous procedures of checking and validating data have been devised, see for example Ashby (1998), Cebon and Ashby (2000) and Cebon and Ashby (2006) for discussion of checking methods, including property range and dimensionless correlations concepts.

The material data lifecycle is described in Figure 35 wherein data is captured and consolidated from external sources, legacy databases as well as internal (possibly proprietary) testing programs. Next data is analyzed and integrated to create/discover useful information and then deployed (disseminated) to the people who need and use it. With the continual maintenance of the whole system (the data and information generated as well as the relationships, or links, between them) being the last yet essential stage of the data lifecycle. To support the various required activities throughout this data lifecycle requires the integration (preferably seamless) of a variety of software tools. These range from data input, reduction/analysis, visualization, reporting tools; material parameter estimation tools; product life management tools (PLM); to structural analysis codes that utilize a central database. These tools should enable material and structural engineers throughout the enterprise to input, manage and utilize information in as an efficient, reliable and user-friendly way as possible. An information management system that was conceived of by the Material Data Management Consortium [www.mdmc.net] and built 


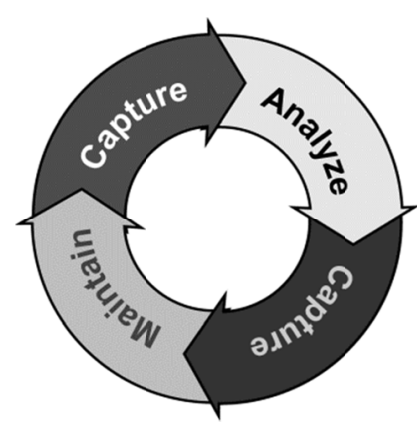

Figure 35.-Four aspects of material data lifecycle.

by Granta Design provides just such an environment and information management toolset. The toolset is composed of two primary components:

1. GRANTA MI: is a comprehensive materials information system accessible from the web. Its unique database is specifically designed to store materials properties, response curves and other data relating to materials. It comprises a series of powerful software tools which help you to control, analyze, and apply your data.

2. CES Selector: is a PC software application that offers advanced graphical analysis of materials data, plus specialist eco design and modeling tools, in support of materials selection and substitution decisions.

\subsection{Conclusions}

Trade-offs are endemic in both everyday life and materials selection. Typically the job of a designer is to balance a variety of functional requirements (i.e., types of loading conditions (tension, compression, bending, vibration, cyclic, etc.) with constraints (manufacturability, geometric limits, environmental aspects, maintainability, to name a few) so as to arrive at the 'optimum' choice of structural concept and material selection for a given weight and/or cost. Herein a systematic, design-oriented, five step approach to material selection has been described: 1) establishing design requirements, 2) material screening, 3) ranking, 4) researching specific candidates and 5) applying specific cultural constraints to the selection process. At the core of this approach was the introduction of performance indices, through mathematical analysis of idealizations representing various engineering problems. Finding a material with a high value of these indexes maximizes the performance of the component. Material selection charts, which plot one property against another, were also introduced and shown to provide a powerful graphical environment wherein one could apply and analyze quantitative selection criteria, such as those captured in performance indices, and make trade-offs between conflicting objectives. Two specific examples pertaining to aerospace (engine blades and pressure vessels) where examined both at room temperature and elevated temperature (wherein time dependent effects were accounted for) to demonstrate the methodology. A discussion with respect to engineered/hybrid materials and how these can be effectively tailored to fill in holes in the material property space so as to enable innovation and increases in performance over monolithic materials. Finally, a brief discussion relative to the data collection, analysis, deployment, and maintenance issues was addressed. 


\section{Appendix A.- Table of Material Indices}

\begin{tabular}{|c|c|c|c|}
\hline Function and constraints & $\begin{array}{c}\text { Stiffness-limited } \\
\text { design }\end{array}$ & $\begin{array}{c}\text { Strength-limited } \\
\text { design }\end{array}$ & $\begin{array}{c}\text { Vibration-limited } \\
\text { design }\end{array}$ \\
\hline \multicolumn{4}{|l|}{ Tie (tensile strut) } \\
\hline Stiffness, length specified; section area free & $E / \rho$ & $\sigma_{f}$ & $E / \rho$ \\
\hline \multicolumn{4}{|l|}{ Shaft (loaded in torsion) } \\
\hline Stiffness, length, shape specified, section area free & $G^{1 / 2} / \rho$ & & \\
\hline Stiffness, length, outer radius specified; wall thickness free & $G / \rho$ & & \\
\hline Stiffness, length, wall-thickness specified; outer radius free & $G^{1 / 3} / \rho$ & & \\
\hline \multicolumn{4}{|l|}{ Beam (loaded in bending) } \\
\hline Stiffness, length, shape specified; section area free & $E^{1 / 2} / \rho$ & & $E^{1 / 2} / \rho$ \\
\hline $\begin{array}{l}\text { Stiffness, length, height specified; width free } \\
\text { All dimensions specified }\end{array}$ & $E / \rho$ & & $E / \rho$ \\
\hline Stiffness, length, width specified; height free & $E^{1 / 3} / \rho$ & $\sigma_{f}^{1 / 2}$ & \\
\hline \multicolumn{4}{|l|}{ Column (compression strut, failure by elastic buckling) } \\
\hline Buckling load, length, shape specified; section area free & $E^{1 / 2} / \rho$ & $\sigma_{f}$ & \\
\hline \multicolumn{4}{|l|}{ Panel (flat plate, loaded in bending) } \\
\hline $\begin{array}{l}\text { Stiffness, length, width specified, thickness free } \\
\text { All dimensions specified }\end{array}$ & $E^{1 / 3} / \rho$ & & $\begin{array}{c}E^{1 / 3} / \rho \\
E / \rho\end{array}$ \\
\hline \multicolumn{4}{|l|}{ Plate (flat plate, compressed in-plane, buckling failure) } \\
\hline Collapse load, length and width specified, thickness free & $E^{1 / 3} / \rho$ & $\sigma_{f}^{1 / 2}$ & \\
\hline \multicolumn{4}{|l|}{ Cylinder with internal pressure } \\
\hline $\begin{array}{l}\text { Elastic distortion, pressure and radius specified; wall } \\
\text { thickness free }\end{array}$ & $E / \rho$ & $\sigma_{f} / \rho$ & \\
\hline \multicolumn{4}{|l|}{ Spherical shell with internal pressure } \\
\hline $\begin{array}{l}\text { Elastic distortion, pressure and radius specified; wall } \\
\text { thickness free }\end{array}$ & $E /(1-v) \rho$ & $\sigma_{f} / \rho$ & \\
\hline
\end{tabular}




\section{B.1 Creep Fracture}

Creep fracture. Time to fracture ("life") $=t_{f} ; n>>1$

\begin{tabular}{|c|c|c|c|}
\hline Mode of loading & Geometry & Design strength & Index \\
\hline Tension; centrifugal loading & Any $b$ and $h$ & $\sigma_{D}=\sigma_{f 0}\left(\frac{t_{f 0}}{t_{f}}\right)^{\frac{1}{q}}$ & $M=\frac{\sigma_{D}}{\rho}$ \\
\hline Bending & $\begin{array}{c}b=\alpha h \\
b \text { fixed } \\
h \text { free } \\
h \text { fixed } \\
b \text { free }\end{array}$ & $\sigma_{D}=\sigma_{f 0}\left(\frac{t_{f 0}}{t_{f}}\right)^{\frac{1}{q}}$ & $\begin{array}{c}M=\frac{\sigma_{D}{ }^{2 / 3}}{\rho} \\
M=\frac{\sigma_{D}^{1 / 2}}{\rho} \\
M=\frac{\sigma_{D}}{\rho}\end{array}$ \\
\hline Torsion & $\begin{array}{l}\text { Solid } \\
R \text { free } \\
t=\alpha R \\
t \text { fixed } \\
R \text { free } \\
R \text { fixed } \\
t \text { free }\end{array}$ & $\sigma_{D}=\sigma_{f 0}\left(\frac{t_{f 0}}{t_{f}}\right)^{\frac{1}{q}}$ & $\begin{aligned} M & =\frac{\sigma_{D}{ }^{2 / 3}}{\rho} \\
M & =\frac{\sigma_{D}{ }^{2 / 3}}{\rho} \\
M & =\frac{\sigma_{D}{ }^{1 / 2}}{\rho} \\
M & =\frac{\sigma_{D}}{\rho}\end{aligned}$ \\
\hline Pressure tubes and vessels & $\begin{array}{c}R \text { fixed } \\
t \text { free }\end{array}$ & $\sigma_{D}=\sigma_{f 0}\left(\frac{t_{f 0}}{t_{f}}\right)^{\frac{1}{q}}$ & $M=\frac{\sigma_{D}}{\rho}$ \\
\hline
\end{tabular}

To minimize cost, replace $\rho$ by $C_{m} \rho$ in the expressions for $M$; to minimize energy content, replace $\rho$ by $q_{m} \rho$. 


\section{B.2 Creep Deflection}

Creep deflection. Time to deflect through $\delta$ ("life") $=t ; \dot{\delta} \propto \delta / t n>>1$

\begin{tabular}{|c|c|c|c|}
\hline Mode of loading & Geometry & Design strength & Index \\
\hline Tension; centrifugal loading & Any $b$ and $h$ & $\sigma_{D}=\sigma_{o}\left(\frac{\dot{\delta}}{L \dot{\varepsilon}_{o}}\right)^{\frac{1}{n}}$ & $M=\frac{\sigma_{D}}{\rho}$ \\
\hline Bending & $\begin{array}{l}b=\alpha h \\
b \text { fixed } \\
h \text { free } \\
h \text { fixed } \\
b \text { free }\end{array}$ & $\sigma_{D}=\sigma_{o}\left(\frac{\dot{\delta}}{L \dot{\varepsilon}_{o}}\right)^{\frac{1}{n}}$ & $\begin{array}{c}M=\frac{\sigma_{D}{ }^{2 / 3}}{\rho} \\
M=\frac{\sigma_{D}{ }^{1 / 2}}{\rho} \\
M=\frac{\sigma_{D}}{\rho}\end{array}$ \\
\hline Torsion & $\begin{array}{l}\text { Solid } \\
R \text { free } \\
t=\alpha R \\
t \text { fixed } \\
R \text { free } \\
R \text { fixed } \\
t \text { free }\end{array}$ & $\begin{array}{l}\sigma_{D}=\sigma_{o}\left(\frac{\dot{\Theta}}{\sqrt{3} \dot{\varepsilon}_{o}}\right)^{\frac{1}{n}} \\
\sigma_{D}=\sigma_{o}\left(\frac{R \dot{\Theta}}{\sqrt{3} L \dot{\varepsilon}_{o}}\right)^{\frac{1}{n}}\end{array}$ & $\begin{aligned} M & =\frac{\sigma_{D}^{2 / 3}}{\rho} \\
M & =\frac{\sigma_{D}^{2 / 3}}{\rho} \\
M & =\frac{\sigma_{D}^{1 / 2}}{\rho} \\
M & =\frac{\sigma_{D}}{\rho}\end{aligned}$ \\
\hline Pressure tubes and vessels & $\begin{array}{c}R \text { fixed } \\
t \text { free }\end{array}$ & $\sigma_{D}=\sigma_{o}\left(\frac{\dot{R}}{R \dot{\varepsilon}_{o}}\right)^{\frac{1}{n}}$ & $M=\frac{\sigma_{D}}{\rho}$ \\
\hline
\end{tabular}

To minimize cost, replace $\rho$ by $C_{m} \rho$ in the expressions for $M$; to minimize energy content, replace $\rho$ by $q_{m} \rho$. 


\section{B.3 Creep Relaxation}

Creep relaxation. Time to relax to $F_{i} / 2$ or $T_{i} / 2$ ("life") $=t_{r} ; n>>1$

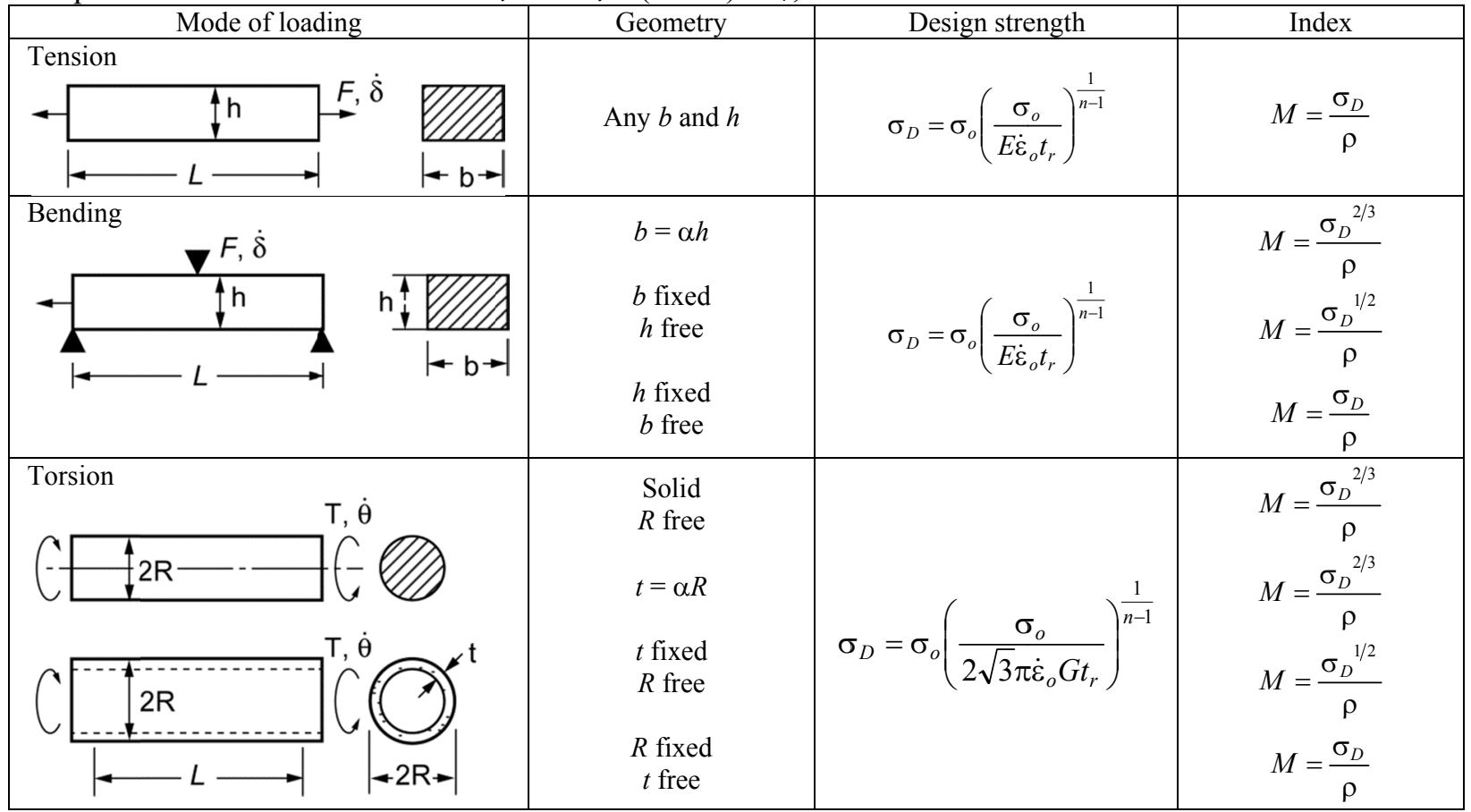

To minimize cost, replace $\rho$ by $C_{m} \rho$ in the expressions for $M$; to minimize energy content, replace $\rho$ by $q_{m} \rho$. 


\section{Appendix B.-Design Strength and Indices For Creep Deflection}

Here the design strength $\sigma_{D}$ is defined and the performance indices $M$ are derived for the creep fracture problem defined in Figure 36. First, the objective function is established; as it describes the quantity (like mass or cost) to be maximized or minimized. Then the constraints are formulated - the acceptable deflection rate or life. Next, the constraints are substituted into the objective function, eliminating free variables, and the design strength, $\sigma_{D}$, is identified and lastly, the performance index $M$, is extracted.

\section{B.1 Simple Tension or Compression: Minimum Weight Design}

A tie of length $L$ and section $A$ carries a tensile load $F$ (Figure 36(a)). The objective function is

$$
m=A L \rho
$$

The extension rate of $\dot{\delta}$ of the tie is

$$
\dot{\delta}=L \dot{\varepsilon}=L \dot{\varepsilon}_{0}\left(\frac{\sigma}{\sigma_{0}}\right)^{n}=L \dot{\varepsilon}_{0}\left(\frac{F}{A \sigma_{0}}\right)^{n}
$$

The free variable is the section area $A$. The mass is reduced by reducing $A$, but $A$ is constrained by the need to carry $F$ without deflecting faster than $\dot{\delta}$. For a prescribed maximum deflection rate, $\dot{\delta}$ the section must equal or exceed

$$
A=\left(\frac{L \dot{\varepsilon}_{0}}{\dot{\delta}}\right)^{\frac{1}{n}} \frac{F}{\sigma_{0}}
$$

This is the constraint. Substituting it into the objective function (B1) to eliminate $A$ gives

$$
m=A L \rho=\frac{L \rho F}{\sigma_{0}}\left(\frac{L \dot{\varepsilon}_{0}}{\dot{\delta}}\right)^{\frac{1}{n}}
$$

Comparing this with the fully plastic solution

$$
m=\frac{L \rho F}{\sigma_{y}}
$$

we can extract the design strength, $\sigma_{D}$ :

$$
\sigma_{D}=\sigma_{0}\left(\frac{\dot{\delta}}{L \dot{\varepsilon}_{0}}\right)^{\frac{1}{n}}
$$

which plays the role, at high temperature, of the yield strength at low. Thus the lightest materials which will support a load $F$ at temperature $T$ without deflecting faster than $\dot{\delta}$ are those with the greatest value of

$$
M=\frac{\sigma_{D}}{\rho}
$$

with $\sigma_{D}$ given by Eq. (B6). To minimize cost instead of mass, the density $\rho$ in this equation is replaced by $C_{m} \rho$, where $C_{m}$ is the cost per $\mathrm{kg}$ of the material. 
(a)
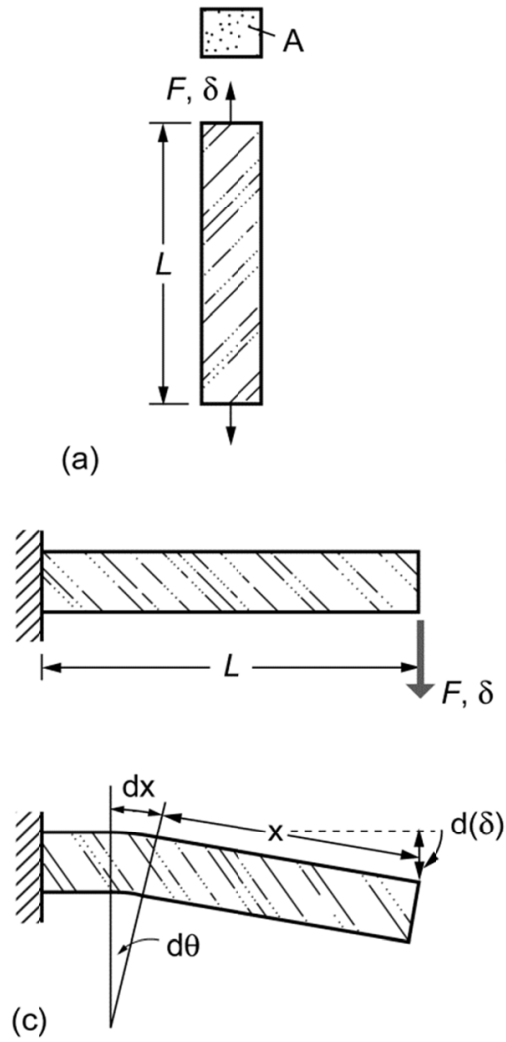

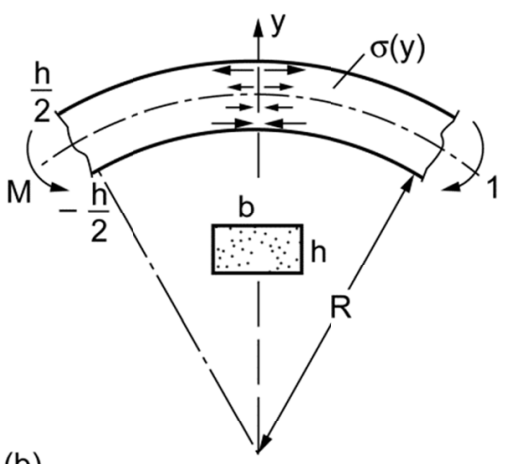

(b)

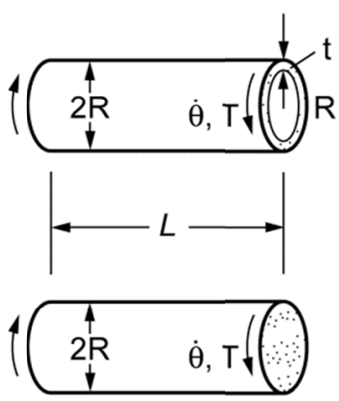

(d)

Figure 36.--Modes of loading: (a) tension, (b) bending, (c) a cantilever and (d) torsion.

\section{B.2 Bending of Beams, Minimum Weight Design}

Consider a beam loaded in bending, as in Figure 36(b). The objective function is given, as before, by Eq. (B1). To develop the constraint we must analyze the creep deflection rate, $\dot{\delta}$, of the beam. Three standard assumptions are made: the bending displacements are small; the neutral axis lies in the plane of symmetry of the beam section; and plane sections remain plane. The bending moment $M$ carried by the beam is related to the stress within it, $\sigma(y)$ by:

$$
M=2 b \int_{0}^{h / 2} y \sigma(y) d y
$$

The strain rate $\dot{\varepsilon}(y)$ at any point in the section is related to the change of curvature, $\dot{K}$ by

$$
\varepsilon(y)=y \dot{K}
$$

Substituting this into Norton's Law (Eq. (B6)) gives the stress distribution

$$
\sigma(y)=\sigma_{0}\left(\frac{\dot{\varepsilon}(y)}{\dot{\varepsilon}_{0}}\right)^{1 / n}=\sigma_{0}\left(\frac{y \dot{K}}{\dot{\varepsilon}_{0}}\right)^{1 / n}
$$

Inserting this into Eq. (B8), integrating and inverting gives the key equation for any creeping-beam problem: 


$$
\dot{K}=\dot{\varepsilon}_{0}\left(\left(\frac{2 n+1}{2 n}\right) \frac{M}{b \sigma_{0}}\right)^{n}\left(\frac{2}{h}\right)^{2 n+1}
$$

We shall apply it to the cantilever of Figure 36(c). The curvature rate, $\dot{K}(x)$ at the point $x$ (Figure 36(c)) contributes

$$
d(\dot{\delta})=X d \dot{\theta}=x \dot{K}(x) d x
$$

to the end deflection rate. The moment at $x$ is

$$
M=F x
$$

Combining Eqs. (B11) and (B13), and integrating along the beam from $x=0$ to $x=L$ gives

$$
\dot{\delta}=\frac{2}{n+2} \dot{\varepsilon}_{0} L^{2}\left\{\frac{4 F L}{\sigma_{0}}\left(\frac{2 n+1}{2 n}\right) \frac{1}{b h^{\frac{2 n+1}{n}}}\right\}^{n}
$$

If the section is rectangular, with $b=\alpha h$ its area $A$ is

$$
A=b h=\alpha h^{2}
$$

Solving Eq. (B14) for $A$ gives an explicit equation for the constraint on $A$; and inserting this into Eq. (B1) for the mass $m$ gives

$$
m=A L \rho=\rho L^{\frac{3 n+3}{3 n+1}} \alpha^{\frac{n+1}{3 n+1}}\left(\left(\frac{2 n+1}{2 n}\right) \frac{4 F L}{\sigma_{D}}\right)^{\frac{2 n}{3 n+1}}
$$

As explained in the main text, the design strength for bending is defined as

$$
\sigma_{D}=\sigma_{0}\left(\left(\frac{n+2}{2}\right) \frac{\dot{\delta}}{L \dot{\varepsilon}_{0}}\right)^{\frac{1}{n}}
$$

because in the limit $n=\infty$, Eq. (B16) reduces to the result for perfect plasticity with $\sigma_{D}=\sigma_{y}$; that is, $\sigma_{D}$ once again plays the role, for high temperatures, of the yield strength $\sigma_{y}$ in room temperature design. Results for other configurations are listed in Section 0.

The quantity $\frac{2 n+1}{2 n} \approx 1, L^{\frac{3 n+3}{3 n+1}} \approx L, \alpha^{\frac{n+1}{3 n+1}} \approx \alpha^{\frac{1}{3}}$ and $\left(\frac{n+2}{n}\right)^{1 / n} \approx 1.3$ for all $n$ between 3 and 10, allowing the good approximation:

$$
m=L \rho \alpha^{1 / 3}\left(\frac{4 F L}{\sigma_{D}}\right)^{2 / 3}
$$

with 


$$
\sigma_{D}=\sigma_{0}\left(\frac{\dot{\delta}}{L \dot{\varepsilon}_{0}}\right)^{1 / n}=\sigma_{0}\left(\frac{\delta}{t L \dot{\varepsilon}_{0}}\right)^{1 / n}
$$

This is the same as the tensile result of the last section although $\dot{\delta}$ now refers to a lateral displacement, not an extension. Thus the lightest materials which will support a given bending moment at temperature $T$ without a bending deflection rate greater than $\dot{\delta}$ are those with the greatest value of

$$
M=\frac{\sigma_{D}^{2 / 3}}{\rho}
$$

When $b$ is fixed and only $h$ is free the definition of $\sigma_{D}$ is unchanged, but the performance index becomes:

$$
M=\frac{\sigma_{D}{ }^{1 / 2}}{\rho}
$$

and when $h$ is fixed and only $b$ varies it becomes instead:

$$
M=\frac{\sigma_{D}}{\rho}
$$

To minimize cost instead of mass, $\rho$ in the last three equations is replaced by $C_{m} \rho$ where $C_{m}$ is the cost per $\mathrm{kg}$ of the material.

\section{B.2.1 Torsion of Shafts, Minimum Weight Design}

Torsion appears simpler, but there is a wrinkle. We seek the highest shaft which will carry a torque $T$ without rotating faster than $\dot{\theta}$. The objective function for a light shaft is given, as before, by Eq. (B1). A rotation rate $\dot{\theta}$ of a thin-walled tube of length $L$, radius $R$ and wall thickness $t$ (Figure 36(d)) gives a strain rate in the wall of

$$
\dot{\gamma}=\frac{R \dot{\theta}}{L}
$$

This generates a shear stress in the wall which is found by rewriting Norton's Law in terms of shear stress $\tau$ and shear strain-rate $\dot{\gamma}$ (using $\tau=\sigma / \sqrt{3}$ and $\gamma=\sqrt{3} \dot{\varepsilon}$ ). Combining this with (B23) gives

$$
\tau=\frac{\sigma}{\sqrt{3}}=\frac{\sigma_{0}}{\sqrt{3}}\left(\frac{R \dot{\theta}}{\sqrt{3} L \dot{\varepsilon}_{0}}\right)^{\frac{1}{n}}
$$

The torque $T_{q}$ is given by $2 \pi R^{2} t \tau$

$$
T_{q}=\frac{2 \pi R^{2} t \sigma_{0}}{\sqrt{3}}\left(\frac{R \dot{\theta}}{\sqrt{3} L \dot{\varepsilon}_{0}}\right)^{\frac{1}{n}}
$$

It is tempting to identify the design strength with the quantity 


$$
\sigma_{D}=\sigma_{0}\left(\frac{R \dot{\theta}}{\sqrt{3} L \dot{\varepsilon}_{0}}\right)^{\frac{1}{n}}
$$

but this is valid only when $R$ is held fixed and $t$ is allowed to vary in optimizing the mass or the cost. When $R$ is a free variable it cannot be included in $\sigma_{D}$ since - in the optimization to minimize mass $-R$ must be eliminated. When $R$ is fixed, we can write (using the definition above of $\sigma_{D}$ ):

$$
T_{q}=\frac{2 \pi R^{2} t \sigma_{0}}{\sqrt{3}}
$$

The minimum section which will carry a torque $T_{q}$ without rotating faster than $\dot{\theta}$ is

$$
A=2 \pi R t=\frac{\sqrt{3} T_{q}}{R \sigma_{D}}
$$

This gives the constraint on $A$. Substituting it into Eq. (B1) gives

$$
m=A L \rho=\frac{\sqrt{3} \rho T_{q}}{R \sigma_{D}}
$$

The mass is minimized by maximizing

$$
M=\frac{\sigma_{D}}{\rho}
$$

When, instead, $t$ is fixed and $R$ can be varied, we must redefine the design strength as

$$
\sigma_{D}=\sigma_{0}\left(\frac{\dot{\theta}}{\sqrt{3} \varepsilon_{0}}\right)^{1 / n}
$$

Replacing this in Eq. (B25), solving for $A$ and using this to calculate the mass $M$, as before, gives:

$$
m=2 \pi t^{\frac{n+1}{2 n+1}} L^{\frac{2 n+2}{2 n+1}} \rho\left[\frac{\sqrt{3} t T_{q}}{\sigma_{D}}\right]^{\frac{n}{2 n+1}}
$$

which, when $n>3$, reduces to

$$
m=2 \pi L \rho\left(\frac{\sqrt{3} t T_{q}}{\sigma_{D}}\right)^{1 / 2}
$$

The mass is minimized by choosing materials with high values of

$$
M=\frac{\sigma_{D}{ }^{1 / 2}}{\rho}
$$


Repeating the calculation for a solid torsion bar gives

$$
T=\frac{2 \pi R^{3} \sigma_{0}}{\sqrt{3}}\left(\frac{n}{3 n+1}\right)\left(\frac{R \dot{\theta}}{\sqrt{3} L \dot{\varepsilon}_{0}}\right)
$$

The definition of design strength remains the same as Eq. (B31). Inserting this in the last equation and solving for the section $A=\pi R^{2}$ gives, via Eq. (B11)

$$
m=C_{3} \pi \rho L^{\frac{3 n+3}{3 n+1}}\left(\frac{3 \sqrt{3} T_{q}}{2 \pi \sigma_{D}}\right)^{\frac{2 n}{3 n+1}}
$$

with

$$
C_{3}=\left(\frac{3 n+1}{3 n}\right)^{\frac{2 n}{3 n+1}}
$$

For all $n>3, C_{3} \approx 1$ and the exponents simplify to give

$$
m_{3}=\pi \rho L\left(\frac{3 \sqrt{3} T_{q}}{2 \pi \sigma_{D}}\right)^{2 / 3}=2.8 T_{q}^{2 / 3} L\left(\frac{\rho}{\sigma_{D}^{2 / 3}}\right)
$$

The lightest shaft is that with the greatest value of

$$
M=\frac{\sigma_{D}^{2 / 3}}{\rho}
$$

A similar calculation for a tube in which the thickness scales as the radius, such that $t=\alpha R$ gives the same result, with the same definition for $\sigma_{D}$. 


\section{References}

Abel, C. A. and Ashby, M. F. (1994), "Materials Selection to Resist Creep and Creep Rupture," Cambridge University Engineering Department Report CUED/C-EDC/TR18, pp. 1-32.

Arnold, S. M., and Saleeb, A. F., (1994), "On the Thermodynamic Framework of Generalized Coupled Thermoelastic-Viscoplastic-Damage Modeling," J. of Int. Plasticity, Vol. 10, No. 3, pp. 263-278.

Arnold, S. M., Saleeb, A. F., Castelli, M. G. (2001), "A General Reversible Hereditary Constitutive Model: Part II Application to Titanium Alloys," JEMT, Vol. 123, pp. 65-73.

Arnold, S. M., Bednarcyk, B.A., Collier, C. S., and Yarrington, P.W. (2007), "Spherical Cryogenic Hydrogen Tank Preliminary Design Trade Studies," NASA/TM-2007-214846.

Arnold, S. M., Goldberg, R. K., and Lerch, B. A., Saleeb, A. F. (2009), “An Overview of Prognosis Health Management Research at Glenn Research Center for Gas Turbine Engine Structures With Special Emphasis on Deformation and Damage Modeling," NASA/TM-2009-215827/REV 1.

Anderson, T.L., (2005), Fracture Mechanics: Fundamentals and Applications, CRC Press, Taylor \& Francis.

Anon (1999), "Megabytes on Coppers II," Copper Development Association.

Anon (2001), "Guide to engineered materials (GEM)," Advanced Materials and Processes, ASM International, Materials Park Ohio. 159.

Anon (2002), MIL-HDBK-5H-CN1. Columbus, Ohio, Battelle Memorial Institute.

Anon (2003), Alloy Center, http://www.asminternational.org/alloycenter/index.jsp, ASM International.

Anon (2003), ASM Handbooks Online http://www.asminternational.org/hbk/index.jsp, ASM International.

Ashby, M. F. (1992), Materials Selection in Mechanical Design, Pergamon Press, Oxford, U.K.

Ashby, M. F. (1998), "Checks and estimates for material properties," Proc Roy Soc A454: pp. 13011321.

Ashby, M. F. (2011), Materials selection in mechanical design, Fourth Edition. Oxford, ButterworthHeinemann.

Ashby, M. F., Evans, A. G., Fleck, N. A., Gibson, Lorna, J., Hutchinson J. W. and Wadley, H. N. G. (2000), "Metal Foams: a Design Guide," Butterworth Heinemann, Oxford. ISBN 0-7506-7219-6.

Ashby, M. F., Cebon, D., Bream, C., Cesaretto, C., and Ball, N. (2010), "The CES Hybrids SynthesizerA White Paper," Granta Design Limited.

Bassetti, D., Brechet, Y., et al. (1998), "Estimates for material properties: The method of multiple correlations," Proc. R. Soc. A454: pp. 1323-1336.

Broek, D., Elementary Engineering Fracture Mechanics, Martinus Nijhoff Publishers, 1982.

Lemaitre, J. and Chaboche, J. L. (1990), "Mechanics of Solid Materials," Cambridge, University Press, New York.

Cebon, D. and Ashby, M. F. (1992), “Computer-aided materials selection for mechanical design," Metals and Materials, January, pp. 25-30

Cebon, D. and Ashby, M. F. (1997), Optimal selection of engineering entities. ISSN 0963-5432, Cambridge University, Engineering Department.

Cebon, D. and Ashby, M. F. (2000), "Information Systems for Material and Processes," Advanced Materials and Processes 157(6): pp. 44-48.

Cebon, D. and Ashby, M. F. (2006), "Engineering materials informatics,” MRS Bulletin, 31. pp. 10041012. ISSN 0883-7694.

Chester T. S., Norman, S. S., William C. H; (1987), Superalloys II, Wiley \& Sons.

CES Selector (2011), Granta Design Ltd, Cambridge, U.K. www.grantadesign.com.

Crane, F. A. A. and Charles, J. A. (1984), Selection and Use of Engineering Materials, Butterworths, London, U.K.

Evans, R. W. and Wilshire, B. (1985), "Creep of Metals and Alloys," The Institute of Metals, London, U.K.

Finnie, I. and Heller, W. R. (1959), Creep of Engineering Materials, McGraw Hill, N.Y. 
Frost, H. J. and Ashby, M. F. (1982), Deformation Mechanism Maps, Pergamon Press, Oxford, U.K.

Gibson, L. J. and Ashby, M. F. (1997) Cellular solids, structure and properties, 2nd edition, Cambridge University Press, Cambridge, U.K. ISBN 0-521-49560-1.

Gittus, J. (1975), Creep, Viscoelasticity and Creep Fracture, Elsevier Applied Science, London, U.K.

Hult, J. (1966), Creep in Engineering Structures, Baisdell Press, London, U.K.

Larson, W. J. and Pranke, L. K. (1999), Human Spaceflight: Mission Analysis and Design, p. 1035, McGraw-Hill, ISBN 978-0077230289

Miracle, D. B., (2001), "Metal Matrix Composites for Space Systems: Current Uses and Future Opportunities. Affordable Metal-matrix Composites for High Performance Applications," A. B. Pandey, K. L. Kendig, and T. J. Watson, eds., TMS, Warrendale, PA, pp. 1-21.

Mital, S. K., Gyekenyesi, J. Z., Arnold, S. M., Sullivan, R. M., Manderscheid, J. M., and Murthy, P. L. N. (2006), "Review of Current State of the Art and Key Design Issues With Potential Solutions for Liquid Hydrogen Cryogenic Storage Tank Structures for Aircraft Applications," NASA/TM-2006214346.

Odqvist, F. (1936), "Theory of Creep Under the Action of Combined Stresses with Applications to High Temperature machinery," Proc. Royal Swedish Institute for Engineering Research, N. 141.

Penny, R. K. and Marriott, D. L. (1971), Design for Creep, McGraw Hill, Boston, U.S.A.

Ramberg, W. and Osgood, W.R. (1943), "Description of stress strain curves by three parameters," Technical Note No. 902, NACA, Washington, D.C.

Rice, R. C. and Jackson J. L. (2003), "Metallic materials properties development and standardization (MMPDS)," Springfield, VA, National Technical Information Service.

Skrzypek J. and Hetnarski, R. (2000), Plasticity and Creep, Theory, Examples, and Problems, CRC Press.

Saleeb, A. F. and Arnold, S. M. (2001), "A General Reversible Hereditary Constitutive Model: Part I Theoretical Developments,” JEMT, Vol. 123, pp. 51-64.

Saleeb, A. F. and Wilt, T. E. (1993), "Analysis of the Anisotropic Viscoplastic Damage Response of Composite Laminates - Continuum Basis and Computational Algorithms," International Journal for Numerical Methods in Engineering, Vol. 36, (10), 1629-1660.

Saleeb, A. F., Arnold, S. M., Castelli, M. G, Wilt, T. E., and Graf, W. E. (2001), “A General Hereditary Multimechanism-Based Deformation Model With Application to The Viscoelastoplastic Response of Titanium Alloys, Int. J. of Plasticity, Vol. 17, No. 10, pp. 1305-1350.

Saleeb, A. F. and Arnold, S. M. (2004), "Specific Hardening Function Definition and Characterization of A Multimechanism Generalized Potential-Based Viscoelastoplasticity Model,” Int. J. of Plasticity, Vol. 20, pp. 2111-2142.

Smithells, C. (1992), Smithells Metals Reference Book. Oxford, UK, Butterworth-Heinemann.

Waterman, N. A. and Ashby M. F. (1996), Materials Selector, Chapman and Hall. 



\begin{tabular}{|c|c|c|c|c|c|}
\hline \multicolumn{5}{|c|}{ REPORT DOCUMENTATION PAGE } & $\begin{array}{l}\text { Form Approved } \\
\text { OMB No. 0704-0188 }\end{array}$ \\
\hline \multicolumn{6}{|c|}{ 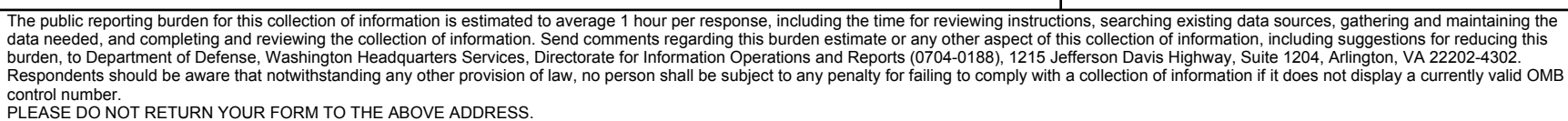 } \\
\hline \multicolumn{2}{|c|}{$\begin{array}{l}\text { 1. REPORT DATE (DD-MM-YYYY) } \\
01-01-2012\end{array}$} & \multicolumn{3}{|c|}{$\begin{array}{l}\text { 2. REPORT TYPE } \\
\text { Technical Memorandum }\end{array}$} & 3. DATES COVERED (From - To) \\
\hline \multirow{3}{*}{\multicolumn{5}{|c|}{$\begin{array}{l}\text { 4. TITLE AND SUBTITLE } \\
\text { Materials Selection for Aerospace Systems }\end{array}$}} & 5a. CONTRACT NUMBER \\
\hline & & & & & 5b. GRANT NUMBER \\
\hline & & & & & 5c. PROGRAM ELEMENT NUMBER \\
\hline \multirow{3}{*}{\multicolumn{5}{|c|}{$\begin{array}{l}\text { 6. AUTHOR(S) } \\
\text { Arnold, Steven, M.; Cebon, David; Ashby, Mike }\end{array}$}} & 5d. PROJECT NUMBER \\
\hline & & & & & 5e. TASK NUMBER \\
\hline & & & & & $\begin{array}{l}\text { 5f. WORK UNIT NUMBER } \\
\text { WBS } 031102.02 .03 .0249 .12\end{array}$ \\
\hline \multicolumn{5}{|c|}{$\begin{array}{l}\text { 7. PERFORMING ORGANIZATION NAME(S) AND ADDRESS(ES) } \\
\text { National Aeronautics and Space Administration } \\
\text { John H. Glenn Research Center at Lewis Field } \\
\text { Cleveland, Ohio 44135-3191 }\end{array}$} & $\begin{array}{l}\text { 8. PERFORMING ORGANIZATION } \\
\text { REPORT NUMBER } \\
\text { E-18042 }\end{array}$ \\
\hline \multirow{2}{*}{\multicolumn{5}{|c|}{$\begin{array}{l}\text { 9. SPONSORING/MONITORING AGENCY NAME(S) AND ADDRESS(ES) } \\
\text { National Aeronautics and Space Administration } \\
\text { Washington, DC 20546-0001 }\end{array}$}} & $\begin{array}{l}\text { 10. SPONSORING/MONITOR'S } \\
\text { ACRONYM(S) } \\
\text { NASA }\end{array}$ \\
\hline & & & & & $\begin{array}{l}\text { 11. SPONSORING/MONITORING } \\
\text { REPORT NUMBER } \\
\text { NASA/TM-2012-217411 }\end{array}$ \\
\hline \multicolumn{6}{|c|}{$\begin{array}{l}\text { 12. DISTRIBUTION/AVAILABILITY STATEMENT } \\
\text { Unclassified-Unlimited } \\
\text { Subject Category: } 39 \\
\text { Available electronically at http://www.sti.nasa.gov } \\
\text { This publication is available from the NASA Center for AeroSpace Information, 443-757-5802 }\end{array}$} \\
\hline \multicolumn{6}{|c|}{$\begin{array}{l}\text { 13. SUPPLEMENTARY NOTES } \\
\text { Submitted to the AIAA Materials Technical Committee for publication in an AIAA Education Series book entitled “Aerospace Materials } \\
\text { and Applications," 2012. An errata was added to this document, October } 2012 .\end{array}$} \\
\hline \multicolumn{6}{|c|}{$\begin{array}{l}\text { 14. ABSTRACT } \\
\text { A systematic design-oriented, five-step approach to material selection is described: 1) establishing design requirements, 2) material } \\
\text { screening, 3) ranking, 4) researching specific candidates and 5) applying specific cultural constraints to the selection process. At the core of } \\
\text { this approach is the definition performance indices (i.e., particular combinations of material properties that embody the performance of a } \\
\text { given component) in conjunction with material property charts. These material selection charts, which plot one property against another, are } \\
\text { introduced and shown to provide a powerful graphical environment wherein one can apply and analyze quantitative selection criteria, such } \\
\text { as those captured in performance indices, and make trade-offs between conflicting objectives. Finding a material with a high value of these } \\
\text { indices maximizes the performance of the component. Two specific examples pertaining to aerospace (engine blades and pressure vessels) } \\
\text { are examined, both at room temperature and elevated temperature (where time-dependent effects are important) to demonstrate the } \\
\text { methodology. The discussion then turns to engineered/hybrid materials and how these can be effectively tailored to fill in holes in the } \\
\text { material property space, so as to enable innovation and increases in performance as compared to monolithic materials. Finally, a brief } \\
\text { discussion is presented on managing the data needed for materials selection, including collection, analysis, deployment, and maintenance } \\
\text { issues. }\end{array}$} \\
\hline \multicolumn{6}{|c|}{$\begin{array}{l}\text { 15. SUBJECT TERMS } \\
\text { Material performance indices; Material properties; Materials for high temperature applications; Corrosion and oxidation; Material data } \\
\text { management }\end{array}$} \\
\hline \multicolumn{3}{|c|}{ 16. SECURITY CLASSIFICATION OF: } & $\begin{array}{l}\text { 17. LIMITATION OF } \\
\text { ABSTRACT }\end{array}$ & $\begin{array}{l}\text { 18. NUMBER } \\
\text { OF }\end{array}$ & $\begin{array}{l}\text { 19a. NAME OF RESPONSIBLE PERSON } \\
\text { STI Help Desk (email:help@sti.nasa.gov) }\end{array}$ \\
\hline $\begin{array}{l}\text { a. REPORT } \\
\text { U }\end{array}$ & $\begin{array}{l}\text { b. ABSTRACT } \\
\mathrm{U}\end{array}$ & $\begin{array}{l}\text { c. THIS } \\
\text { PAGE } \\
\text { U }\end{array}$ & UU & $\begin{array}{l}\text { PAGES } \\
74\end{array}$ & $\begin{array}{l}\text { 19b. TELEPHONE NUMBER (include area code) } \\
443-757-5802\end{array}$ \\
\hline
\end{tabular}



